\title{
PREDICTORS OF ACCENT-BASED PREJUDICE
}

\author{
by
}

David Matthew Sumantry

B.Sc. Mathematics, MacEwan University, 2014

B.A. Hon. Psychology, MacEwan University, 2016

\author{
A thesis \\ presented to Ryerson University \\ in partial fulfillment of the \\ requirements for the degree of \\ Master of Arts \\ in the program of \\ Psychology
}

Toronto, Ontario, Canada, 2018

(C) David Sumantry 2018 


\section{AUTHOR'S DECLARATION FOR ELECTRONIC SUBMISSION OF A THESIS}

I hereby declare that I am the sole author of this thesis. This is a true copy of the thesis, including any required final revisions, as accepted by my examiners.

I authorize Ryerson University to lend this thesis to other institutions or individuals for the purpose of scholarly research.

I further authorize Ryerson University to reproduce this thesis by photocopying or by other means, in total or in part, at the request of other institutions or individuals for the purpose of scholarly research.

I understand that my thesis may be made electronically available to the public. 


\begin{abstract}
Predictors of Accent-Based Prejudice

Master of Arts 2018

David Sumantry

Psychology

Ryerson University

This thesis investigated accent-based stereotyping and prejudice - a line of research originating in Lambert et al. (1960) - by studying perceptions of four accented groups. Participants recruited from Amazon's Mechanical Turk listened to audio clips where the speakers had native accents from either Toronto, Latin America, Arabic countries, or India. They then evaluated the speakers on several dimensions based on the Stereotype Content Model (SCM) and the solidarity-status-dynamism model (SSD), and completed direct measures of prejudice. Speakers were not evaluated differently on measures of prejudice but were stereotyped differently. Participants higher in right-wing ideologies held more negative stereotypes of speakers and demonstrated greater prejudice. Comparing theoretical models indicated that the more commonly-used SCM provides a suitable alternative to the SSD model. Implications for research on accent-based prejudice are discussed.
\end{abstract}




\section{Acknowledgements}

Without the unending support of a metric tonne of people, this thesis would have never happened. Thanks to Becky Choma - my supervisor, and quite possibly the best supervisor in the world - for putting up with my perpetual lateness and my love/hate relationship with writing. Thanks to Eric Hehman and Frank Russo for their excellent feedback and willingness to be on my committee; I am quite the noob, and they have been very gracious. Thanks to my MA 2018 cohort and my labmates, who have made my life in Toronto a blast. Board games and friendship fuel my soul. Thanks to Ryerson University, Carson Pun, and everyone else in the Psychology department. They deserve two thumbs up. The last thanks go out to my family, who have held me up through my uncountable life transitions until I found what I love doing. 


\section{Table of Contents}

List of Tables............................................................

List of Figures......................................................... vii

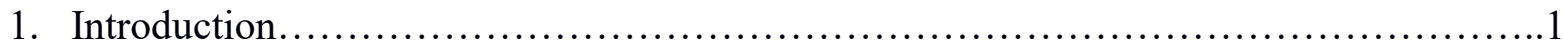

2. Landmarks in Accent-Based Prejudice.........................................2

3. Accent-Based Discrimination...............................................

4. Stereotypes and Prejudice.................................................... 8

5. Sociopolitical Ideologies............................................... 12

a. Right-Wing Authoritarianism....................................... 12

b. Social Dominance Orientation.......................................... 15

c. The Dual Process Model................................................ 18

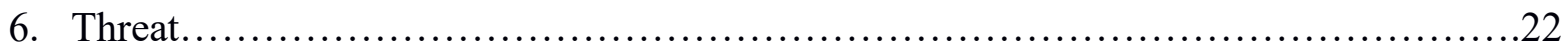

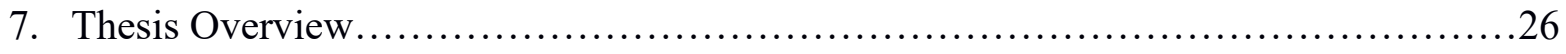

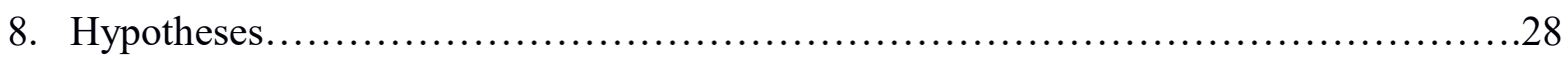

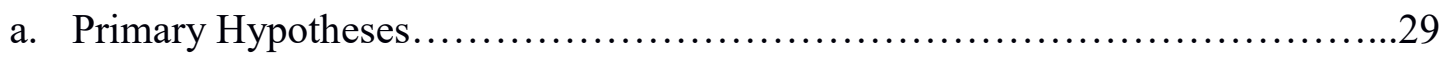

b. Secondary Hypotheses............................................. 30

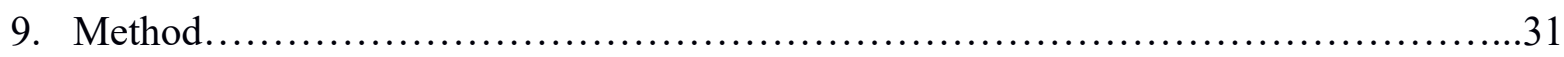

a. Participants...............................................................

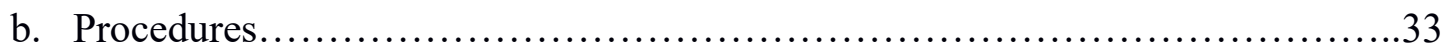

c. Measures........................................................... 34

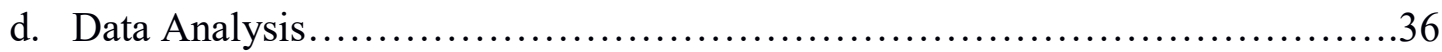

10. Results............................................................. 38

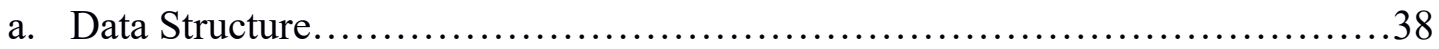




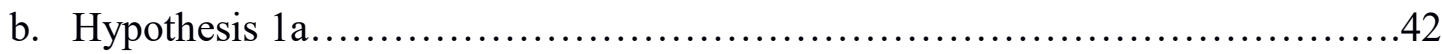

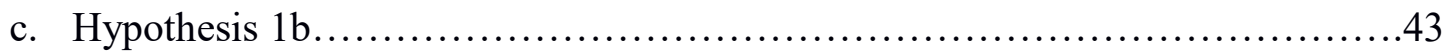

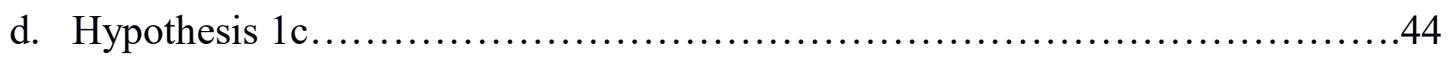

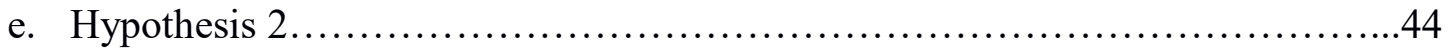

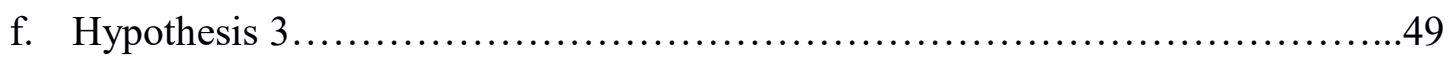

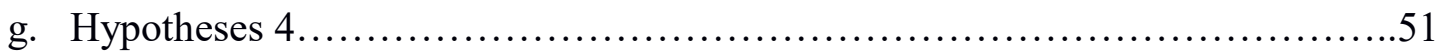

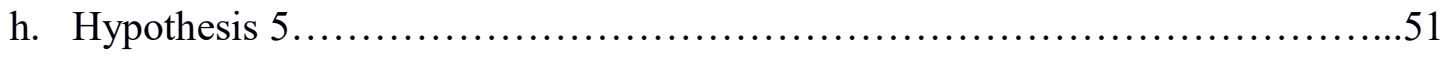

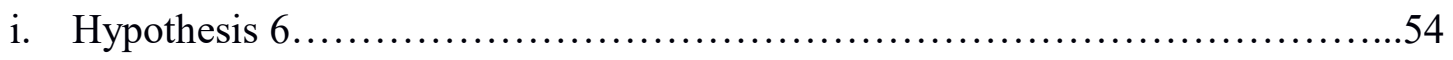

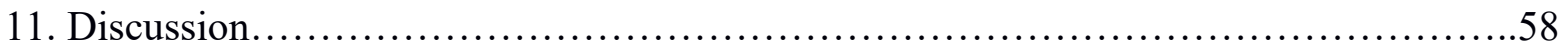

a. Mean differences between accents.........................................59

b. Right-wing ideologies as predictors of accent-based prejudice..................62

c. Intergroup anxiety and target evaluations...................................65

d. Ethnic evaluations versus target evaluations.................................68

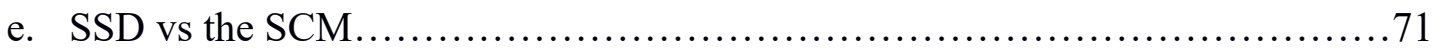

f. Limitations and directions for future research...............................74

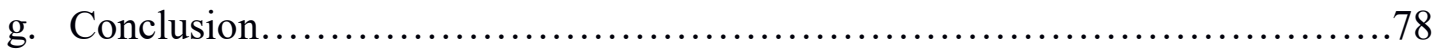

Appendix A: Additional tables and figures...................................... 80

Appendix B: Software for data analyses.......................................... 84

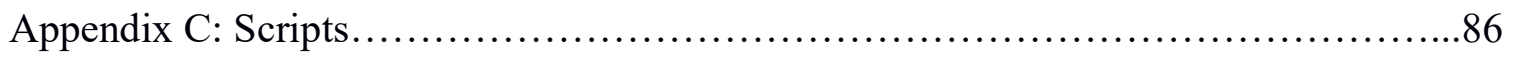

Appendix D: Consent form, measures and debrief................................. 89

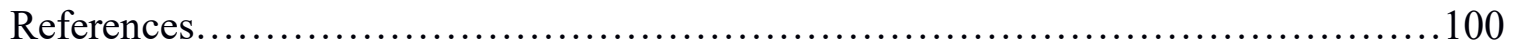




\section{List of Tables}

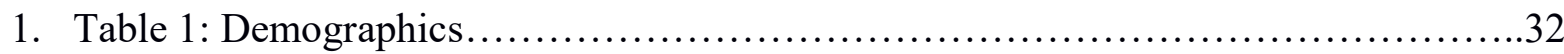

2. Table 2: Variable means and (standard deviations) by accent...........................

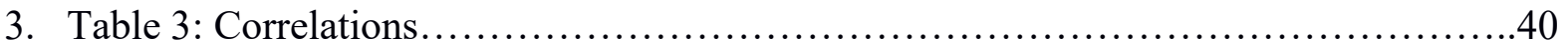

4. Table 4: Standardized confirmatory factor analysis loadings for RWA, SDO, and the ACT subscales............................................................45

5. Table 5: Predicting the Stereotype Content Model with ideology via multilevel structural equation modeling ......................................................46

6. Table 6: Predicting competence with ideology via multilevel modeling...............48

7. Table 7: Predicting warmth with ideology via multilevel modeling..................48

8. Table 8: Predicting intergroup anxiety with ideology via multilevel modeling..........50

9. Table 9: Predicting target thermometers with ideology via multilevel modeling........50

10. Table 10: Predicting target evaluations with ethnic evaluations via multilevel modeling

11. Table 11: Standardized regression coefficients comparing the Stereotype Content Model to the solidarity, status, dynamism model.......................................53

12. Table 12: Predicting solidarity, status, and dynamism with ideology via multilevel structural equation modeling.....................................................56

13. Table 13: Standardized regression coefficients comparing RWA to ACT..............57 


\section{List of Figures}

1. Figure 1: The Dual Process Model.............................................. 19

2. Figure 2: Predictions of SCM quadrants for each tested accent.....................29

3. Figure 3: Target means of warmth and competence by accent with $95 \%$ confidence interval ellipses........................................................42 
In the past few years, immigration and asylum for refugees have been topics of much global debate. Countries such as Egypt, Iraq, and Turkey have been inundated with refugees, as nearly 5 million people have sought asylum around the world (UNICEF, 2016). In 2016, the United Nations Refugee Agency declared that the issues surrounding the Syrian civil war have produced the "biggest humanitarian and refugee crisis of our time" (United Nations High Commissioner for Refugees, 2016a). While some countries like Germany and Sweden have each taken over 100000 refugees, others like Canada, the US, and the UK have been relatively conservative in the number of people they are willing to accept (United Nations High Commissioner for Refugees, 2016b). Yet, immigrants play an increasingly important role in the growth of western societies in terms of population and economy (OECD, 2014). For example, Canada focuses on bringing highly skilled workers into the country, as they are most likely to bring benefit to its economy as a whole (Reitz, 2012).

Before the rise of globalization, skin tone was a relatively reliable indicator of whether strangers belong to the national ingroup. An Asian in North America would be an anomaly among the White and Indigenous peoples. However, as people from all ethnic backgrounds have spread across the globe, there are growing numbers of people whose nationality does not match the traditional or expected ethnicity of that nation: many nations are becoming more multicultural. Consequently, skin colour is becoming a decreasingly reliable cue of foreignness. Conversely, accents remain a salient indicator of foreignness in a multicultural environment. Therefore, as skin tone slips in its accuracy to detect foreignness, accents might be utilized to correctly identify members of an outgroup.

Researchers have developed theoretical frameworks which have been shown to explain ethnic prejudice and stereotyping (e.g. Duckitt, 2001; Fiske, Cuddy, Glick \& Xu, 2002; Stephan 
\& Stephan, 2000); however, minimal research in social psychology has studied whether these models explain accent-based prejudice and stereotypes. Rather, psycholinguistic researchers have developed well-supported models specific to accent-based prejudice (e.g. Zahn \& Hopper, 1985). The present thesis utilizes models from both social psychological and psycholinguistic traditions and examines: a) whether people with accents are evaluated similarly to visible outgroups and b) whether sociopolitical ideologies associated with visual prejudices similarly relate to accent-based prejudices.

\section{Landmarks in Accent-Based Prejudice}

In 1960, Lambert, Hodgson, Gardner, and Fillenbaum pioneered research in accent-based prejudice. Based solely on vocal qualities, English- and French-speaking participants from Montreal (a bilingual city) judged targets who spoke English with either a standard regional accent or a French accent. Participants rated the speakers on a variety of characteristics, including their intelligence, height, likability, and kindness. Results showed that participants, regardless of whether they were English- or French-speaking, evaluated the English speakers more positively. Some exceptions included English-speakers evaluating the French voices as having a stronger sense of humour, and French-speakers evaluating the French voices as being more religious and kind. These evaluations are consistent with stereotypes that English- and French-Canadians have of each other. However, for the most part, the high-status Englishspeakers were viewed more favourably across participant language. In other words, the authors proposed that regardless of whether English-speakers were the ingroup or the outgroup, their high-status position seemed to play a greater role in how they were evaluated than their language choice. 
Consistent with Lambert et al.'s (1960) assertions, later research confirmed that the role of status in accent research is foundational. To examine status, Giles (1970) compared 17 different accents that could be found in the United Kingdom. While he used accents that would be understood as ostensibly "foreign," such as Indian or Italian, Giles also included various UK accents that could be distinguished based on region or social class, such as Birmingham and Liverpool accents. Perceptions of accents varied widely. In general, the standard English accent (also known as the $\mathrm{BBC}$ accent) was rated more positively than any of the other accents. Surprisingly, the Birmingham and Cockney accents were rated much less favourably, often more negatively than accents from foreign countries. These results were found despite the same-race connotation that the within-UK accents have. Giles concluded that accent seems to be inextricably related to class and social status. Studies performed in other countries have reported similar findings. For example, the prototypical American (high status) accent was evaluated as more superior than was the Hispanic-American (low-status) accent (Giles, Williams, Mackie, \& Rosselli, 1995). Therefore, accent-based prejudice seems to relate to both foreignness and status. For the purpose of this thesis in its Canadian context, and because Toronto's local accent is likely the regional high-status accent, I will refer to anything other than the local accent as a foreign accent.

Following Lambert et al.'s (1960) and Giles' (1970) pioneering work, a significant amount of research was conducted emphasizing how people with foreign or low-status accents are viewed compared to people with local or high-status accents. However, because researchers designed their own scales, it was difficult to compare findings between studies. Williams generated bipolar adjective scales based on recorded interviews with various groups (e.g. Hopper, 1977; Hopper \& Williams, 1973), Giles (1971) adapted trait ratings from other research 
domains, and many other researchers constructed measures through a variety of different methods (see Zahn \& Hopper, 1985 for a comprehensive overview).

To synthesise the research methods employed in accent-based prejudice research, Zahn and Hopper (1985) collected data using the majority of the rating scales utilized by researchers in the 25 years prior. Popular scale items included ratings of attractiveness, competence, and solidarity. A total of 152 items were identified then reduced to 56 after accounting for redundancy and relevancy. Participants were 572 undergraduate students who listened to job interviews and rated the interviewer and interviewee on the 56 items. The interviews had been conducted in various locations across the US, so a wide variety of American English accents were studied. In total, 25 interviews were rated. Using a principal axes factor analysis, they discovered three dimensions on which people with foreign accents differ: solidarity (social attractiveness), status (superiority), and dynamism. Solidarity is a measure of the listener's relatedness to the speaker. It consists of items of warmth, friendliness, honesty, and other interpersonal personality traits similar to the notion of agreeableness. Status refers to where the speaker fits in the social hierarchy. Questions of class, literacy, intelligence, and socio-economic status comprise this factor. Last, dynamism relates closely to extraversion and efficacy. Some of its items relate to how aggressive, confident, active, and talkative the speaker seems to be. Together, these traits accounted for $64.5 \%$ of the variance in participant ratings. The dimensions continue to be used in contemporary accent research (e.g. Dragojevic \& Giles, 2016).

A meta-analysis by Fuertes, Gottdiener, Martin, Gilbert, and Giles (2012) compared local accent (to where the individual study was conducted) to one or more other accents on the statussolidarity-dynamism dimension triad. While the authors identified 153 possible studies published between 1972 and 2003 which discussed speech or accents, only 70 of them were quantitative in 
nature. Further, the list of applicable studies was reduced to 20 due to insufficient statistical reporting. All of the studies in the meta-analysis had participants rate the accented speaker on a variety of characteristics representative of the three dimensions; contexts differed between studies. Results of the meta-analysis revealed that overall, local or high-status speakers were rated more positively than their foreign or low-status counterparts, across all studies. This effect was strong, with a Cohen's $d$ of 0.82 . Further, across solidarity, status, and dynamism individually, local/high-status accented speakers were rated significantly more positive than foreign/low-status speakers. This effect was found despite variation in how studies operationalized the three dimensions. Overall, a Fail-Safe N of 10547 was calculated to determine the number of nil-effect studies that would have had to been missed by the researchers during collection for the findings of the meta-analysis to become non-significant. Therefore, empirical evidence shows that evaluations of accents are linked to status, solidarity, and dynamism - where the local (usually high-status) accent is perceived more favourably across all three dimensions.

\section{Accent-Based Discrimination}

Consistent with the research showing that people rate those with foreign accents less positively, discrimination against people with foreign accents is well documented. People with non-local accents claim to experience discrimination on a regular basis (Berk-Seligson, 1984). They also tend to be evaluated more negatively when looking for employment (Hosoda, Nguyen, \& Stone-Romero, 2012; Hansen \& Dovidio, 2016), housing (Zhao, Ondrich, \& Yinger, 2006), or they are being suspected of a crime (Dixon, Mahoney, \& Cocks, 2002). The strength of the accent matters as well. Numerous studies have shown that accent thickness is related to lower wages, particularly for women (Hamilton, 2008; McManus, 1990; Hellerstein \& Neumark, 
2003). Immigrant women who have accents also have a harder time accessing health care (Weerasinghe, 2012).

How people with accents are treated can have negative psychological outcomes. Wated and Sanchez (2006) examined how Hispanic employees with accents perceived their treatment and position in the workplace. Even though the county from which they chose their sample had the highest Hispanic population of any county in the US (57\%), the participants' accents were a significant source of stress in their work life. Their perceived discrimination based on accent was related to their job satisfaction and the amount of workplace tension they experienced. Similarly, Archuleta (2015) examined a variety of variables predicting economic and occupational stress in American Hispanics. The researcher found that the extent to which Hispanics acculturated linguistically had a similar effect to how they acculturated socially and to the quality of friendships they had. In other words, the closer Hispanics were to mastering American speech, the less financial stress they had, and the less stress they had in the workplace. Thus, accentbased discrimination can have both practical and psychological consequences.

One might argue that the tension that people with accents experience and the negative evaluations they receive are, in part, associated with communication problems; that is, misunderstanding someone can be frustrating. Indeed, research by Dragojevic and Giles (2016) suggests that processing fluency plays a crucial role in how speech is evaluated. Speech that was more difficult to understand (obscured by noise) caused the speaker to be rated lower in affective and status measures. This effect happened for both accented and non-accented speech. Thus, independent of stereotypes and ethnic attributions, people who are easier to understand are viewed more positively. Still, variations between foreign accents suggest that comprehension alone does not account for accent-based prejudice and discrimination. Gluszek and Dovidio 
(2010) examined from where accented individuals perceived their discrimination as stemming. Their results suggested that the strength of a foreign accent is directly related to communication problems and how "at home" people feel in a country. In a different study, the authors also showed that the amount of time immigrants spent in the US and identification with American culture related to having more of an American accent, having less communication challenges, and feeling more "at home" in the US (Gluszek, Newheiser, \& Dovidio, 2011). Hence, accent is linked to migrant success and well-being in their host country.

In studying accent-based prejudice, it may be tempting to attribute its effects solely to race. Race, region, and linguistics have long been intertwined. Evidence suggests that race can be guessed from vocal cues at above-chance levels (e.g. Newman \& Wu, 2011; Walton \& Orlikoff, 1994). Moreover, there are vocal patterns more common in certain ethnicities than in others (Ryalls, Zipprer, \& Baldauff, 1997; Sapienza, 1997). Baugh (2003) describes multiple criminal cases where eyewitnesses claimed that a suspect sounded Black, despite not having seen the person. However, the relatedness between accent and race, and the accuracy of this linguistic profiling are topics of controversy (see Yarmey, 1995); though stereotypes likely adhere to the accent-race connection, the accuracy of identifying an individual's race based on their voice may rely on other variables. Specifically, differences in culture, class, and education could affect how clusters of ethnic groups speak (see Lippi-Green, 2001). Research by Perrachione, Chiao, and Wong (2010) supports the notion that learned dialect (i.e. cues attributable to social influences) accounts for differential vocal qualities better than do biological differences (i.e. cues attributable to race). Moreover, as shown in Giles (1970), one race (in this case, English), can be home to many different regional accents, and prejudice can exist between them. Therefore, as 
globalization erodes the relation between region and race, accent will become more associated with region and culture than it does race.

In summary, research shows that accent-based prejudice exists and that it affects groups such as immigrants in tangible ways. Despite the literature investigating evaluations and outcomes regarding accents (e.g. Souza, Byers-Heinlein, \& Poulin-Dubois, 2013; Stephan, Ybarra, \& Bachman, 1999), less research has been done on identifying the psychological underpinnings and characteristics of accent-based prejudice. Nor have there been substantive attempts to place accent-based prejudice in the theoretical frameworks which outline the origins of generalized prejudice. In this way, it is unclear whether these well-supported models can similarly account for accent-based prejudice. For example, do judgements of accented speakers approximate how their stereotyped ethnicity is judged? What sort of sociopolitical ideologies underlie accent-based prejudice? Is accent-based prejudice rooted in perceiving various types of threats? Does verbal content matter when determining how threatening an accented speaker is? To give framework to these questions, I posit that theories traditionally applied to racial discrimination or intergroup prejudice can apply to the realm of accents as well.

\section{Stereotypes and Prejudice}

One of the founders of modern prejudice research, Gordon Allport (1954), discussed stereotypes as a direct antecedent of prejudice. Since then, understanding of stereotypes and prototypical group members has grown to embrace its multidimensionality across groups and valances. For example, feminist women are stereotyped to be highly capable, yet lacking in empathy (e.g. Nielsen \& Doyle, 1975). Older Black women, on the other hand, are stereotyped as kind and caring, yet submissive and not very intelligent (e.g. Jewel, 1993). Hence, not only are 
stereotypes complex, they can be positive and negative depending on the content of the stereotype.

To address the ways in which stereotypes vary, Fiske, Cuddy, Glick, and Xu (2002) developed the Stereotype Content Model (SCM). They proposed two dimensions of stereotype content along which groups vary: warmth and competence. These dimensions are related to the goals an individual/group is stereotyped as having, particularly with respect to their competitiveness and their social status. A warmer group is stereotyped to react with more positive intent toward others to achieve cooperative goals, and not perceived as being competitive. On the other end, a colder group has more negative intent and is more callous to the value of other groups. These groups tend to be perceived as more competitive. A more competent group is stereotyped to be more effective in reaching their goals, thus tending to be higher status. A less competent group is less able to further themselves in society or be successful; they are also lower status. Crossing the orthogonal two dimensions creates four quadrants. The authors theorized that societal groups cluster in these quadrants. In other words, groups which are evaluated similarly in warmth and competence share similar stereotype content. Consequentially, the clustered groups are treated in similar ways.

According to Fiske et al. (2002), the four quadrants of the SCM can be categorised by unique types of prejudice. Prejudice toward groups who are high in warmth and low in competence, is labelled paternalistic prejudice. These groups are low-status and garner pity from outgroups. They are not seen as capable of actively competing with high-status groups, so other groups are willing to cooperate with them. Groups low in warmth but high in competence are targeted via envious prejudice. These people are perceived as highly competitive, high-status, yet lacking empathy. Outgroups view them with jealousy, as their success is resented. In the low/low 
quadrant, contemptuous prejudice is shown to these groups. They are considered to be the parasites of society. Other groups (particularly high-status groups) experience anger and disgust towards them, because rather than being capable of succeeding in society, they rely on feeding off the success of others. Last, in the high competence/high warmth quadrant, the majority group and their allies are found. They are admired with pride, and though they are high-status, they are not viewed as competition. These groups do not have a classification of prejudice associated with them, as they are only regarded positively. In this way, groups in the same quadrant share characteristics in how others treat them.

In order to verify their model, Fiske et al. (2002) examined ratings of 23 different social groups in the US across four studies on dimensions of warmth, competence, competition, and status. Evidence pointed to the validity of their model, as most groups were shown to have stereotype content with some combination of the warmth and competence dimensions. Further, these groups fell into identifiable clusters. Groups falling into the paternalistic prejudice quadrant include the elderly, housewives, and the disabled. Asians, Jews, feminists, and Indians fall into the envious prejudice quadrant. Lastly, the contemptuous prejudice category contained poor people, welfare recipients, and the homeless (in North America). Some groups fell into multiple quadrants, depending on how they were defined. For example, Black people were rated relatively neutrally overall, yet distinctions between subgroups of Blacks caused this neutrality to polarize. Here, Black professionals were considered competent, yet not warm, whereas lowerclass Blacks were considered warm, yet incompetent. These results have been replicated in other studies (e.g. Cuddy, Fiske \& Glick, 2008) and evidence points to clusters existing in Asian cultures toward outgroups as well (Cuddy et al., 2009). 
Consistent with the authors' (Fiske et al., 2002) predictions, warmth and competence were predicted by competitiveness (negatively) and status, respectively. Researchers have surmised that being competitive "costs" warmth, and status "buys" competence (Binggeli, Krings, \& Sczesny, 2014). In other words, for people or groups to be competitive, they must be willing to sacrifice some of their warm, empathetic qualities. This competition is best operationalized when considering the tension over resources and cultural values (Fiske \& North, 2015; see also Stephan \& Stephan, 2000). Similarly, a group's competence can only be judged based on how successful the group is. If a group has secured a place of high status in society, they will be viewed as competent based on the assumption that they achieved their standing by merit. These relationships have been shown to exist in the other direction as well (Durante, Capozza, \& Fiske, 2010). That is, when a group's warmth or competence is demonstrated, people assume that the group is cooperative or high-status, respectively. Therefore, status and competence are linked in a way which makes it difficult for groups to break through stereotyped boundaries.

Research has also shown that the warmth and competence dimensions, and their associated quadrants, are associated with prejudicial behaviours (Cuddy, Fiske, \& Glick, 2007). Specifically, how cold a group was perceived to be predicted both willingness to help others damage the group and willingness to actively harm the group. How helpless a group was perceived to be predicted willingness to both let others harm and to passively facilitate harm against the group. The authors provided evidence that these relations were mediated by particular quadrant-related emotions (admiration, contempt, envy, and pity) The SCM then, can predict both attitudes and behaviours toward stereotyped groups. 
In summary, the SCM is useful in differentiating between how different groups are judged. It provides evidence that groups are not evaluated solely on a positive versus negative dimension, but on perpendicular dimensions of warmth and competence, which are valenced within themselves. No research (that I am aware of) has investigated how people with accents are stereotyped in the SCM framework. However, as discussed earlier, status plays a crucial role in accent-based prejudice (Giles, 1970). Therefore, one goal of the present thesis is to study whether the SCM dimensions of warmth and competence can be linked to prejudice against people with accents.

\section{Sociopolitical Ideologies}

Ideology is a robust predictor of intergroup attitudes. In particular, right-wing authoritarianism (RWA, Altemeyer, 1998, 1996, 1988, 1981) and social dominance orientation (SDO, Ho et al., 2015; Pratto, Sidanius, Stallworth, \& Malle, 1994; Sidanius \& Pratto, 1999) have together been shown to account for half of the variance in intergroup attitudes (Altemeyer, 1998). This section reviews theory and research on RWA and SDO and their potential relevance to accent-based prejudice.

\section{Right-Wing Authoritarianism}

One key predictor of generalized prejudice in existing literature is a person's alignment with an authoritarian ideal. Originally conceptualized by Adorno, Frenkel-Brunswick, Levinson, and Sanford (1950), the authoritarian personality was theorized to explain the rise of overt antiSemitism before and during World War II. The authors suggested that rather than there being something specific about Jews which inspired hatred in others, there were traits within people that manifested in hatred toward outgroups. Though the authors described these traits as an ideology, they defined the tendency to hold such an ideology as a personality characteristic. 
"Authoritarian" was meant to describe people who prioritize their ingroup, have a firm respect for the rule of law and powerful leaders, and hold traditions that they expect others to follow.

To measure authoritarianism, Adorno et al. (1950) developed the Fascism scale (F-scale). The F-scale was based on nine dimensions: conventionalism, authoritarian submission, authoritarian aggression (punishing people who defy conventions), anti-intraception (rigidity, objectivity, and callousness), superstition and stereotypy (categorical thinking and a belief in fate), power and toughness (obsession with power structures), destructiveness and cynicism (general hostility), projectivity (in a Freudian sense), and sex (belief in strong punishment for sexual deviance). Early research showed that scores predicted a preference for authoritarian political leaders (Milton, 1952), a strict parenting style (Willis, 1956), likelihood to stereotype (Siegal, 1954), and xenophobia (Campbell \& McCandless, 1951).

Research on the F-scale and its construction showed it to be fairly dubious, however. Notably, the anti-intraception, projectivity, and sex dimensions were based on psychodynamic theories (Adorno et al., 1950). Though the other dimensions centered around dispositional and attitudinal themes, the psychodynamic dimensions relied on the notion that specific behaviours or patterns of thought were due to disturbances in early life. These issues, along with the use of the Thematic Apperception Test, were highly criticized (e.g. Martin, 2001). Further, there were many instances where the F-scale theoretically predicted beliefs or behaviours, but data did not support the theory. For instance, it failed to predict prejudice, political party affiliation in the US, or general intolerance (Christie \& Cook, 1958). It was also consistently shown to be multidimensional (as cited in Duckitt, 2001). Research using the F-scale and on authoritarianism waned until the 1980s. 
In 1981, Altemeyer reconceived the notion of an authoritarian ideology into what he called Right-Wing Authoritarianism (RWA). Rather than using the nine components of Adorno et al.'s (1950) Authoritarianism, RWA has a more parsimonious model, with three theoretical attitude clusters that covary. Importantly, Altemeyer's aspects are devoid of psychodynamic influence. First, people who are higher in RWA tend to defer to leadership (authoritarian submission). That is, they believe that legitimate authorities should be respected and obeyed. In positive contexts, these followers obey the laws set forth by the government. In negative contexts, they are reluctant to challenge authority despite questionable actions. Second, those with higher RWA scores are willing to participate in aggressive acts on behalf of authorities (authoritarian aggression). Consider the atrocities committed during WWII. Many of the people who perpetrated these atrocities claimed they were simply "following orders." In this way, they did not believe they were responsible for their actions (Altemeyer, 2006). In spite of inhumane acts, a soldier designates their self as a tool for authorities. Third, RWA is defined by traditionalism and a fear of change (conventionalism). People who enjoy rigid societies and environments tend to have higher RWA scores; they discourage breaking social norms and promote conformity. These three components work together to comprise the RWA construct.

Altemeyer (2006) theorized that, in line with theories of social learning (Bandura, 1977), people higher on RWA are so because of how others in their life perceive the world. Altemeyer posited that some parents present the world to their children as being rife with danger. The parents instilled a fear of the outside world and insisted that deviance from the chosen path would lead to sinful consequences. One of the consequences of being inundated with these ideas is growing up with a belief in a Dangerous World. For people with this belief, humanity is descending into chaos, and the only thing that can be done to halt its descent is by adhering to a 
strict rule of law and punishing all those who dissent. Those with strong Dangerous World beliefs are more sensitive to threats and often have an apocalyptic view. Longitudinal research supports the causal relation between socialization in early life and Dangerous World beliefs: for example, preschool children who were more fearful and rigid were more likely to have conservative views as young adults (Block \& Block, 2006). Further, RWA scores tend to be correlated with those of participants' parents, suggesting that perhaps both genetic and social learning influences are involved in determining the extent to which someone lines up with the authoritarian ideal (Altemeyer 2006; Meeusen \& Dhont, 2015).

There is extensive data supporting the association between RWA and political and intergroup attitudes. For example, higher RWA scores are related to having unsubstantiated, conspiracy-theory-esque beliefs in both university students and their parents (Altemeyer, 1988). People higher on the RWA scale are also less likely to endorse democracy or protections of human rights (Altemeyer, 1996). In relation to prejudice, homosexuals, Jews, ethnic minorities, and the homeless are rated less positively by people higher in RWA (Altemeyer, 1996). Further, RWA has been shown to be related to benevolent sexism (Sibley, Wilson, \& Duckitt, 2007). Therefore, RWA tends to be most strongly related to prejudice toward groups that concern social norm violations. The present thesis examines RWA as a predictor of accent-based prejudice.

\section{Social Dominance Orientation}

Complementing Altemeyer's $(1981,1988,1996)$ theory of right-wing authoritarianism, Pratto and Sidanius proposed Social Dominance Theory (SDT; Pratto et al., 1994; Pratto, Sidanius, \& Levin, 2006). According to SDT, people naturally organize societies into hierarchies, where certain groups have more power than others. SDT recognizes three hierarchies common to most societies: a) an age system by which adults have more power than children or 
young adults, b) a gender system where men have more power compared to women, and c) an arbitrary-set system, which is not based on biologically-relevant factors. For instance, race, class, and religion are all arbitrary sets. The universality of these structures is conditioned by the extent to which they exist. That is, societies operate under these hierarchies differently.

According to SDT (Sidanius \& Pratto, 1999; Sidanius, Cotterill, Sheehy-Skeffington, Kteily, \& Carvacho, 2016), social hierarchies develop and are maintained due to hierarchylegitimizing myths. Specifically, there are hierarchy-enhancing legitimizing myths and hierarchyattenuating legitimizing myths, which are in contention. In the case of hierarchy-enhancing legitimizing myths, there are justifications for why systemic oppression and inequality should be maintained. Racism, sexism, belief in a just world, and karma are all ways in which people promote intergroup differences; they suggest that the social system works best when groups carry out their respective roles. Hierarchy-attenuating legitimizing myths work in the opposite direction: against oppression and inequality. Egalitarianism, feminism, the concept of basic human rights, and communism all work to undermine existing hierarchies. Both myths have institutions which support them: traditional military structures underscore the importance of hierarchies, whereas women's rights groups fight for equality. These myths exist on a systemwide level.

On the individual level, support for social hierarchies is reflected by the strength of one's Social Dominance Orientation (SDO; Pratto et al., 1994). There are five factors which may predict a strong SDO (Pratto et al., 2006). First, people who are already at the top of a group hierarchy are more motivated to maintain their position in society. Consequently, they tend to be higher in SDO than other groups (Sidanius, Levin, Liu, \& Pratto, 2000). Second, having different perceptions of social contexts may influence how much someone supports a social hierarchy. 
When a group that was once low in the hierarchy gains power, they begin to show greater support for the hierarchal system (Levin, 2004). Third, specific individual differences can predict higher SDO scores. For instance, empathy has been shown to be negatively related to SDO (Chiao, Marthur, Harada, \& Lipke, 2009), and an individual's SDO seems to be stable over time (Sidanius, Levin, van Laar, \& Sears, 2006). Fourth, men tend to have higher SDO scores than women (Levin, 2004). Fifth, there are likely socialization effects which cause development of a SDO over time. However, these have not been extensively researched (Pratto et al., 2006). Via these five factors, an individual may be more or less likely to support social hierarchies.

A significant amount of research has provided evidence that SDO scores on Pratto et al.'s (1994) scale predict prejudice and discrimination. The authors found that SDO is related to economic conservativism, anti-Black racism, less support for women's rights, participant social status, and other similar attitudes. Subsequent research since SDO's conceptualization has shown a similar pattern of findings. Higher scores predict discrimination in minimal group paradigms (Amiot \& Bourhis, 2005), they are also associated with a preference for meritocracies, at the expensive the needy (Pratto, Tatar, \& Conway-Lanz, 1999), generalized prejudice (Ekehammar, Akrami, Gylje, \& Zakrisson, 2004), and a variety of discriminatory actions (e.g. Altemeyer, 1998; Duckitt \& Sibley, 2016; Duckitt \& Sibley, 2009).

Important to this proposal is a recent study by Hansen and Dovidio (2016) examining SDO and evaluations of people with accents. The authors tested a moderated mediation model, where the perceived comprehensibility of an accented speaker mediated the relation between SDO scores and hirability ratings of the speaker. The relation between SDO and subjective comprehensibility was moderated by which accent was presented: Asian (Mandarin Chinese) or Latino (Spanish). SDO scores directly predicted hirability, and the relation was partially 
mediated by subjective comprehensibility, such that higher SDO related to greater difficulty in understanding the accents. Thus, while the ability of people to understand an accented person partially accounted for SDO's (negative) predictive power on hirability, it did not fully account for its effects. In other words, even when participants subjectively understood an accented person to the same degree, stronger SDO predicted greater discrimination against the accented person in an employment context. Further, the moderation effect of accent origin approached significance: Latinos compared to Asians were subjectively understood less by higher SDOs. The indirect effect of the moderated mediation model was significant for Latinos, but not for Asians. In other words, comprehensibility did not account for SDO's effect on Asian hirability, yet it did for Latino hirability. Notably, though Hansen and Dovidio had participants recall details of the accented speech (i.e. presented a difficult quiz asking about the speech content), objective comprehensibility (i.e. number of correct quiz answers) was not significant in their model. Thus, those higher in SDO may have an affective bias against low-status groups particularly, which affects how easy they think the groups are to understand.

\section{The Dual Process Model}

According to the Dual Process Model (DPM; Duckitt, 2001), RWA and SDO work together to independently predict prejudice (see Figure 1). Duckitt and Sibley (2016) describe this two-pathway model as having three sets of explanations for prejudice. First, RWA and SDO are two dimensions of ideological attitudes that represent different sets of motivations. Second, RWA and SDO have unique worldviews which are predicated by social and personality constructs that theoretically cause their development. Third, distinct perceptions (i.e. social threats, competitiveness) mediate the relation between ideology and prejudice. The three sets of explanations are described in greater detail below. 


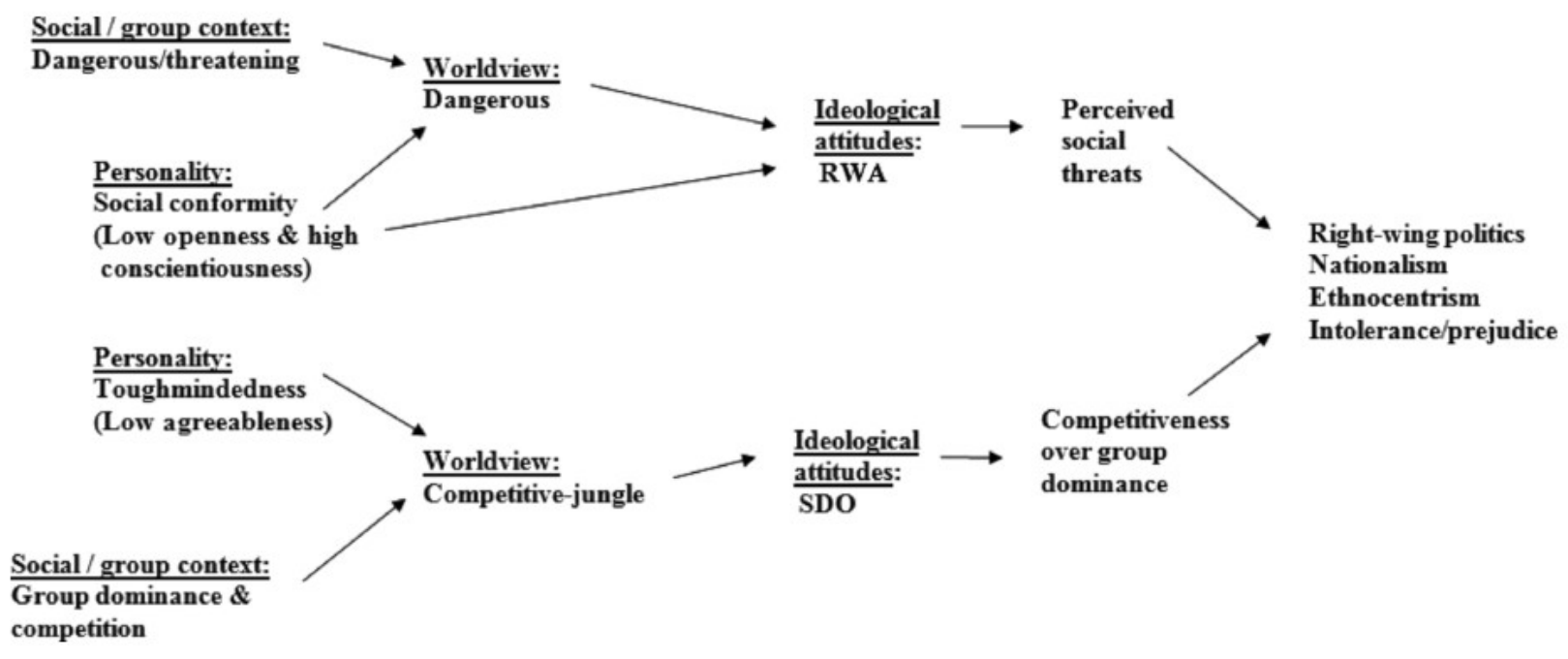

Figure 1: The Dual Process Model. Taken from Duckitt \& Sibley (2009)

Duckitt (2001) proposed that RWA and SDO are unique constructs that serve distinct motivations. Using values inventories from Schwartz (1992), research has shown that higher (vs. lower) RWA is related to the Conservation (vs. Openness) value dimension; that is, those higher in RWA value security, conformity, and tradition, whereas those lower in RWA value stimulation and self-direction values (Altemeyer, 1998; McFarland \& Adelson, 1996). Higher (vs. lower) SDO, on the other hand, is related to Self-Enhancement (vs. Self-Transcendence) value dimension; people higher in SDO value achievement, power, and hedonism, whereas those lower in SDO value universalism and benevolence (see also Choma, Ashton, \& Hafer, 2010). RWA and SDO having different corresponding value systems supports Duckitt's (2001) conceptualization of the DPM: the roots of prejudice differ depending on the ideological path taken.

As mentioned earlier, RWA was shown to originate in a belief in a Dangerous World (Altemeyer, 2006). Complimenting this relation, Duckitt (2001) theorized that SDO originates in a perception of the world as a Competitive Jungle. In this way, whereas people higher in RWA feel more strongly that the world is more threatening and that law is necessary to maintain safety 
and security, people higher in SDO are more likely to believe that society is dog-eat-dog, and that they must be ruthless to survive. Although people with stronger SDO may not think that brash competition is the best way to live, they are more likely to believe that they must compete to succeed. Thus, RWA and SDO are theorized to be predicted by Dangerous World and Competitive Jungle worldviews, respectively.

Distinct personality traits and social contexts are thought to differentially predict the distinct worldviews held by those higher ( $v s$. lower) in RWA and SDO (Duckitt, 2001; Sibley \& Duckitt, 2009). Duckitt (2001) predicted that the tendency to hold Dangerous World beliefs is caused by an individual's dispositional social conformity. In terms of the Big Five personality traits, low Openness to Experience and high Conscientiousness represent social conformity, which predicts Dangerous World beliefs (Duckitt \& Sibley, 2009). Further, Duckitt (2001) predicted that the tendency to hold Competitive World beliefs is caused by an individual's toughmindedness. This can be described by low Agreeableness (Duckitt \& Sibley, 2009). Put simply, people who prefer consistency and conformity are more likely to perceive change brought on by others as dangerous. People who are less cooperative or empathetic, in contrast, are more likely to view the world as a cold rat race. While social conformity and tough-mindedness were originally theorized to also directly predict RWA and SDO respectively, evidence has indicated that only the social conformity-RWA link is significant (Duckitt, 2001).

Worldviews are also predicated by environmental threats (Duckitt, 2001). Dangerous World beliefs are predicted by contexts defined by dangers to social norms. That is, whether imagined (Mirisola, Roccato, Russo, Spagna, \& Vieno, 2014), such as via parental influence, or genuine threats (Onraet, Dhont, \& Van Hiel; 2014), such as a loss of culture. Competitive World beliefs, on the other hand, are predicted by a social context where resources are scarce and 
inequality already exists (Duckitt \& Fisher, 2003; et al., 2007). These threats combined with dispositions to specific personality traits, provide the building blocks for Dangerous and Competitive worldviews, which then develop stronger RWA and SDO.

Though general threats influence the development of RWA and SDO in an individual, the type of threat a specific group is perceived as posing determines how the individual reacts to the group (Duckitt \& Sibley, 2016). That is, how someone perceives an intergroup threat determines how they are prejudiced toward the group. People higher in RWA are more likely to perceive greater social threats. They will then react to these social threats with prejudice or by adopting particular sociopolitical attitudes. On the other hand, people higher in SDO are more likely to perceive greater group competitiveness; again, they tend to respond with prejudice and discrimination. This differential pattern of effects for RWA and SDO on outcomes via social threats and perceived competitiveness is known as the 'differential mediation hypothesis'. As one example of this effect, RWA and SDO both predict support for the 2003 US attack on Iraq, but via their respective social threat and competitiveness paths (McFarland, 2005).

RWA and SDO can also predict different outcomes. Sibley and their colleagues (2007) found that whereas RWA predicts benevolent sexism (support for traditional gender roles), SDO predicts hostile sexism (support for male dominance over women). Ethnocentrism has also been differentially predicted, with RWA predicting intragroup ethnocentrism (ethnic identification) and SDO predicting intergroup ethnocentrism (ethnic superiority; Bizumic, Duckitt, Popadic, Dru, \& Krauss, 2009). These differential outcomes are often explained by their respective paths. For example, Duckitt (2006) found that RWA predicted negative attitudes toward drug dealers and rock stars via social threats, whereas SDO predicted negative attitudes to housewives and the 
physically disabled via perceived competition. Therefore, evidence suggests that the DPM is effective in explaining prejudice from both RWA and SDO.

In summary, the Dual Process Model provides a theoretical framework that outlines various predictors of prejudice (Duckitt, 2001). However, it is unclear whether these predictors, or the model in general, inform accent-based prejudice. Significant research with the DPM has been done on immigrants, a group likely to have an accent. Therefore, a goal of the present thesis was to test whether ideological beliefs and perceptions of threat outlined in the DPM can predict accent-based prejudice.

More recently, Duckitt and colleagues have expanded the operationalization and conceptualization of right-wing authoritarianism (Duckitt, Bizumic, Krauss, \& Heled, 2010; Duckitt \& Bizumic, 2013). They argue that RWA's three-pronged approach - authoritarian submission, authoritarian aggression, and conventionalism - are best treated as distinct constructs that differentially predict prejudice. In this way, they reimagined RWA as authoritarianism, conservatism, and traditionalism, or ACT. Consistent with this reconceptualization, the new scales differentially predict various political and social positions across samples from multiple countries (Duckitt et al., 2010; Duckitt \& Bizumic, 2013). Thus, measuring right-wing authoritarianism - and by extension, the DPM - may be better operationalized by using ACT than RWA.

\section{Threat}

Crucial to both the Dual Process Model (Duckitt, 2001) and a general understanding of why immigrants are stigmatized, is the conceptualization that immigration is a threat to society. Though the DPM accounts for social and group dominance threat, Intergroup Threat Theory (ITT; Stephan \& Stephan, 2000) is a ubiquitous model in social psychology describing different 
kinds of perceived threats that groups pose to one another (Stephan, Ybarra, \& Morrison, 2015). Originally called "Integrated Threat Theory," ITT posits four distinct threat constructs: realistic threat, symbolic threat, intergroup anxiety, and negative stereotyping (Stephan \& Stephan, 2000).

Realistic threat stems from realistic group conflict theory (Bobo, 1988), and describes the extent to which people feel their resources or power are endangered by the outgroup (Stephan \& Stephan, 2000). According to realistic group conflict theory, because people form groups in order to maximize feasible cooperation, they tend to compete over limited resources in their environment. While the theory suggested that groups are in competition for physical resources, ITT expanded the notion of realistic threat to include any threats to the physical well-being of an individual or group (Stephan \& Stephan, 2000). For example, someone might feel threatened about immigrants coming to take their jobs. It is important to note that realistic threat does not need to be genuine threat to a person or group. The "realism" of the threat is in what the threat is targeting. People can perceive the realistic threat of a foreign nation coming to invade and steal their land for instance, even when if it is a highly unlikely event.

Symbolic threat, on the other hand, finds its origins in symbolic threat theory (Sears, 1988), and refers to threats to a person or society's way of life. Symbolic threat theory explained the Black-White divide in the United States by discussing the notion of symbolic racism. Here, Blacks are not a threat to White resources or territory, but rather to White culture. Symbolic threat has been expanded to other intergroup conflicts. In this category, spreading a foreign religion, dismantling traditions, and bringing a new culture into a region are all forms of symbolic threat. Whereas realistic threat addresses measurable outcomes, symbolic threats address what is unquantifiable. One way in which immigrants pose symbolic threat is through their language. Speaking a language other than English in public can cause others to view them 
with suspicion. Another symbolic threat would be the threat posed by a group like Black Lives Matter. They threaten White dominance in society, even though they do not (outright) propose that the jobs or positions Whites have should be given to Blacks.

Intergroup anxiety relates to the emotions people feel during or in anticipation of an intergroup interaction (Stephan, 2014; Stephan \& Stephan, 1985). There are three components which form this construct. The affective component is how exactly a person feels when engaging an outgroup member or considering engaging them. Research has shown that intergroup contact makes people feel uneasy and distressed (Amodio, 2009). The cognitive component to intergroup anxiety is related to the perceived consequences of an intergroup reaction. People may think they will be ridiculed, harmed, rejected, or misunderstood around the interaction. It will also seem more difficult than an interaction with an ingroup member. The final component is the physiological component. People who engage in intergroup contact have higher electrodermal activity, blood pressure, cortisol levels, etc. (Trawalter, Adam, Chase-Lansdale, \& Richeson, 2012). These components feed off one another. For example, imagining negative consequences can lead to negative feelings and subsequent physiological arousal. Alternatively, people may have a physiological response, attribute it to their intergroup situation, then experience feelings that would normally be associated with the response.

In the context of the DPM and prejudice, intergroup anxiety is thought to play a crucial role. Intergroup anxiety has consistently been shown to directly predict prejudice (e.g. Choma, Jagayat, Hodson, \& Turner, 2018; Riek, Mania \& Gaertner, 2006). Moreover, it may mediate the relation between sociopolitical ideology and prejudice. Research by Costello and Hodson (2011), for example, showed that SDO predicted modern prejudice, entirely via intergroup anxiety. Miller, Smith, and Mackie (2004) suggested that intergroup anxiety (among other negative 
intergroup emotions) partially mediated the relation between SDO and prejudice as defined by both the Modern Racism Scale and feeling thermometers. Finally, in studying prejudice against people with disabilities, Crowson and Brandes (2010) showed that intergroup anxiety fully mediated the relation between SDO and prejudice. Still, these effects have not been studied under the context of generalized prejudice, nor under the context of accents.

Negative stereotyping refers explicitly to negatively-valenced stereotypes (Stephan \& Stephan, 1993). As seen in the SCM, stereotypes can be positive as well as negative. Kenyans are stereotyped as being fast runners, whereas African-Americans are stereotyped as having good rhythm. Yet, negative stereotypes specifically, activate threat responses. Lower-class young Blacks who are stereotyped as being prone to theft and violence may cause an individual to respond as though they were a realistic threat. In this way, negative stereotypes suggest that people may be threatening in specific ways, due to their group membership(s).

Research has supported ITT's relation to prejudice. A meta analysis by Riek, Mania, and Gaertner (2006) examined the effects of various threats across 95 studies to verify their predictive power. Only studies which directly examined realistic and symbolic threats were used. The authors discovered five threats that consistently predicted negative attitudes: realistic threats, symbolic threats, intergroup anxiety, negative stereotypes and a group esteem threat. ITT threats have been shown to predict specific intergroup attitudes including White-Black relations (Stephan et al., 2002), gender attitudes (Stephan, Stephan, Demitrakis, Yamada, \& Clason, 2000), and attitudes toward immigrants (Stephan, Ybarra, \& Bachman, 1999). On a behavioural level, threats have been shown to correlate with a desire to prevent the spread of Islamic ideas (Matthews \& Levin, 2012) and avoiding intergroup contact (Barlow, Louis, \& Terry, 2010). Thus, Intergroup Threat Theory has strong support for its relation to prejudice. 
In summary, the present thesis examines the role of perceived threat in prejudice. Though the DPM has its own indices of threat, the significant research behind ITT suggests that it may account for threats which the DPM does not fully cover (e.g. intergroup anxiety). Therefore, this thesis examines the role of intergroup anxiety, specifically, testing whether it can be predicted by RWA and SDO, and if it mediates the relation between ideology and prejudice.

\section{Thesis Overview}

This thesis examines accent-based prejudice and its predictors, drawing on the Stereotype Content Model (Fiske et al., 2002), the solidarity/status/dynamism model (Fuertes et al., 2012), the Dual Process Model (Duckitt, 2001), and intergroup anxiety as outlined by Intergroup Threat Theory (Stephan \& Stephan, 2000). The SCM provides a model most similar to the existing solidarity/status/dynamism tritactic model in the accent literature (Zahn \& Hopper, 1985). Thus, by incorporating the SCM and the triad, I compare how well each model captures accent-based prejudice. The DPM (Duckitt, 2001) is an outline for the origins of prejudice. The ideological antecedents outlined in the DPM have not been researched with accents (see Hansen \& Dovidio, 2016 for an exception). Using RWA and SDO under the DPM umbrella allows me to determine whether the predictors for accent-based prejudice are the same as for non-accent, generalized and specific prejudice. Intergroup anxiety provides a potential mediator between ideology and accent-based prejudice. While experiencing anxiety about outgroups is not the same as having negative attitudes toward them, the two are linked, with intergroup anxiety often mediating the

relation between SDO and prejudice (e.g. Costello \& Hodson, 2011; Crowson \& Brandes, 2010). Therefore, including intergroup anxiety presents a unique perspective to perceptions of accents due to its relation with both ideology and prejudice. The present thesis examines the utility of the DPM and intergroup anxiety for predicting accent-based prejudice. To summarise, my thesis 
merges theory used to study accent-based prejudice (i.e. the solidarity/status/dynamism model) with the SCM, the DPM, and intergroup anxiety, which have traditionally been used to study ethnic/colour-based stereotypes and prejudice.

To evaluate accents, I utilized stimuli comprised of accented speech. The distinction between evaluating an accent and evaluating an accented speaker is important. First, people likely rely on ethnic stereotypes when evaluating an accent. For example, showing a participant the words "Chinese accent" may prime them to think of someone who is ethnically Chinese, rather than focusing on the speech itself. While this priming is also likely to occur via the auditory stimulus, whereby the participant imagines the ethnicity of the speaker, I can ascribe that priming to the accent, rather than the written words. Second, there may be differences in how people rate an ethnic prototype (e.g. Chinese person) compared to how they would rate the traditionally-associated accent (e.g. Chinese accent). One possibility is that multicultural contact with non-accented people may have already reduced prejudice against the ethnicity (or nationality, etc.), but not people with the accent. If an individual has many Chinese friends who do not have accents, for example, they may classify those people differently than they would a Chinese person who does have an accent.

Despite the advantages of using recorded accents, it is important to maximize standardization; speakers have individual vocal qualities that differ from one person to another. Moreover, all speakers read from the same scripts. Using scripts controls for idiomatic speech that might be more common in one accent's culture than another. Research has shown that there are gender effects in how people perceive accents (Nelson, Signorella, \& Botti, 2016). To account for these effects, I used multiple speakers for each accent, as to control for individual factors and gender. Speakers were recorded saying phrases three times, and the best "take" was 
be chosen by raters. Audio was normalized in volume, and if 'takes' contained mistakes, files were edited - splicing recordings across takes to create as clean and error-free of an audio clip as possible ${ }^{1}$.

\section{Hypotheses}

The purpose of my study was to investigate how accents are evaluated using the SCM framework (Fiske et al., 2002) and the solidarity/status/dynamism triad (Zahn \& Hopper, 1985), and consider ideological predictors of accent-based prejudice (Duckitt, 2001). According to the SCM, stereotyped groups fall into quadrants based on societal evaluations of high versus low warmth and high versus low competence. I test whether accents are similarly organized on the SCM as their ethnicities (see Lee \& Fiske, 2006 for organization of ethnicities), with sharp distinctions between quadrants (see Figure 2). Two primary hypotheses and four secondary hypotheses were evaluated.

\footnotetext{
${ }^{1}$ While splicing within a take was necessary for over $75 \%$ of takes (participants were allowed to pause and restart a sentence if they felt they made a mistake), splicing across takes was much more rare, with less than $5 \%$ of takes requiring this level of edits.
} 


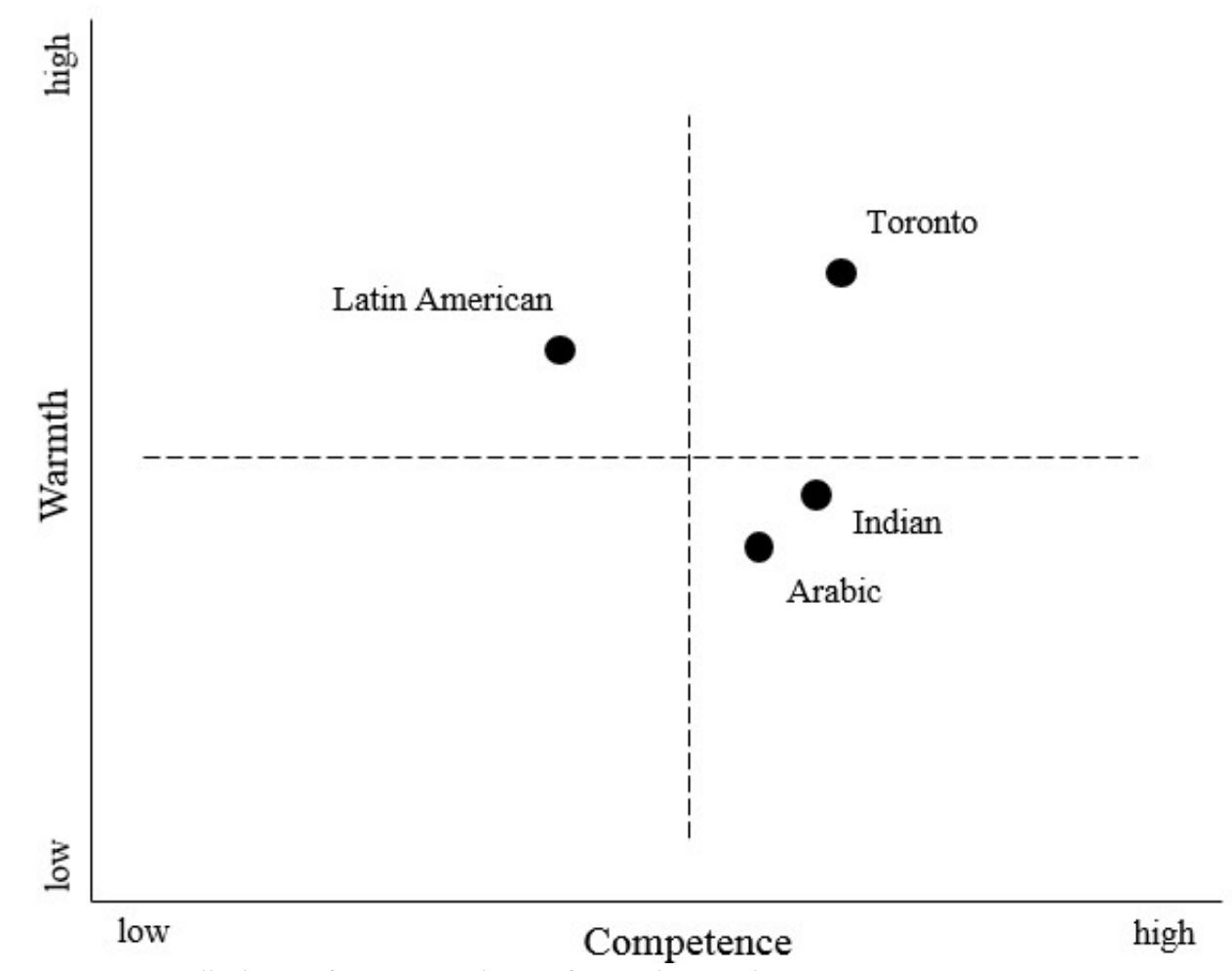

Figure 2. Predictions of SCM quadrants for each tested accent

\section{Primary Hypotheses}

Hypothesis 1a: Participants will rate the Indian-, Arabic-, and Latin American-accented speakers as perceived by society to be less warm and/or less competent than the Torontoaccented speakers (see Figure 2). Thus, evaluations of accents will be contextualized under the Stereotype Content Model (SCM; Fiske et al., 2002). In particular, I predict that the Indian- and Arabic-accented targets will be stereotyped as lower in warmth and higher in competence (contemptuous prejudice), the Latin American-accented targets stereotyped as higher in warmth and lower in competence (paternalistic prejudice), and the Toronto-accented targets stereotyped as higher in both warmth and competence (allies to the ingroup).

Hypothesis 1b: The Indian, Arabic, and Latin American accented speakers will also be evaluated as lower in solidarity, status, and dynamism (Fuertes et al., 2012) than their Toronto- 
accented counterparts. Specifically, the Toronto-accented targets will be higher in solidarity, status, and dynamism than the other speakers. Indian- and Arabic-accented targets will be higher in status and lower in solidarity. Latin American-accented targets will be lower in status and higher in solidarity. No specific prediction is made for dynamism.

Hypothesis 1c: Further, participants will evaluate the Toronto-accented speakers more favourably than speakers with any of the other three accents. In this way, there will be accentbased prejudice against people with the Arabic, Indian, or Latin American accents.

Hypothesis 2: Right-wing ideology (RWA and SDO; see Duckitt, 2001) will predict negative stereotypes against accented groups. Through stereotypes outlined by the SCM (Fiske et al., 2002), participants who hold stronger right-wing ideologies will perceive foreign-accented speakers more negatively than the Toronto-accented speakers.

\section{Secondary Hypotheses}

Hypothesis 3: Intergroup anxiety (see Stephan, 2014) and target thermometer measures will also be predicted by RWA and SDO (see Duckitt, 2001). Higher RWA and SDO will predict greater intergroup anxiety, as well as more negative evaluations of all targets: Toronto-, Indian-, Latin American-, and Arabic-accented speakers.

Hypothesis 4: Accent evaluations will relate to evaluations of their associated ethnic group. However, this relation will only be of moderate strength due to the potential mismatch of accent and ethnicity. In other words, there will be a stronger association between evaluations of an accent and those of their (stereo)typical ethnic group than there would be between evaluations of an accent and those of other ethnic groups. Participants will display prejudice more similarly toward people who come from a region/culture and people who speak with an accent that typically originates from that region/culture than they would between those same people from 
the region/culture and people who speak with a different accent. For example, Torontonians will be evaluated more similar to Toronto-accented targets than they will to Indian-accented targets.

Hypothesis 5: The SCM (Fiske et al., 2002) and the solidarity/status/dynamism model (Furetes et al., 2012) will overlap. In other words, warmth and solidarity will be highly correlated, as will competence and status. Moreover, each pair will similarly predict target ratings (accent-based prejudice). However, dynamism will be a third dimension that uniquely explains a proportion of accent-based prejudice not accounted for by the Stereotype Content Model.

Hypothesis 6: Duckett et al.'s ACT measure (2010) will account for prejudice more comprehensively than will RWA. In other words, target and ethnic evaluations will be predicted to a greater degree by authoritarianism, conservatism, traditionalism, and SDO than do RWA and SDO.

\section{Method}

Participants. Participants were recruited using the Amazon's Mechanical Turk in exchange for a small amount of compensation (\$1 USD). Only workers living in Canada or the US were permitted to sign up for the study. A power analysis using PANGEA software (Westfall, 2016) indicated that a sample size of 150 would provide power of .92, assuming a moderate effect size $(d=.45)$ and $67 \%$ of variance being accounted for by error and an accentparticipant interaction. Differences between groups in the SCM tend to have effect sizes that range from non-significant (within-quadrant) to large (between opposite quadrants; e.g. Cuddy et al., 2009); thus, assuming a moderate effect size should provide enough power to measure the between-quadrant differences. 
Table 1

Demographics

\begin{tabular}{|c|c|c|}
\hline & $\begin{array}{c}\text { Total } N=124 \\
\text { Mean }(\mathrm{SD}) \text { or } N\end{array}$ & $\%$ of Sample \\
\hline Age & $38.1(12.6)$ & \\
\hline Gender & $64 \mathrm{~F}, 59 \mathrm{M}, 1$ other & $52 \% \mathrm{~F}$ \\
\hline \multicolumn{3}{|l|}{ Ethnic background ${ }^{1}$ : } \\
\hline Chinese & 2 & $1.5 \%$ \\
\hline South Asian & 2 & $1.5 \%$ \\
\hline African-American & 17 & $12.8 \%$ \\
\hline Arab/West Asian & 1 & $.8 \%$ \\
\hline South East Asian & 4 & $3.0 \%$ \\
\hline Latin American & 5 & $3.8 \%$ \\
\hline Japanese & 2 & $1.5 \%$ \\
\hline Korean & 1 & $.8 \%$ \\
\hline Native American/Indigenous & 4 & $3.0 \%$ \\
\hline Caucasian & 95 & $71.4 \%$ \\
\hline \multicolumn{3}{|l|}{ Education: } \\
\hline High school graduate & 20 & $16.1 \%$ \\
\hline Some college & 28 & $22.6 \%$ \\
\hline Certificate/diploma & 13 & $10.5 \%$ \\
\hline College degree & 39 & $31.5 \%$ \\
\hline Graduate degree & 24 & $19.4 \%$ \\
\hline \multicolumn{3}{|l|}{ Annual income: } \\
\hline$<\$ 10,000$ & 2 & $1.6 \%$ \\
\hline$\$ 10,000-\$ 19,999$ & 9 & $7.3 \%$ \\
\hline$\$ 20,000-\$ 29,999$ & 24 & $19.4 \%$ \\
\hline$\$ 30,000-\$ 39,999$ & 23 & $18.5 \%$ \\
\hline$\$ 40,000-\$ 49,999$ & 15 & $12.1 \%$ \\
\hline$\$ 50,000-\$ 59,999$ & 11 & $8.9 \%$ \\
\hline$\$ 60,000-\$ 69,999$ & 8 & $6.5 \%$ \\
\hline$\$ 70,000-\$ 79,999$ & 13 & $10.5 \%$ \\
\hline$\$ 80,000-\$ 89,999$ & 2 & $1.6 \%$ \\
\hline$\$ 90,000-\$ 99,999$ & 7 & $5.6 \%$ \\
\hline$\$ 100,000-\$ 149,999$ & 9 & $7.3 \%$ \\
\hline$>\$ 150,000$ & 1 & $.8 \%$ \\
\hline English as a first language & Yes: 119, No: 5 & Yes: $96.0 \%$ \\
\hline Identify as an immigrant & Yes: 11, No: 112 & Yes: $8.9 \%$ \\
\hline \multicolumn{3}{|l|}{ Born in: } \\
\hline Canada & 1 & $.8 \%$ \\
\hline US & 119 & $96.0 \%$ \\
\hline Neither & 4 & $3.2 \%$ \\
\hline \multicolumn{3}{|l|}{ Citizenship } \\
\hline US citizen & 118 & $95.2 \%$ \\
\hline US resident & 6 & $4.8 \%$ \\
\hline
\end{tabular}

Notes. ${ }^{1}$ Participants could choose more than one option. 
During the recruitment process, I encountered some unforeseen challenges. After having finished recruiting the desired 150 participants, I began to examine the data. I found that almost half the participants did not listen to the audio clips in full: i.e. they did not spend enough time on the page to do so. Because the study would be underpowered with the small number of remaining participants, I edited the study to not allow participants to skip past the recordings without having spent enough time on the page to listen to them. The participants who had not spent enough time on the pages were excluded from analyses. Then, I recruited additional participants to reach my sample size goal. Of the 310 remaining individuals who participated in the study, 11 revoked consent for having their data included in the analyses, 1 indicated that they did not pay sufficient attention to the study for their data to be valid, 34 did not make it past the audio check, 16 failed to answer any questions, 5 were cases of people returning to the study for a second time (their first set of responses was used and their second set was deleted), and 119 did not spend enough time on the pages to listen to the audio clips in full. After removing invalid data from across the two waves of data collection, 124 cases remained whose data I analyzed. Participants tended to be female (52\%), middle-aged $(M=38.1, S D=12.6$, range $=19-71)$, white (71.4\%), well educated (84\% greater than high school education), American citizens (95.2\%). Complete demographic breakdowns can be found in Table 1 .

Procedures. The entirety of the study was conducted online using a Qualtrics survey. After giving consent, participants were asked to listen to a brief audio clip, where the speaker said the word, "situation". They then needed to enter this word in order to progress in the survey. Participants then listened to an audio clip randomly from 22 potential targets who had read from a script (see Appendix $\mathrm{C}$ for all scripts). There were four scripts that were presented in a consistent order. The first script, "Stella" was taken from the Speech Accent Archive 
(Weinberger, 2015) and described a shopping request. The second script, "Gina's Pizza Shop" was taken from Baker and Bradlow (2009) and provided fictional directions to a pizza parlour. The third script, "North Wind" is from Aesop's Fables and is recommended for use in the study of phonetics by the International Phonetics Association (1999). Finally, the fourth script, "Comma" is a short story about a veterinary nurse and was taken from the International Dialects of English Archive (2000). The target had one of the following accents: Toronto (6 speakers), Indian (6), Latin American (5), or Arabic (5). After listening to the clip, participants provided evaluations of the target and their accented group. This procedure was repeated for the Gina's Pizza Shop, North Wind, and Comma scripts. Each time, the target was fully randomized - the speaker (and thus accent) could be listened to multiple times, albeit with a different script. Finally, participants evaluated ethnic groups, completed measures of sociopolitical ideology, completed demographic questions, and read a debriefing form.

\section{Measures.}

Right-Wing Authoritarianism. Participants were scored on RWA using a measure developed by Altemeyer (2006). The 12-item scale assesses an individual's tendency to defer to authorities. Items are on a Likert-type scale from 1 (strongly disagree) to 7 (strongly agree).

Social Dominance Orientation. The SDO7 were administered (Ho, Sidanius, Kteily, Sheehy-Skeffington, Pratto, Henkel, Foels, \& Stewart, 2015). Participants completed the 16-item long version of the measure which is rated on a Likert-type scale from 1 (strongly disagree) to 7 (strongly agree).

$\boldsymbol{A C T}$. Participants were also given the shortened 18-item version of Duckitt et al.'s (2010) authoritarianism, conservatism, and traditionalism scale. Similar to RWA, the Likert-type 
scale asked participants rate their agreement with certain statements from 1 (strongly disagree) to 7 (strongly agree).

Intergroup Anxiety. Two items were used as a proxy for intergroup anxiety. The first asked how anxious participants would feel interacting with someone who had the target's accent from 1 (not anxious at all) to 7 (very anxious). The second item asked how comfortable participants would feel interacting with the person from 1 (not comfortable at all) to 7 (very comfortable).

Accent evaluations. Participants completed measures of societal prejudice via the SCM. The measure developed by Fiske et al. (1999) is a 9-item-long 7-point Likert-type scale and asks participants to rate members of a group "as viewed by society" according to specific adjectives. Examples of adjectives include competent, independent, warm, and sincere. Measures of solidarity, status, and dynamism were taken via adjective ratings highlighted by Zahn and Hopper (1985) on 7-point Likert-type scales. In total, 17 unique items were used: 5 designed to measure competence, 4 for warmth, 3 for status, 2 for solidarity, and 3 for dynamism. One warmth item was used as the third solidarity item (overlapping scales).

Target evaluations (prejudice) ${ }^{2}$. A measure of individual prejudice was also included: a thermometer scale asking participants to rate the accented target from 0 -extremely unfavourable to 100 - extremely favourable. Additionally, participants were asked to rate how easy/difficult the target was to understand on a 7-point scale from 1 (very easy to understand) to 7 (very difficult to understand).

\footnotetext{
2 Target evaluations were grouped by accent in the analyses to measure accent-based prejudice
} 
Ethnic group evaluations (prejudice). Participants completed thermometer scales asking for attitudes of people from Toronto, people from India, people from Latin American countries, and people from Arabic countries. These ratings were given on a scale from 0 - extremely unfavourable to 100 - extremely favourable.

\section{Data Analysis}

Data were analyzed using a variety of statistical techniques from multiple software packages $^{3}$ (see Appendix B for a list of software used). ANOVAs were used to detect differences between accents on all averaged IVs and DVs, using an alpha of .05 as the standard for significance. Because I was interested in how accents differ from one another, planned contrasts using $t$-tests were conducted when ANOVAs detect significant differences. Each scale requires a confirmatory factor analysis (CFA) to verify the factor structure initiated by theory. In particular, warmth, competence, solidarity, status, dynamism, RWA, SDO, authoritarianism, conservatism, and traditionalism had CFAs performed.

Importantly, the mixed methods (within-subjects and between-subjects) design of this study required that multilevel modeling be used in most analyses, including the CFAs. One assumption of single-level statistical tests is that each response is independent from another. However, when designs include a within-subjects component, a single participant will respond to a dependent variable multiple times, and their initial responses may impact subsequent responses. Multilevel models allow researchers to parse variance into within- and betweensubject partitions. Predictors and covariates can then be analyzed on one (or both) of these levels. Individual differences, such as personality or political ideology, would be analyzed at the between-participant level, but manipulations between trials might be placed at the within-

\footnotetext{
${ }^{3}$ Data and limited R code can be found at https://osf.io/s4bza
} 
participant level. For the current study, scores were clustered by participant ID to help account for non-independence of responses. All target-directed variables (e.g. warmth and competence) were analyzed at the within-participant and between-participant levels, as each participant listened to four targets. The average individual may have perceived the various accented targets differently, but the extent of these differences may have varied between people. All measures of ideology (e.g. ACT) and ethnic prejudice (e.g. people who come from Arabic countries) were analyzed at the between-participant level. A participant's ideology or perceptions of ethnic groups should not differ depending on the target they listen to, but ideologies and perceptions may differ between individuals. When analyzing structural models, latent variables were constructed for all scales. Accent effects were predicted to occur at both the within- and between-participant levels: participants would perceive targets differently depending on the target's accent, and there would be variation among participants in what those differences are perceived to be. See Figure A1 for an example of a structural model that was tested.

While multilevel structural equation modeling is the most recent and comprehensive method of analyzing this type of data, RWA, SDO, and the SCM have historically been tested using averaged scores rather than latent constructed variables. In this way, the theory around ideology and stereotype content have been built and validated using these averages. Furthermore, the SCM has traditionally examined warmth and competence separately, whereas my analyses were multivariate. While it is unlikely that there would be great differences in findings between the two analysis methods, I decided to also re-run the analyses using averaged variables to verify that the same pattern of results holds.

This second set of analyses that relied on variables calculated by averaging items, used likelihood ratio tests (LRT) based on restricted maximum likelihood to determine the 
significance of random effects (Morrell, 1998). LRTs examine whether variance components in a multilevel model are significantly different from zero. The test statistic, simply $L R T$ (also seen as $L R_{\text {REML }}$ or $\lambda$ ), is tested against a chi-squared distribution, and results in a $p$-value. An alpha of 05 was used as the criterion for significance in these analyses. These analyses also involved calculation of the intraclass correlation coefficient (ICC) for certain models. The ICC refers to the proportion of variance in the dependent variable that can be accounted for by between-cluster effects - specifically, random intercepts. Higher ICC values indicate that a greater proportion of the dependant variable is accounted for by using clustering via multilevel modeling.

\section{Results}

\section{Data structure}

For each of the dependent and independent variables, values were averaged across items to calculate general scale scores. Additionally, the accent of each stimulus was noted. The averaged scores for each scale were separated by accent, then means and standard deviations were calculated (see Table 2). One-way ANOVAs were used to verify that ideology did not vary by accent. Finally, I calculated Cronbach's as for each scale and recorded correlations between continuous variables (see Table 3 ). 


\section{Table 2}

Variable means and (standard deviations) by accent

\begin{tabular}{|c|c|c|c|c|c|c|c|c|}
\hline & Overall & Toronto & Indian & Latin American & Arabic & $F$-statistic & $p$-value & $\eta_{\mathrm{p}}{ }^{2}$ \\
\hline RWA & $3.07(1.58)$ & $3.16(1.50)$ & $3.02(1.64)$ & $3.03(1.70)$ & $3.05(1.51)$ & $F(3,492)=.21$ & .890 & .001 \\
\hline SDO & $2.58(2.28)$ & $2.64(1.33)$ & $2.64(1.33)$ & $2.54(1.46)$ & $2.49(1.31)$ & $F(3,492)=.39$ & .762 & .002 \\
\hline Authoritarianism & $3.69(1.57)$ & $3.68(1.42)$ & $3.67(1.56)$ & $3.69(1.76)$ & $3.73(1.58)$ & $F(3,480)=.03$ & .992 & .000 \\
\hline Conservatism & $3.45(1.56)$ & $3.47(1.41)$ & $3.39(1.57)$ & $3.43(1.72)$ & $3.51(1.60)$ & $F(3,484)=.15$ & .932 & .001 \\
\hline Traditionalism & $3.26(1.68)$ & $3.35(1.66)$ & $3.20(1.73)$ & $3.14(1.70)$ & $3.31(1.64)$ & $F(3,492)=.40$ & .750 & .002 \\
\hline Competence & $5.02(1.35)$ & $5.57(1.08)$ & $5.04(1.36)$ & $4.32(1.31)$ & $4.99(1.37)$ & $F(3,491)=19.06$ & $<.001$ & .104 \\
\hline Warmth & $4.85(1.19)$ & $4.99(1.26)$ & $4.91(1.21)$ & $4.64(1.07)$ & $4.78(1.17)$ & $F(3,491)=2.03$ & .108 & .012 \\
\hline Solidarity & $4.95(1.18)$ & $5.06(1.23)$ & $5.10(1.24)$ & $4.68(1.00)$ & $4.86(1.17)$ & $F(3,491)=3.20$ & .023 & .019 \\
\hline Status & $4.75(1.46)$ & $5.46(1.09)$ & $4.82(1.50)$ & $3.79(1.39)$ & $4.70(1.39)$ & $F(3,491)=30.40$ & $<.001$ & .157 \\
\hline Dynamism & $4.30(1.11)$ & $4.57(1.11)$ & $4.17(1.18)$ & $4.03(1.00)$ & $4.39(1.07)$ & $F(3,491)=5.85$ & $<.001$ & .035 \\
\hline Anxious & $2.67(1.81)$ & $2.28(1.70)$ & $2.82(1.90)$ & $2.74(1.81)$ & $2.90(1.78)$ & $F(3,490)=3.12$ & .026 & .019 \\
\hline Comfortable & $5.47(1.62)$ & $5.71(1.61)$ & $5.52(1.63)$ & $5.20(1.68)$ & $5.36(1.53)$ & $F(3,490)=2.12$ & .097 & .013 \\
\hline Understand $^{1}$ & $2.83(1.65)$ & $1.72(1.36)$ & $3.28(1.63)$ & $3.54(1.37)$ & $2.97(1.55)$ & $F(3,490)=37.52$ & $<.001$ & .187 \\
\hline Target evaluations & $70.9(20.4)$ & $71.0(23.3)$ & 71.7(19.9) & $69.8(19.6)$ & $70.9(18.4)$ & $F(3,490)=.16$ & .920 & .001 \\
\hline Ethnic evaluations & & $79.8(19.0)$ & $68.0(25.7)$ & $72.1(23.5)$ & $61.1(28.7)$ & $F(3,121)=36.8$ & .001 & .184 \\
\hline
\end{tabular}

Notes. All non-thermometer measures used 7-point Likert-type scales. Evaluations asked participants to rate the individual/group on a scale from 0 (cold) to 100 (warm).

${ }^{1}$ Higher numbers indicate greater difficulty understanding the speaker. 


\section{Table 3}

Correlations

\begin{tabular}{|c|c|c|c|c|c|c|c|c|c|c|c|c|c|c|c|c|c|}
\hline Measure & 1 & 2 & 3 & 4 & 5 & 6 & 7 & 8 & 9 & 10 & 11 & 12 & 13 & 14 & 15 & 16 & 17 \\
\hline 1. RWA & .95 & .94 & .89 & .91 & .91 & & & & .91 & .89 & .90 & .92 & .64 & & & & \\
\hline 2. SDO & $.74 *$ & & & & & & & & & & & & & & & & \\
\hline 3. Authoritarian & $.84 *$ & $.58^{*}$ & & & & & & & & & & & & & & & \\
\hline 4. Conservative & $.86^{*}$ & $.64^{*}$ & $.86^{*}$ & & & & & & & & & & & & & & \\
\hline 5. Traditional & $.92 *$ & $.60 *$ & $.80 *$ & $.83 *$ & & & & & & & & & & & & & \\
\hline 6. Anxious & $.40^{*}$ & $.39 *$ & $.28 *$ & $.29 *$ & $.35^{*}$ & & & & & & & & & & & & \\
\hline 7. Comfortable & $-.32 *$ & $-.23 *$ & $-.27 *$ & $-.23 *$ & $-.29 *$ & $-.60 *$ & & & & & & & & & & & \\
\hline 8. Difficulty & $.27^{*}$ & $.27 *$ & $-18 *$ & $.19 *$ & $.23 *$ & $.45^{*}$ & $-.43 *$ & & & & & & & & & & \\
\hline 9. Competence & .01 & -.01 & .01 & .05 & .02 & -.07 & $.32 *$ & $-.36^{*}$ & & & & & & & & & \\
\hline 10. Warmth & -.05 & -.03 & $-.10^{\dagger}$ & -.01 & -.04 & $-.19 *$ & $.43^{*}$ & $-.24 *$ & $.53 *$ & & & & & & & & \\
\hline 11. Solidarity & -.04 & -.06 & -.06 & .03 & -.03 & $-.18 *$ & $.41 *$ & $-.23 *$ & $.55^{*}$ & $.91 *$ & & & & & & & \\
\hline 12. Status & -.01 & -.01 & .00 & .03 & .00 & $-.09^{\dagger}$ & $.28 *$ & $-.39 *$ & $.84 *$ & $.56^{*}$ & $.58 *$ & & & & & & \\
\hline 13. Dynamism & .06 & .08 & .05 & .04 & .06 & $.14^{\dagger}$ & $.13^{\dagger}$ & -.08 & $.62 *$ & $.28 *$ & $.29 *$ & $.48 *$ & & & & & \\
\hline 14. Target & $-.20 *$ & $-.25^{*}$ & $-.15^{*}$ & -.05 & $-.13^{\dagger}$ & $-.42 *$ & $.62 *$ & $-.33 *$ & $.42 *$ & $.61^{*}$ & $.58 *$ & $.37 *$ & $.21 *$ & & & & \\
\hline 15. Toronto & -.09 & $-.17 *$ & .06 & $.13^{\dagger}$ & -.02 & $-.25 *$ & $.16^{*}$ & $-.12^{\dagger}$ & $.16^{\dagger}$ & $.21 *$ & $.23 *$ & $.15^{*}$ & .00 & $.39 *$ & & & \\
\hline 16. India & $-.36^{*}$ & $-.42 *$ & $-.24 *$ & $-.16^{*}$ & $-.24 *$ & $-.28 *$ & $.35^{*}$ & $-.18 *$ & $.25^{*}$ & $.28^{*}$ & $.25^{*}$ & $.18^{*}$ & $.11^{\dagger}$ & $.51 *$ & $.54 *$ & & \\
\hline 17. Latin America & $-.28 *$ & $-.35^{*}$ & $-.19 *$ & -.08 & $-.17 *$ & $-.30 *$ & $.40^{*}$ & $-.21 *$ & $.25^{*}$ & $.27^{*}$ & $.26^{*}$ & $.18^{*}$ & $.15^{*}$ & $.53 *$ & $.59^{*}$ & $.79 *$ & \\
\hline 18. Arabic nations & $-.38 *$ & $-.40 *$ & $-.33 *$ & $-.26^{*}$ & $-.28 *$ & $-.24 *$ & $.38^{*}$ & $-.17 *$ & $.25^{*}$ & $.26^{*}$ & $.22 *$ & $.17^{*}$ & $.14^{\dagger}$ & $.47^{*}$ & $.46^{*}$ & $.83^{*}$ & $.75^{*}$ \\
\hline
\end{tabular}

Note. Correlations are below the diagonal and scale reliability Cronbach's $\alpha$ s are in the first row. RWA = right wing authoritarianism, $\mathrm{SDO}=$ social dominance orientation. Authoritarian, conservative, and traditional refer to the subscales of the ACT measure.

Competence and warmth refer to subscales of the Stereotype Content Model. Solidarity, status, and dynamism are subscales of the SSD measure. Anxious and comfortable are measures of intergroup anxiety. Difficulty represents how difficult the speaker was to understand. Measures 14 through 18 were thermometer evaluations of the target, and of people from the respective regions.

${ }^{\dagger} p<.05$

$* p<.001$ 
To investigate the properties of each scale in more detail, skew, range, and kurtosis were examined (see Field, 2013). If visual inspection or abnormally high skew/kurtosis values (e.g. > 3) indicated great deviation from the normal distribution, non-parametric tests were used in lieu of parametric ones. Ideology - as measured through RWA and SDO - demonstrated positive skew, RWA: $b_{1}=.21, S E=.11$; SDO: $b_{1}=.51, S E=.11$. In other words, more participants were in the right tail of the distribution than would be found had the distribution been normal.

Additionally, kurtosis values were negative for RWA, $b_{2}=-1.01, S E=.22$, and SDO, $b_{2}=-.68$, $S E=.22$, indicating wide spreads of values. An examination of the histograms for right-wing ideology showed that the distributions were bimodal; scores were clustered on the low end (near 1 on the scale from 1 to 9 ) and the middle of the distribution (near 4). However, the lack of scores is not surprising, as Mechanical Turk workers tend to be more left-wing on social issues and less authoritarian than the general American population (Clifford, Jewell, \& Waggoner, 2015). As expected, the ACT subscales showed similar trends, except for traditionalism, which had a monomodal distribution.

The primary dependent variables: warmth, competence, solidarity, status, dynamism, and target evaluations, showed distributions that were acceptably normal. Positive skewness emerged for anxiety, $b_{1}=.77, S E=.11$, and negative skewness for comfort, $b_{1}=-.98, S E=.11$. All ethnic thermometers were negatively skewed, Toronto: $b_{1}=-1.03, S E=.11$; Indian: $b_{1}=-.77, S E=.11$; Arabic: $b_{1}=-.46, \mathrm{SE}=.11$; Latin American: $b_{1}=-.94, S E=.11$. Large sample size, visual inspection, and relatively low skewness values are reason to consider these distributions within the bounds of normality (see Field, 2013). 


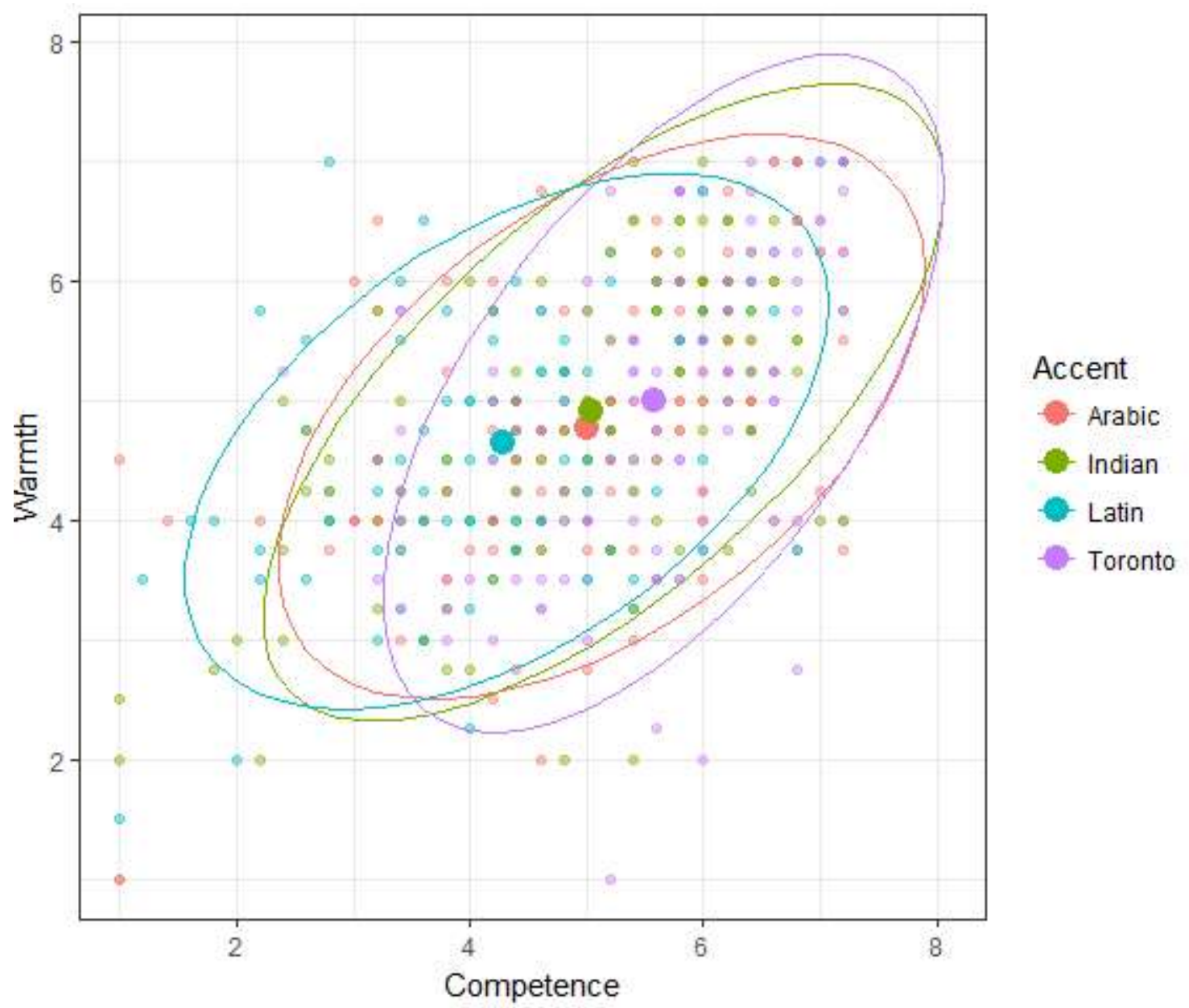

Figure 3: Target means of warmth and competence by accent with $95 \%$ confidence interval ellipses.

\section{Hypothesis 1a: Mean differences in warmth and competence}

To examine whether the Toronto-accented targets were perceived as warmer or more competent than people with Indian, Arabic, or Latin American accents, I conducted two one-way ANOVAs. Planned contrasts compared the Toronto accent (coded as 0 ) to the other accents (coded as 1 in dummy codes; see Figure 3 for plotted means). For warmth, no differences were found between the Toronto, $M=4.99, S D=1.26$; Indian, $M=4.91, S D=1.21$; Latin American, $M=4.64, S D=1.07$; and Arabic accents, $M=4.78, S D=1.17 ; F(3,491)=2.03, p=.108, \eta_{\mathrm{p}}{ }^{2}=$ .012. On the other hand, with respect to competence, the Toronto, $M=5.57, S D=1.08$; Indian, $M=5.04, S D=1.36$; Latin American, $M=4.32, S D=1.31$; and Arabic accented targets, $M=$ 
4.99, $S D=1.37$, were perceived differently, $F(3,491)=19.06, p<.001, \eta_{\mathrm{p}}{ }^{2}=.001$. Moreover, contrasts revealed that the Toronto accent was evaluated as more competent than the Indian accent, $t(272)=3.58, p<.001$; Latin American accent, $t(240)=8.15, p<.001$; and Arabic accent, $t(251)=3.37, p<.001$. The Latin American accent was also considered less competent than the Indian, $t(240)=4.16, p<.001$, and Arabic accents, $t(219)=3.74, p<.001$. Therefore, results were partially consistent with Hypothesis 1a: the Toronto accent was perceived as more competent - but not warmer - than the other three accents.

\section{Hypothesis 1b: Mean differences in solidarity, status, and dynamism}

Similarly, three one-way ANOVAs were conducted to compare the Toronto accent to the other three accents on measures of solidarity, status, and dynamism. Significant differences were discovered between accents on all three scales: solidarity, $F(3,491)=3.20, p=.023, \eta_{\mathrm{p}}{ }^{2}=.019$; status, $F(3,491)=30.40, p<.001, \eta_{\mathrm{p}}{ }^{2}=.157$; and dynamism, $F(3,491)=5.85, p<.001, \eta_{\mathrm{p}}{ }^{2}=$ .035. Tests which were significant were followed up by contrast analyses. Both the Toronto, $t(237)=2.41, p=.017$, and Indian targets, $t(237)=2.71, p=.007$, were rated as higher in solidarity than the Latin American targets. The Toronto targets were rated as higher-status than the other three targets: Indian, $t(267)=4.27, p<.001$; Latin American, $t(238)=10.36, p<.001$; and Arabic, $t(247)=4.94, p<.001$. Moreover, the Latin American accent was considered lower status than either the Indian, $t(237)=5.19, p<.001$, or Arabic accents, $t(217)=4.73, p<.001$. The Toronto targets were rated more dynamic than the Indian, $t(272)=2.96, p=.003$, and Latin American targets, $t(240)=3.92, p<.001$. The Arabic targets were also more dynamic than the Latin American targets, $t(217)=2.56, p=.011$. In summary, in line with Hypothesis $1 \mathrm{~b}$, there were differences in how accents were perceived in terms of solidarity, status, and dynamism. 
However, in contrast to my predictions, the Toronto accent was not consistently rated higher than the other accents across the scales.

\section{Hypothesis 1c: Mean differences in target evaluations}

For the final analysis of differences in accent-based prejudice, I conducted a one-way ANOVA on the thermometer measure where participants rated the targets directly. Contrary to my Hypothesis, the groups were not evaluated differently: there were no significant differences found between the Toronto, $M=71.0, S D=23.3$; Indian, $M=71.7, S D=19.9$; Latin American, $M=69.8, S D=19.6$; or Arabic-accented targets, $M=70.9, S D=18.4 ; F(3,490)=.16, p=.920$, $\eta_{\mathrm{p}}^{2}=.001$

\section{Hypothesis 2: Right-wing ideologies as predictors of accent-based prejudice}

The primary purpose of this thesis was to examine the predictors of accent-based prejudice. Specifically, to test whether the right-wing ideologies RWA and SDO - which together traditionally strongly predict ethnic prejudice - also predict accent-based prejudice. As anticipated, participant RWA and SDO scores did not differ depending on the accents they listened to (see Table 2). Confirmatory factor analyses were run on our predictor measures of right-wing ideology (see Table 4). The 12-item RWA measure loaded onto a single latent factor, and the 16-item SDO measure loaded onto a second latent factor. For both RWA and SDO, model fit was poor (CFIs $=.726$ and .734 respectively). Ideally, CFI values approach 1, with good fit being >.95 (Schreiber, Stage, King, Nora, \& Barlow, 2006). Measurement models (CFAs) tend to have higher CFI values, as the index decreases based on the number of parameters. RWA and SDO not having reasonable indices suggest that the constructs are poor or non-unidimensional in this sample. However, because these scales have been well-established in prejudice literature (e.g. Ho et al., 2015), I decided to continue with the multi-level analyses. 
Table 4

Standardized confirmatory factor analysis loadings for RWA, SDO, and the ACT subscales

\begin{tabular}{|c|c|c|c|c|c|}
\hline Item number/statistic & RWA & $\mathrm{SDO}$ & Authoritarianism & Conservatism & Traditionalism \\
\hline 1 & .581 & .806 & .556 & .675 & .559 \\
\hline 2 & .668 & .926 & .827 & .811 & .909 \\
\hline 3 & .849 & .901 & .657 & .751 & .893 \\
\hline 4 & .881 & .859 & .886 & .861 & .758 \\
\hline 5 & .896 & .648 & .665 & .872 & .874 \\
\hline 6 & .615 & .681 & .885 & .703 & .683 \\
\hline 7 & .542 & .354 & & & \\
\hline 8 & .927 & .452 & & & \\
\hline 9 & .542 & .810 & & & \\
\hline 10 & .843 & .617 & & & \\
\hline 11 & .698 & .802 & & & \\
\hline 12 & .898 & .650 & & & \\
\hline 13 & & .698 & & & \\
\hline 14 & & .672 & & & \\
\hline 15 & & .712 & & & \\
\hline 16 & & .654 & & & \\
\hline$\chi^{2}(d f)$ & $1595(54)$ & $1808(104)$ & 212(9) & 296(9) & 281(9) \\
\hline$p$-value & $<.001$ & $<.001$ & $<.001$ & $<.001$ & $<.001$ \\
\hline CFI & .726 & .734 & .884 & .855 & .876 \\
\hline RMSEA & .247 & .186 & .216 & .256 & .247 \\
\hline$p$-value & $<.001$ & $<.001$ & $<.001$ & $<.001$ & $<.001$ \\
\hline
\end{tabular}

Note: All loadings are standardized and significant at the $p<.001$ significance level. RMSEA $p$-value refers to a test of the alternative hypothesis that RMSEA > .05. 
Table 5

Predicting the Stereotype Content Model with ideology via multilevel structural equation modeling

\begin{tabular}{|c|c|c|c|c|}
\hline $\begin{array}{l}\text { Level, scale, } \\
\text { and variable }\end{array}$ & $\begin{array}{l}\text { Model } 1 \\
\text { MLCFA } \\
\end{array}$ & $\begin{array}{l}\text { Model } 2 \\
\text { Ideology }\end{array}$ & $\begin{array}{c}\text { Model } 3 \\
\text { Predictors } \\
\end{array}$ & $\begin{array}{c}\text { Model } 4 \\
\text { Constrained }\end{array}$ \\
\hline \multicolumn{5}{|l|}{ Level 1 (within) } \\
\hline \multicolumn{5}{|l|}{ Competence } \\
\hline Competent & 1.000 & 1.000 & 1.000 & 1.000 \\
\hline Independent & .771 & .785 & .783 & .826 \\
\hline Competitive & .671 & .703 & .678 & .775 \\
\hline Intelligent & .849 & .871 & .858 & .901 \\
\hline Confident & .913 & .932 & .912 & .973 \\
\hline \multicolumn{5}{|l|}{ Warmth } \\
\hline Warm & 1.000 & 1.000 & 1.000 & 1.000 \\
\hline Sincere & .998 & .980 & .969 & 1.013 \\
\hline Tolerant & .981 & .997 & .990 & .999 \\
\hline Good-natured & .935 & .933 & .921 & .947 \\
\hline \multicolumn{5}{|l|}{ Competence } \\
\hline Accent effect & & & .288 & .243 \\
\hline \multicolumn{5}{|l|}{ Warmth } \\
\hline Accent effect & & & .079 & .073 \\
\hline \multicolumn{5}{|l|}{ Covariances } \\
\hline Comp + Warm & .669 & .730 & .658 & .808 \\
\hline \multicolumn{5}{|l|}{ Level 2 (between) } \\
\hline \multicolumn{5}{|l|}{ Competence } \\
\hline Competent & 1.000 & 1.000 & 1.000 & 1.000 \\
\hline Independent & 1.005 & .903 & .907 & .782 \\
\hline Competitive & .631 & .496 & .579 & .177 \\
\hline Intelligent & .970 & .913 & .945 & .759 \\
\hline Confident & .744 & .698 & .743 & .477 \\
\hline \multicolumn{5}{|l|}{ Warmth } \\
\hline Warm & 1.000 & 1.000 & 1.000 & 1.000 \\
\hline Sincere & 1.387 & 1.548 & 1.617 & 2.546 \\
\hline Tolerant & 1.247 & 1.201 & .226 & 1.701 \\
\hline Good-natured & .982 & .976 & 1.029 & 1.021 \\
\hline \multicolumn{5}{|l|}{ Competence } \\
\hline $\mathrm{RWA}^{\dagger}$ & & & -.148 & -.128 \\
\hline $\mathrm{SDO}^{\dagger}$ & & & -.111 & -.147 \\
\hline Accent effect & & & 2.597 & .058 \\
\hline \multicolumn{5}{|l|}{ Warmth } \\
\hline RWA & & & -.068 & -.037 \\
\hline SDO & & & -.102 & -.066 \\
\hline Accent effect & & & 1.755 & .835 \\
\hline \multicolumn{5}{|l|}{ Covariances } \\
\hline Comp + Warm & .346 & .337 & .536 & .135 \\
\hline Comp + RWA & & -.047 & & \\
\hline Comp + SDO & & -.071 & & \\
\hline Warm + RWA & & .059 & & \\
\hline Warm + SDO & & -.159 & & \\
\hline $\mathrm{RWA}+\mathrm{SDO}$ & & -1.456 & -1.455 & -1.458 \\
\hline$\chi^{2}(d f)$ & $145(52)$ & $1652(649)$ & $1700(748)$ & $1752(700)$ \\
\hline$p$ value & $<.001$ & $<.001$ & $<.001$ & $<.001$ \\
\hline CFI & .967 & .761 & .761 & .747 \\
\hline RMSEA & .061 & .059 & .058 & .059 \\
\hline$p$ value & .059 & $<.001$ & $<.001$ & $<.000$ \\
\hline
\end{tabular}

Notes: Loadings are unstandardized. Those in bold were significant at the $p<.05$ level. ${ }^{\dagger}$ Measures of ideology used latent variables at the between-participant level. Loadings were omitted for conciseness. See Table 4 for general factor loadings for ideology. RMSEA p-value refers to a test of the alternative hypothesis that RMSEA > 05 . 
For the first model, a multi-level confirmatory factor analysis was conducted. Latent factors of competence (5 items) and warmth ( 4 items) were constructed at the within- and between-participant levels without any predictor variables (see Table 5 for Hypothesis 2 models). In this case, model fit was strong $(C F I=.967)$, with a significant relations between competence and warmth at the within-participant level, $B=.669, p<.001$, and the betweenparticipant level, $B=.346, p<.001$. For the second model, latent RWA and latent SDO were introduced as between-participant variables, allowing them to covary with other variables but not treating them as predictors. Mirroring the CFA results for ideology, model fit was poor $(C F I=$ .761). Further, neither RWA or SDO covaried with competence or warmth, $p \mathrm{~s}>.05$. Model 3 added effect-coded accent (Toronto vs. others) as a predictor of competence and warmth at both the within- and between-participant levels, and treated RWA and SDO as predictors at the between-participant level. While at the within-participant level, the Toronto accent was perceived as warmer, $B=.079, p=.015$, and more competent, $B=.288, p<.001$, there were no significant effects of accent or ideology at the between-participant level, $p \mathrm{~s}>.05$. Moreover, model fit was again poor $(C F I=.761)$, and certain variance estimates were (impossibly) negative. In attempt to rectify the latter issue, warmth and competence items had their variances constrained to zero at the between-subject level in model 4. However, estimates remained relatively stable and model fit was poorer than that of model $3(C F I=.747)$.

Examining models using averaged values, the results for competence echoed those of the latent variable models (see Table 6), where the Toronto accent was perceived as more competent than the other accents at the between- and within-participant levels. However, those for warmth showed a marginal but insignificant accent effect at the within-participant level (see Table 7), $B$ 
$=.060, S E=.034, p=.081$, such that the Toronto accent was perceived as warmer than the other

accents at only the between-participant level.

Table 6

Predicting competence with ideology via multilevel modeling

\begin{tabular}{|c|c|c|c|c|c|}
\hline Level and Variable & $\begin{array}{c}\text { Model } 1 \\
\text { Null model }\end{array}$ & $\begin{array}{l}\text { Model } 2 \\
\text { Ideology }\end{array}$ & $\begin{array}{c}\text { Model } 3 \\
\text { Accent Int. }\end{array}$ & $\begin{array}{c}\text { Model } 4 \\
\text { Accent Slope }\end{array}$ & $\begin{array}{c}\text { Model } 5 \\
\text { Accent Only }\end{array}$ \\
\hline \multicolumn{6}{|l|}{ Level 1 (within) } \\
\hline Intercept & 5.024 & 5.024 & 5.001 & 5.011 & 5.012 \\
\hline Accent effect & & & .207 & .200 & .200 \\
\hline \multicolumn{6}{|l|}{ Level 2 (between) } \\
\hline RWA & & .024 & .017 & .038 & \\
\hline SDO & & -.032 & -.032 & -.053 & \\
\hline \multicolumn{6}{|l|}{ Variance components } \\
\hline Within-participant variance & 1.396 & 1.396 & 1.236 & 1.002 & 1.002 \\
\hline L2 intercept variance & .424 & .423 & .468 & .520 & .520 \\
\hline L2 accent variance & & & & .069 & .069 \\
\hline L2 accent-intercept correlation & & & & -.75 & -.75 \\
\hline ICC & .233 & .233 & .275 & & \\
\hline-2 log likelihood (FIML) & -834.1 & -834.0 & -811.8 & -795.0 & -795.1 \\
\hline Number of estimated parameters & 3 & 5 & 6 & 8 & 6 \\
\hline Conditional R-squared & .233 & .233 & .329 & .457 & .456 \\
\hline
\end{tabular}

Notes: Loadings are unstandardized. Those in bold were significant at the $p<.05$ level. Accent effect contrasted the Toronto accent (3) to the Indian, Latin American, and Arabic accents (-1s). Random effect significance was estimated using likelihood ratio tests.

Table 7

Predicting warmth with ideology via multilevel modeling

\begin{tabular}{|c|c|c|c|c|c|}
\hline Level and Variable & $\begin{array}{c}\text { Model } 1 \\
\text { Null model }\end{array}$ & $\begin{array}{l}\text { Model } 2 \\
\text { Ideology }\end{array}$ & $\begin{array}{c}\text { Model } 3 \\
\text { Accent Int. }\end{array}$ & $\begin{array}{c}\text { Model } 4 \\
\text { Accent Slope }\end{array}$ & $\begin{array}{c}\text { Model } 5 \\
\text { Accent Only }\end{array}$ \\
\hline \multicolumn{6}{|l|}{ Level 1 (within) } \\
\hline Intercept & 4.844 & 4.844 & 4.837 & 4.827 & 4.826 \\
\hline Accent effect & & & .066 & .060 & .060 \\
\hline \multicolumn{6}{|l|}{ Level 2 (between) } \\
\hline RWA & & -.005 & -.008 & -.009 & \\
\hline SDO & & -.052 & -.052 & -.044 & \\
\hline \multicolumn{6}{|l|}{ Variance components } \\
\hline Within-participant variance & 1.029 & 1.029 & 1.016 & .845 & .844 \\
\hline L2 intercept variance & .390 & .384 & .384 & .424 & .432 \\
\hline L2 accent variance & & & & .048 & .048 \\
\hline L2 accent-intercept correlation & & & & -.13 & -.17 \\
\hline ICC & .275 & .275 & .281 & & \\
\hline-2 log likelihood (FIML) & -766.6 & -766.0 & -763.1 & -756.7 & -757.1 \\
\hline Number of estimated parameters & 3 & 5 & 6 & 8 & 6 \\
\hline Conditional R-squared & .275 & .275 & .291 & .412 & .413 \\
\hline
\end{tabular}

Notes: Loadings are unstandardized. Those in bold were significant at the $p<.05$ level. Accent effect contrasted the Toronto accent (-3) to the Indian, Latin American, and Arabic accents (1s). Random effect significance was estimated using likelihood ratio tests. 


\section{Hypothesis 3: Intergroup anxiety and target evaluations}

While ratings of warmth and competence were my primary dependent measures for use in multilevel models, I also examined intergroup anxiety and target evaluations to probe whether they would yield similar results. For the sake of parsimony and because intergroup anxiety only consisted of two items, I used average scores in these analyses rather than latent constructs. Beginning with the null (intercept-only) model, multilevel regressions were conducted in a stepwise fashion: adding ideology and accent in the second and third models respectively (see Table 8). In the final models, intergroup anxiety was predicted by RWA between participants, $B=.295$, $S E=.088, p=.001$, but not by SDO, $B=.147, S E=.103, p=.155$. The Toronto accent was less anxiety-provoking than the other accents at the within level, $B=-.138, S E=.039, p<.001$, and a significant portion of variance (using a likelihood ratio test) in intergroup anxiety could be explained by variations in slopes by accent, $L R T=.091, p<.001$; there was significant variance accounted for by the random slopes (see Kuznetsova, Brockhoff, \& Christensen, 2017). In other words, the average person felt that the Toronto accent made them less anxious than the other accents, but this effect differed significantly between people.

Target evaluations on the other hand, were not significantly associated with RWA, $B=$ $.501, S E=1.252, p=.690$, but were with SDO, $B=-3.375, S E=1.472, p=.024$ (see Table 9). Surprisingly, accent did not predict target evaluations at the within level, but a likelihood ratio test showed it accounted for a significant portion of variance at the between level, $L R T=26.98, p$ $<.001$. Therefore, while the average person did not evaluate Toronto-accented targets and otheraccented targets differently, there was variation among people in the extent of the differences. 
Table 8

Predicting intergroup anxiety with ideology via multilevel modeling

\begin{tabular}{lccc}
\hline Level and Variable & $\begin{array}{c}\text { Model 1 } \\
\text { Null model }\end{array}$ & $\begin{array}{c}\text { Model 2 } \\
\text { Ideology }\end{array}$ & $\begin{array}{c}\text { Model 3 } \\
\text { Accent }\end{array}$ \\
\hline Level 1 (within) & & & \\
$\quad$ Intercept & $\mathbf{2 . 5 9 6}$ & $\mathbf{2 . 5 9 6}$ & $\mathbf{2 . 6 0 7}$ \\
Accent effect & & & $\mathbf{- . 1 3 8}$ \\
Level 2 (between) & & $\mathbf{2 9 5}$ & $\mathbf{. 2 8 4}$ \\
$\quad$ RWA & & .147 & .161 \\
SDO & & 1.152 & .789 \\
Variance components & 1.152 & $\mathbf{. 8 0 1}$ & .839 \\
Within-participant variance & $\mathbf{1 . 1 9 4}$ & & $\mathbf{. 0 9 1}$ \\
L2 intercept variance & & & -.11 \\
L2 accent variance & .509 & .410 & \\
L2 accent-intercept correlation & -838.8 & -819.7 & -791.0 \\
ICC & 3 & 5 & 8 \\
-2 log likelihood (FIML) & .509 & .509 & .665 \\
Number of estimated parameters & & & \\
Conditional R-squared & & & \\
\hline Notes: Loadings are unstandardized. Those
\end{tabular}

Notes: Loadings are unstandardized. Those in bold were significant at the $p<.05$ level. Accent effect contrasted the Toronto accent (3) to the Indian, Latin American, and Arabic accents (-1s). Random effect significance was estimated using likelihood ratio tests.

Table 9

Predicting target thermometers with ideology via multilevel modeling

\begin{tabular}{lccc}
\hline & $\begin{array}{c}\text { Model 1 } \\
\text { Lull model }\end{array}$ & $\begin{array}{c}\text { Model 2 } \\
\text { Ideology }\end{array}$ & $\begin{array}{c}\text { Model 3 } \\
\text { Accent }\end{array}$ \\
\hline Level 1 (within) & & & \\
Intercept & $\mathbf{7 0 . 9 0}$ & $\mathbf{7 0 . 9 0}$ & $\mathbf{7 0 . 9 1}$ \\
Accent effect & & & .448 \\
Level 2 (between) & & & \\
RWA & & -.437 & -.501 \\
SDO & & $\mathbf{- 3 . 4 1 0}$ & $\mathbf{- 3 . 3 7 5}$ \\
Variance components & 217.8 & 217.8 & 130.67 \\
Within-participant variance & $\mathbf{1 9 8 . 9}$ & $\mathbf{1 7 2 . 8}$ & 177.54 \\
L2 intercept variance & & & $\mathbf{2 6 . 9 8}$ \\
L2 accent variance & & & -.05 \\
L2 accent-intercept correlation & .477 & .442 & \\
ICC & -2125.8 & -2119.0 & -2082.3 \\
-2 log likelihood (FIML) & 3 & 5 & 8 \\
Number of estimated parameters & .477 & .477 & .689 \\
Conditional R-squared & & & \\
\hline
\end{tabular}

Notes: Loadings are unstandardized. Loadings in bold were significant at the $p<.05$ level. Accent effect contrasted the Toronto accent (3) to the Indian, Latin American, and Arabic accents (-1s). Random effect significance was estimated using likelihood ratio tests. 


\section{Hypothesis 4: Comparing target accent and ethnicity}

In relating accent to ethnicity, I tested whether people who have more negative perceptions of an accented group also hold negative perceptions of that group's typical ethnicity. For example: are negative evaluations of Indian-accented targets associated more with negative evaluations of Indians than negative evaluations of Arabs? I conducted multiple multilevel regressions to answer this question. Targets with the accent of interest were coded as 1 while the other targets were coded as 0 . Then, this variable moderated the relation between target evaluations and associated ethnic group evaluations. Thus, I tested whether the relation between a specific ethnic prejudice and evaluations of targets was higher when the target had an accent typically associated with that ethnicity (see Table 10). Statistically, a significant positive accentethnicity interaction would signify a stronger association between target ratings and associated ethnicity ratings when examining the target's accent of interest. There were no stronger associations found between perceptions of Torontonians and perceptions of targets when listening to the Toronto accent as opposed to listening to other accents, $B=.011, S E=.123, p=$ 928; nor were there stronger associations between perceptions of Latin Americans and perceptions of targets when listening to the Latin American accent compared to listening to other accents, $B=.027, S E=.082, p=.742$. However, perceptions of Indians and of targets were more strongly related when participants listened to the Indian accent than when listening to other accents, $B=.209, S E=.060, p<.001$. Further, perceptions of Arabs and of targets were more related when participants listened to the Arabic accent than when listening to other accents, $B=$ $.156, S E=.064, p=.016$. 
Table 10

Predicting target evaluations with ethnic evaluations via multilevel modeling

\begin{tabular}{lcccc}
\hline & \multicolumn{4}{c}{ Target Accent } \\
Level and Variable & Torontonian & Indian & Latin American & Arabic \\
\hline Level 1 (within) & & & & \\
Intercept & $\mathbf{7 0 . 4 5 8}$ & $\mathbf{7 0 . 8 1 7}$ & $\mathbf{7 1 . 4 8 2}$ & $\mathbf{7 1 . 0 8 6}$ \\
Accent effect & 1.723 & 1.061 & -2.745 & -1.355 \\
Corresponding ethnic evaluations & $\mathbf{. 3 8 9}$ & $\mathbf{. 3 3 1}$ & $\mathbf{. 4 5 9}$ & $\mathbf{. 3 0 9}$ \\
Accent-ethnicity interaction & .011 & $\mathbf{. 2 0 9}$ & .027 & $\mathbf{. 1 5 6}$ \\
Level 2 (between) & & & & \\
Variance components & 131.2 & 202.69 & 216.91 & 213.5 \\
Within-participant variance & 202.6 & 125.37 & 76.38 & 124.0 \\
L2 intercept variance & $\mathbf{4 1 7 . 3}$ & 15.18 & 1.18 & 22.7 \\
L2 ethnicity variance & -.55 & -1.00 & 1.00 & -1.00 \\
L2 ethnicity-intercept correlation & -2072.6 & -2082.1 & -2086.0 & -2092.4 \\
-2 log likelihood (FIML) & .685 & .515 & .479 & .485 \\
Conditional R-squared & $<.05 .615$ \\
\hline
\end{tabular}

Note: Loadings in bold were significant at the $p<.05$ level. Accent effects compared the target accent (1) to the others (0). Random effect significance was estimated using likelihood ratio tests.

\section{Hypothesis 5: Solidarity, status, and dynamism}

One secondary, yet important goal of this thesis was to compare the theoretical model of ethnic stereotypes (SCM) to the model of accent-based evaluations (SSD). The former has been operationalized through warmth and competence, while the latter through solidarity, status, and dynamism. While the two are conceptually distinct, there is significant overlap in how they are measured; these two theories align nicely, with solidarity and warmth, and status and competence being very similar at face value (this similarity is also noted in Fuertes et al., 2012). In order to verify whether these concepts are the same - and whether dynamism is distinct - I conducted correlations and regressions. Indeed, warmth and solidarity were highly correlated, $r=$ $.91, p<.001$, as were status and competence, $r=.85, p<.001$. Then, investigating target evaluations, I conducted a stepwise regression to determine if the solidarity/status/dynamism model accounts for significantly more variance than the SCM (see Table 11). In the first step, 
only competence and warmth predicted target evaluations in the model. In the second step, solidarity was added; third, status. Finally, dynamism was added in the fourth step.

Table 11

Standardized regression coefficients comparing the Stereotype Content Model to the solidarity, status, dynamism model

\begin{tabular}{lcccc}
\hline Dependent variable & Model 1 & Model 2 & Model 3 & Model 4 \\
\hline Target evaluations & $R^{2}=.382$ & $R^{2}=.382$ & $R^{2}=.388^{*}$ & $R^{2}=.387$ \\
Warmth & $\mathbf{. 5 4 2}$ & $\mathbf{. 4 8 2}$ & $\mathbf{. 4 8 2}$ & $\mathbf{. 4 8 1}$ \\
Competence & $\mathbf{. 1 2 9}$ & $\mathbf{. 1 2 3}$ & $\mathbf{. 2 4 4}$ & $\mathbf{. 2 6 7}$ \\
Solidarity & & .069 & .097 & .096 \\
Status & & & $\mathbf{- . 1 6 2}$ & $\mathbf{- . 1 6 6}$ \\
Dynamism & & & & -.031 \\
\hline
\end{tabular}

Note: Loadings in bold were significant at the $p<.05$ significance level. All models were significant at the $p<.001$ significance level. $R^{2}$ values given are adjusted to account for the number of predictors in each model. * indicates a statistically significant $(p<.05)$ increase in the amount of variance explained by the model compared to the previous model.

Using target evaluations as a dependent variable, warmth and competence accounted for $38 \%$ of the variance by themselves, $R^{2}$ adj $=.382$. Adding solidarity increased the r-squared value to .391 , but the adjusted $r$-squared value remained unchanged, $\Delta F=.605, p=.437$. In the third step, the inclusion of status significantly raised the r-squared value to $.397, R^{2}$ adj $=.388 ; \Delta F=$ $5.625, p=.018$. Lastly, dynamism failed to account for any additional variance in the model, $\Delta F$ $=.452, p=.502$.

In a final test of the solidarity-status-dynamism model, I conducted identical multilevel modeling analyses as those conducted for the Stereotype Content Model. Grouping responses by participant ID, four multilevel models were created (see Table 6). In the first model, a multilevel confirmatory factor analysis was created which investigated the loadings of solidarity, status, and dynamism at the within- and between-participant levels. Data fit the model fairly well $(C F I=$ .957), but dynamism's “aggressive” item proved to be problematic, with a poor factor loading on the within-participant level, $B=.379, p<.001$, and a non-significant loading at the between- 
participant level, $B=.019, p=.947$. Still, the same factor structure was used in the second step, including latent RWA and SDO at level 2; fit was poor $(C F I=.743)$. RWA and SDO did not covary with solidarity, status, or dynamism $(p \mathrm{~s}>.05)$, but related strongly with each other, $B=$ $1.450, p<.001$. The third model included effect-coded accent (Toronto: 3 , Others: -1 ) that was treated as a predictor of the three dependent variables at the within-participant level and joined RWA and SDO as a predictor at the between-participant level. At level 1, the Toronto accent (compared to the other accents) predicted higher status, $B=.297, p<.001$; and dynamism, $B=$ $.149, p<.001$; but did not predict solidarity, $B=.055, p=.082$. At level 2 , there were no significant coefficients for the regressions of solidarity or status, but dynamism was predicted by both RWA, $B=.241, p=.03$; and SDO, $B=-.217, p=.01$. Altogether however, poor model fit $(C F I=.742)$ and negative calculated variances call into question the legitimacy of these findings.

Further, the fourth model, where between-participant variances would be constrained to zero, did not converge.

\section{Hypothesis 6: ACT as an improvement over RWA}

Duckitt et al. (2010) proposed authoritarianism, conservatism, and traditionalism as three subscales which together were more reliable, valid, and comprehensive than the older RWA measure, while addressing the same construct. To test whether this claim could be supported in my data, I regressed target and ethnic evaluations onto averaged RWA and SDO, adding the individually-averaged ACT subscales one at a time in subsequent steps. When all four models were constructed, an ANOVA was conducted to determine whether the amount of variance accounted for by the models significantly increased with each step (see Table 12). SDO was a significant predictor of prejudice against all target and ethnic groups in model 1; RWA only predicted prejudice against people from Arabic countries. For the Toronto and Indian 
thermometer measures, adding the authoritarian scale accounted for additional variance in the models, $\Delta F=31.36, p<.001$ and $\Delta F=5.68, p=.018$ respectively. Further, adding the conservatism scale in model 3 resulted in a significant increase in the amount of variance accounted across all measures: accented targets, $\Delta F=32.70, p<.001$; Torontonians, $\Delta F=$ 51.37, $p<.001$; people from India, $\Delta F=48.66, p<.001$; people from Latin America, $\Delta F=$ 57.84, $p<.001$; and people from Arabic countries, $\Delta F=15.92, p<.001$. Finally, the traditionalism scale contributed a significant increase in variance for evaluations of people from India, $\Delta F=8.33, p=.004$; Latin American countries, $\Delta F=5.63, p=.018$; and Arabic countries $\Delta F=9.15, p=.003$.

When comparing regressions of the DVs onto RWA and SDO against ACT and SDO, the ACT-based models consistently accounted for more variance than the RWA-based models: prejudice against accented targets, $\Delta F=12.91, p<.001, \Delta R_{\text {adj }}^{2}=.045$; Torontonians, $\Delta F=$ 30.53, $p<.001, \Delta R^{2}$ adj $=.108$; Indians, $\Delta F=13.19, p<.001, \Delta R^{2}$ adj $=.040 ;$ Latin Americans, $\Delta F$ $=19.77, p<.001, \Delta R^{2}{ }_{\text {adj }}=.065$; and Arabs, $\Delta F=4.11, p=.017, \Delta R^{2}$ adj $=.010$. Oddly, the way in which the variance was accounted for was not as expected. Rather than greater values of authoritarianism, conservatism, and traditionalism each predicting more negative evaluations of the target or ethnic group, there was significant variation in effect strength and direction for each of the three scales. For the accented targets, the weight of authoritarianism was negative, $\beta=-$ $.322, p<.001$; but the weight of conservatism was positive, $\beta=.505, p<.001$; and the effect of traditionalism was non-significant, $\beta=-.096, p=.247$. This pattern was repeated for the antiIndian prejudice, anti-Latin American prejudice, and anti-Arabic prejudice (see Table 13). Prejudice against Torontonians however, did not regress significantly onto authoritarianism, $\beta=$ - 
$.009, p=.919$; yet did so positively onto conservatism, $\beta=.624, p<.001$, and traditionalism, $\beta=$ $-.309, p<.001$

Table 12

Predicting solidarity, status, and dynamism with ideology via multilevel structural equation modeling

\begin{tabular}{|c|c|c|c|c|}
\hline $\begin{array}{l}\text { Level } \\
\quad \text { Scale } \\
\end{array}$ & Variable/item & $\begin{array}{l}\text { Model } 1 \\
\text { MLCFA }\end{array}$ & $\begin{array}{l}\text { Model } 2 \\
\text { Ideology }\end{array}$ & $\begin{array}{c}\text { Model } 3 \\
\text { Predictors } \\
\end{array}$ \\
\hline \multicolumn{5}{|l|}{ Level 1 (within) } \\
\hline \multirow{3}{*}{ Solidarity $=\sim$} & Nice & 1.000 & 1.000 & 1.000 \\
\hline & Kind & .981 & .953 & .964 \\
\hline & Good-natured & .896 & .868 & .873 \\
\hline \multirow[t]{3}{*}{ Status $=\sim$} & Literate & 1.000 & 1.000 & 1.000 \\
\hline & Educated & 1.021 & 1.023 & 1.022 \\
\hline & Upper class & .779 & .821 & .824 \\
\hline \multirow[t]{3}{*}{ Dynamism $=\sim$} & Active & 1.000 & 1.000 & 1.000 \\
\hline & Talkative & .818 & .858 & .859 \\
\hline & Aggressive & .379 & .420 & .420 \\
\hline Solidarity & Accent effect & & & .055 \\
\hline Status & Accent effect & & & .297 \\
\hline Dynamism & Accent effect & & & .149 \\
\hline Solidarity & Status & .783 & .805 & .740 \\
\hline Solidarity $\sim$ & Dynamism & .457 & .498 & .457 \\
\hline Status $\sim \sim$ & Dynamism & .908 & .982 & .825 \\
\hline \multicolumn{5}{|l|}{ Level 2 (between) } \\
\hline \multirow[t]{3}{*}{ Solidarity $=\sim$} & Nice & 1.000 & 1.000 & 1.000 \\
\hline & Kind & .678 & .705 & .693 \\
\hline & Good-natured & .740 & .787 & .776 \\
\hline \multirow[t]{3}{*}{ Status $=\sim$} & Literate & 1.000 & 1.000 & 1.000 \\
\hline & Educated & 1.079 & 1.057 & 1.056 \\
\hline & Upper class & .911 & .776 & .761 \\
\hline \multirow[t]{3}{*}{ Dynamism $=\sim$} & Active & 1.000 & 1.000 & 1.000 \\
\hline & Talkative & .578 & .605 & .624 \\
\hline & Aggressive & .019 & -.537 & -.403 \\
\hline \multirow[t]{3}{*}{ Solidarity } & RWA & & & .158 \\
\hline & SDO & & & -.163 \\
\hline & Accent effect & & & .947 \\
\hline \multirow[t]{3}{*}{ Status $\sim$} & RWA & & & .132 \\
\hline & SDO & & & -.117 \\
\hline & Accent effect & & & 1.836 \\
\hline \multirow[t]{3}{*}{ Dynamism } & RWA & & & .241 \\
\hline & SDO & & & -.217 \\
\hline & Accent effect & & & 1.972 \\
\hline \multirow[t]{4}{*}{ Solidarity $\sim \sim$} & Status & .420 & .392 & .485 \\
\hline & Dynamism & .437 & .362 & .455 \\
\hline & RWA & & -.015 & \\
\hline & SDO & & -.168 & \\
\hline \multirow[t]{3}{*}{ Status $\sim$} & Dynamism & .301 & .228 & .422 \\
\hline & RWA & & .025 & \\
\hline & SDO & & -.086 & \\
\hline
\end{tabular}




\begin{tabular}{|c|c|c|c|c|}
\hline Dynamism $\sim \sim$ & RWA & & .015 & \\
\hline & SDO & & -.192 & \\
\hline RWA & SDO & & 1.450 & 1.449 \\
\hline & $\chi^{2}(d f)$ & $2741(72)$ & $1687(643)$ & $1736(683)$ \\
\hline & $p$ value & $<.001$ & $<.001$ & $<.001$ \\
\hline & CFI & .957 & .743 & .742 \\
\hline & RMSEA & .070 & .061 & .059 \\
\hline & $p$ value & .003 & $<.001$ & $<.001$ \\
\hline
\end{tabular}

Note: Loadings are unstandardized. Those in bold were significant at the $p<.05$ level. ${ }^{\dagger}$ Measures of ideology used latent variables at the between-participant level. Loadings were omitted for conciseness. See Table 4 for general factor loadings. RMSEA p-value refers to a test of the alternative hypothesis that RMSEA > .05 .

Table 13

Standardized regression coefficients comparing $R W A$ to $A C T$

\begin{tabular}{|c|c|c|c|c|c|}
\hline Dependent variable & Model 1 & Model 2 & Model 3 & Model 4 & Model 5 \\
\hline Speaker thermometer & $R^{2}=.056$ & $R^{2}=.054$ & $R^{2}=.114^{*}$ & $R^{2}=.115$ & $R^{2}=.101$ \\
\hline RWA & -.032 & -.053 & -.290 & -.430 & \\
\hline SDO & -.220 & -.219 & -.245 & -.217 & -.320 \\
\hline Authoritarianism & & .024 & -.254 & -.254 & -.322 \\
\hline Conservatism & & & .568 & .542 & .505 \\
\hline Traditionalism & & & & .154 & -.096 \\
\hline Toronto thermometer & $R^{2}=.025$ & $R^{2}=.078^{*}$ & $R^{2}=.167^{*}$ & $R^{2}=.166$ & $R^{2}=.133$ \\
\hline RWA & .083 & -.296 & -.583 & -.641 & \\
\hline $\mathrm{SDO}$ & -.221 & -.196 & -.228 & -.217 & -.369 \\
\hline Authoritarianism & & .431 & .094 & .094 & -.009 \\
\hline Conservatism & & & .690 & .679 & .624 \\
\hline Traditionalism & & & & .064 & -.309 \\
\hline Indian thermometer & $R^{2}=.177$ & $R^{2}=.184^{*}$ & $R^{2}=.258^{*}$ & $R^{2}=.269 *$ & $R^{2}=.217$ \\
\hline RWA & -.099 & -.250 & -.512 & -.796 & \\
\hline $\mathrm{SDO}$ & -.347 & -.337 & -.366 & -.312 & -.500 \\
\hline Authoritarianism & & .172 & -.135 & -.134 & -.262 \\
\hline Conservatism & & & .628 & .575 & .508 \\
\hline Traditionalism & & & & .314 & -.149 \\
\hline Latin American thermometer & $R^{2}=.124$ & $R^{2}=.128$ & $R^{2}=.221 *$ & $R^{2}=.228^{*}$ & $R^{2}=.189$ \\
\hline RWA & -.048 & -.169 & -.462 & -.702 & \\
\hline $\mathrm{SDO}$ & -.321 & -.313 & -.346 & -.300 & -.466 \\
\hline Authoritarianism & & .138 & -.207 & -.206 & -.318 \\
\hline Conservatism & & & .704 & .659 & .599 \\
\hline Traditionalism & & & & .265 & -.143 \\
\hline Arabic thermometer & $R^{2}=.169$ & $R^{2}=.168$ & $R^{2}=.192 *$ & $R^{2}=.205^{*}$ & $R^{2}=.179$ \\
\hline RWA & -.172 & -.112 & -.263 & -.573 & \\
\hline $\mathrm{SDO}$ & -.273 & -.277 & -.294 & -.234 & -.370 \\
\hline Authoritarianism & & -.069 & -.246 & -.245 & -.337 \\
\hline Conservatism & & & .363 & .305 & .256 \\
\hline Traditionalism & & & & .343 & .009 \\
\hline
\end{tabular}

Note: Loadings in bold were significant at the $p<.05$ significance level. All models were significant at the $p<.001$ significance level. $R^{2}$ values given are adjusted to account for the number of predictors in each model. * indicates a statistically significant $(p<.05)$ increase in the amount of variance explained by the model compared to the previous model. 
Because the ANOVAs showed that authoritarianism, conservatism, and traditionalism predicted the target evaluations and prejudice measures better than RWA, I re-ran the multilevel model analyses substituting RWA for the ACT scales. As with RWA, the ACT model showed poor fit $(C F I=.765)$. Furthermore, neither SDO nor any of the ACT subscales predicted warmth or competence (see Table A1 in the Appendix for these results), $p \mathrm{~s}>.05$.

\section{Discussion}

Though prejudice research has long-examined the role of skin colour and other visual cues in ethnic prejudice, auditory cues - specifically accents - have been comparatively understudied. Yet, the consequences of linguistic biases are no less important, as having a foreign accent can affect employability (e.g. Carlson \& McHenry, 2006), well-being (e.g. Wated \& Sanchez, 2006), and potential to find housing (Zhao et al., 2006). This thesis examined accentbased prejudice and attitudes toward accents using two theoretical models: the Stereotype Content Model (SCM; Fiske et al., 2002) and the solidary, status, dynamism model (SSD; Fuertes et al., 2012). The SCM compares how groups are evaluated according to societal stereotypes of warmth and competence (Fiske et al., 2002). The SSD model, on the other hand, compares accented groups along the three dimensions (Fuertes et al., 2012). The present thesis explored differences in model-driven perceptions of four accents foreign to America (i.e. Toronto, Indian, Latin American, and Arabic accents) and ideological and threat-based predictors of accent evaluations.

Building on work by Lambert et al. (1960), Giles (1971, 1970), Gluszek and Dovidio (e.g. 2010), and others, this thesis examined accent-based stereotypes and prejudice. In contrast to the work done by the pioneers in the field, the results from this thesis did not provide evidence 
of accent-based prejudice; at least for the accents studied in this thesis. However, there were differences found between groups on accent-based stereotypes.

\section{Mean differences between accents}

Consistent with Hypothesis 1a, the Toronto accent was perceived as more competent than the Arabic and Indian accents, which were perceived as more competent than the Latin American accent. Inconsistent with Hypothesis 1a however, the Toronto accent was rated significantly warmer than the Latin American accent, with no other significant differences between groups. There are several noteworthy differences between the present findings and those by Lee and Fiske (2006). In their study of immigrant stereotypes, Indians and Canadians were in the highcompetence/mid-warmth quadrant, middle-easterners were mid-competence/low-warmth, and Latin Americans were low-competence/mid-warmth. Comparing the present findings to theirs descriptively -, Indian targets were perceived as lower in competence (as predicted), and Toronto and Latin American targets were lower in warmth. Moreover, whereas differences in warmth between groups in Lee and Fiske (2006) at times exceeded one point on their 5-point scale, differences between the Toronto accent and the others never exceeded .5 on the 7-point scale used in the present research. In other words, the effect sizes for Lee and Fiske (2006) greatly outweighed those reported here, suggesting that the lack of significant differences for warmth in my study was not due to a lack of statistical power. Despite these differences however, in the present research, the SCM did sufficiently well in outlining differences in how the accented targets were perceived. Hence, the SCM may be a suitable model for comparing evaluations between accents.

Evidence for Hypothesis $1 \mathrm{~b}$ was mixed as only moderate support for Fuertes et al. (2012) SSD model was found. As predicted, the Toronto accent was considered higher status than any 
of the other accents; and the Arabic and Indian accents were rated higher than the Latin American accent. The Toronto-accented and Indian-accented targets were evaluated as higher in solidarity (i.e. pleasantness) than Latin American-accented targets, inconsistent with the prediction that Latin American-accented targets would rank just below the Toronto-accented targets and higher than Indian- and Arabic-accented targets. Finally, dynamism (i.e. liveliness) provided a third dimension of comparison between the accents: the Toronto and Arabic accents were rated more dynamic than the Latin American accent. This finding lends support to the notion that dynamism provides unique insight into accent-based prejudice that status and solidarity (and consequently, competence and warmth) do not encapsulate (Fuertes et al., 2012). This idea is expanded later in the discussion.

Target evaluations, in terms of how favourable (warm) or unfavourable (cold) speakers were evaluated, provided a potential third insight into how accented speakers may be differentially perceived. Contrary to Hypothesis $1 \mathrm{c}$, no differences between accented groups emerged on the feeling thermometer ratings. This is surprising for a few reasons. First, the literature on accent-based prejudice clearly indicates that bias against outgroup accents exists (e.g. Kinzler et al., 2009; Ng, 2007; Wang, Arndt, Singh, Biernat, \& Liu, 2013). Second, the literature is clear that there are downstream consequences of accent-based prejudice in the form of discrimination (e.g. Deprez-Sims et al., 2010; Hosoda et al., 2012; Segrest Purkiss et al., 2006). Third, within this study, participants indicated prejudice toward the ethnic groups with which these accents are associated.

There are several potential explanations for this lack of bias toward targets. First, the liberally-skewed sample may have intentionally given similar scores across targets. People who identify as left wing tend to not be overtly prejudiced, instead expressing their biases in more 
subtle ways (see Dovidio, Gaertner, \& Pearson, 2017). Therefore, the similar scores could have possibly been due to attempts at political correctness. Yet as mentioned previously, biases were expressed overtly when participants were asked to evaluate ethnicities. Moreover, it would be reasonable to assume that there are stronger social repercussions for holding explicit ethnic biases than for holding explicit accent biases. To elaborate, biases toward accents have not yet entered the realm of public consciousness in the way biases toward ethnicities have (Derwing, 2003). While the cultural zeitgeist of political correctness dictates that prejudice or discrimination against people because of their ethnicity, sexual orientation, gender, etc. is not permissible behaviour, blatant disrespectful behaviour against foreign-accented individuals is not uncommon (e.g. Creese \& Kambere, 2003; Wang et al., 2013) and people can be marginalized due to their perceived linguistic proficiency (Hellerstein \& Neumark, 2003). Anecdotally, even left-wing comedians (e.g. Trevor Noah, John Oliver) "try on" accents from other regions or cultures while mocking those who culturally appropriate from those same regions or cultures. In this way, it is possible that if participants were to respond to questions in a socially desirable way, they would likely be more compelled to evaluate ethnicities similarly than they would accented targets. Thus, it is unlikely that the lack of bias toward targets can be attributed to socially desirable responding.

A second potential reason for the lack of bias toward the targets could be that people in general (i.e. the population) do not perceive targets differentially. In other words, there may not be accent-related differences in target evaluations in this present sample or in the population. However, the differences found across competence, warmth, solidarity, status, dynamism, and intergroup anxiety contradict this position: encountering type II error on this scale (i.e. not finding differences on feeling thermometer ratings between accents in the sample despite there 
being differences in the population) is more likely than encountering type I error (i.e. finding differences in accents in the sample despite there not being effects in the population) across all six other scales. Thus, the lack of accent effects in target evaluations could be anomalous. Nevertheless, the small $F$ statistic suggests that an incredibly large sample size would be required to achieve the power to find a significant effect.

Third, differences between target perceptions could be accounted for by higher-level effects. As tested in Hypothesis 4, there were significant differences between accents between participants, but not within; how individuals rated the accents varied widely but averaging across people nullified the effect. A more in-depth examination of within- and between-subject differences is discussed later, where Hypothesis 4 is critiqued. The effect of higher-level effects in explaining the lack of findings for the feeling thermometer is also supported by the nature of the study's design. Participants rated ethnicities side-by-side, able to enter scores for each group and visually compare how they evaluated each one. In contrast, targets were evaluated serially: one after another with no potential to compare current target evaluations to past or future ones. Additionally, the target for each script was completely random. In this way, whereas some participants may have listened to each of the four accents, it was more likely for there to be overlap, with participants only listening to 2 or 3 accents instead. Not having access to all accents combined with the inability to directly compare accent evaluations may have affected the ability of the average individual to give differential target ratings.

\section{Right-wing ideologies as predictors of accent-based prejudice}

The second Hypothesis examined the role of right-wing ideologies in predicting attitudes toward accented groups. RWA and SDO are consistently found to be robust unique predictors of prejudice against a variety of groups (see Duckitt, 2001, 2006; Duckitt \& Sibley, 2016). 
Therefore, by combining ideology with SCM, I was able to test whether attitudes toward various accents could be predicted by sociopolitical ideology. The weak correlations of RWA and SDO with warmth and competence suggested that the relationships, if they exist, would need to be qualified, and a multistep process was used to explore these connections in more detail.

First, confirmatory factor analyses were used to examine the structure of the RWA and SDO scales. Results indicated poor fit for both scales, with factor loadings as low as .542 for RWA and .354 for SDO. These results are consistent with some previous research. The RWA scale has been shown to be an inferior construct when treated as a single factor as opposed to using a three-factor model. Work by Mavor, Louis, and Sibley (2009), for example, showed that a single-factor model had poor fit $(C F I=.742)$, but a three-factor model with a second order factor had excellent fit $(C F I=.987)$. The same argument could be applied to SDO. Ho et al. (2015) illustrated that model fit for a one-factor model of the 16-item SDO scale ranged from superb $(C F I=.97)$ to atrocious $(C F I=.55)$ depending on the sample. In fact, they provided evidence across many samples that a four-factor structure was essential to ideally encapsulating SDO. Notwithstanding these measurement issues, because the DPM (Duckitt, 2001) was developed with RWA and SDO as individual constructs, planned analyses were conducted.

In model 1, a multilevel CFA illustrated excellent fit for warmth and competence. Here, the relation between the two SCM variables was significant at both the within- and betweenparticipant levels. In model 2 however, the inclusion of RWA and SDO had detrimental impact on model fit - likely due to their poor individual CFA results. In model 3, RWA and SDO did not predict warmth or competence, inconsistent with Hypothesis 2. Though it might be argued that averaged variables would be more accurate to the intention of RWA and SDO in previous literature and the DPM, substituting them for the latent constructs did not improve the models. 
To further investigate these findings, ACT was examined as a potentially morecomprehensive measure of authoritarianism than RWA. Duckitt and colleagues (2010) reconceptualised RWA into three individual factors (i.e. authoritarianism, conservatism, and traditionalism) that have been shown to differentially predict various aspects of prejudice. Consistent with Hypothesis 6, comparing of the two models showed that both accent-based and ethnic prejudices were better predicted by the ACT than RWA. However, the findings were unusual. In the final models, higher authoritarianism predicted more negative evaluations of accented targets and ethnically-foreign groups as anticipated, except for Torontonians, where the relation was not significant. Conservatism unexpectedly predicted more positive evaluations of both accented targets and ethnic groups. Higher traditionalism on the other hand, only predicted more negative evaluations of Torontonians, as its other effects on other prejudices were not significant. Covariance among SDO, authoritarianism, conservatism, and traditionalism might help to understand this pattern of associations. When conducting a linear regression, high multicollinearity can cause regression estimates to be misleading (Baguley, 2012). Though model statistics remain accurate, strong correlations among variables in a model greatly restricts the degree to which the effects of individual predictors can be estimated. The correlations between the ACT scales ranged from .80 to .86 , which are very strong. Further, adding the conservatism scale in model 3 consistently moved the effects of RWA and authoritarianism in the negative direction. An examination of the variance inflation factors showed that the VIF for conservatism the highest among the ACT measures and SDO: greater than 5. In this way, collinearity with conservatism was the most problematic among the relations between the scales. Nonetheless, because $R^{2}$ estimates and model statistics remain valid, the increase in variance accounted for by ACT over RWA is meaningful. The significance and magnitude of each 
predictor in the regressions however, is not. On the other hand, the correlations between individual subscales and target/ethnic evaluations more accurately illustrates the extent of the relations between the variables. Therefore, results were fairly consistent with the hypotheses: authoritarianism, conservatism, and traditionalism each predicted negative evaluations of Indians, Latin Americans (except conservatism), and Arabs; moreover, ACT was a consistent improvement over RWA in this sample.

A possible explanation for why sociopolitical ideologies and the SCM components did not relate significantly, is that prejudice and stereotypes are functionally and conceptually distinct. RWA (and transitively, ACT) and SDO are used to predict prejudice in the DPM, whereas warmth and competence illustrate variations in stereotypes. These differences can be clearly seen in the measures I used. The target/ethnic evaluations (prejudice) reflected how participants felt about each of the groups. The SCM/SSD measures (stereotypes) on the other hand, reflected how participants thought society evaluates the groups. Moreover, Fiske (2018) describes RWA and SDO as measuring "old-fashioned" biases, where people who hold the ideologies are blatantly biased against groups. In contrast, she implicates the SCM as measuring ambivalent bias, where the stereotypes are often mixed and subtle - existing beyond the personal level. Thus, prejudice is individual-focused whereas stereotypes is societally-focused. To my knowledge, right-wing ideologies and the SCM components have not previously been compared in research. Future research is needed to determine whether this lack of association are an exception or a restricted to the present data.

\section{Intergroup anxiety and target evaluations}

Two additional dependent measures - intergroup anxiety and target evaluations - were examined and expected to be predicted by ideology. The former reflects the feeling of discomfort 
in interacting with (or anticipating interacting with) an outgroup member and has been shown to relate to various prejudices (Stephan, 2014); the latter is accent-based prejudice. Consistent with Hypothesis 3, higher RWA predicted greater intergroup anxiety. Further, the Toronto accent was less anxiety-provoking than the Indian, Latin American, and Arabic accents. Although SDO's effects were not statistically significant, $B=.161$, its $p$-value of .11 suggests that a more strongly-powered study might reveal significant effects. This pattern of relations is consistent with previous work comparing intergroup anxiety and ideology. Choma, Jagayat, Hodson, and Turner (2018), for instance, showed that both RWA and SDO were related positively to intergroup anxiety in their study of attitudes toward Muslims. Higher SDO specifically has been consistently linked with higher intergroup anxiety (e.g. Costello \& Hodson, 2011; Miller et al., 2004).

When examining target thermometers (i.e. prejudice), more negative perceptions of speakers were predicted by higher SDO, whereas RWA did not predict target evaluations. These results were surprising, as prejudice was anticipated to be uniquely predicted by RWA and SDO as it is in ethnic prejudice research (Duckitt, 2001, 2006; Duckitt \& Sibley, 2016; Sibley, Wilson, \& Duckitt, 2007). Though SDOs effects on accent-based discrimination have been shown in past research (Hansen \& Dovidio, 2016), whether it can be predicted by RWA has not been studied. It is possible that RWA and SDO were impacted by similar multicollinearity issues as ACT. The correlation between RWA and SDO in this sample was strong $(r=.74)$, unlike previous research, where the strength of the relation was often weak to moderate (e.g. $r=.55$ in Matthews \& Levin, 2012; $r=.27$ in Sibley, Wilson, \& Duckitt, 2007). Further, both ideologies related to negative target evaluations, as shown in the correlation tables. Therefore, it is possible that multicollinearity is responsible for RWAs null effect on target evaluations in the regression 
models - while RWA and SDO both predicted negative target evaluations, only SDO did so independent from the other.

Further, the lack of within-participant accent effects was contrary to Hypothesis 3, as the average participant was predicted to perceive the Toronto accent more positively than the other accents. However, there was significant variance in random slopes for accents. Similar to Hypothesis 1, this suggests that while the average participant did not evaluate the targets differently, this was inconsistent across participants: some perceived the Toronto accent more positively than other accents, while the inverse was true for other participants. In this way, participants seem to vary widely in what they think about particular accents compared to others. This finding suggests that moderator variables that were not examined in this study may be responsible for the differential perceptions between participants. One such individual difference might be the likelihood of someone having fully listened to the audio clips; participants who skimmed the clips or were distracted while listening may not have responded in an equivalent way to how they would have otherwise. Another individual difference may be personality traits; the DPM outlines agreeableness, conscientiousness, and openness to experience as indirect predictors of prejudice (Duckitt, 2001), but it may be worth testing if they moderate the relation between ideology and stereotypes of accents via the SCM. How often participants have interacted with people who have foreign accents could also influence how they differentially evaluated accents, with more familiarity leading to more positive evaluations (i.e. contact effects, see Tropp \& Pettigrew, 2006). Future studies might probe for potential moderators in more detail. Additional attention checks, including objective and subjective comprehension measures (i.e. Hansen \& Dovidio, 2016); measures of common personality traits, such as the five factors of extraversion, openness to experience, neuroticism, conscientiousness, and agreeableness 
(Digman, 1990); questions probing familiarity with accents (Huang, Alegre, \& Eisenberg, 2016); and whether or not participants themselves have the accents are potential starting points for moderation analyses.

\section{Ethnic evaluations versus target evaluations}

Key to accent-based prejudice is the notion that accents provide cues for outgroup biases that are similar to those of race. For this reason, I hypothesized that there should be a stronger relation between perceptions of targets and evaluations of ethnicities when the target accent aligned with the associated ethnicity than when they are misaligned (i.e. Hypothesis 4). For instance, the perceptions of Arabic-accented speakers should be related to perceptions of people from Arabic countries to a greater degree than of people from other regions. Results were mixed, but generally, were consistent with Hypothesis 4. Specifically, perceptions of Arabic and Indian targets aligned more closely with evaluations of their respective ethnicities than did perceptions of non-related targets. However, perceptions of Toronto-accented targets and Latin American targets did not differ from non-related targets in the degree to which they related to their respective regional/ethnic groups. This is not to say that perceptions of Torontonians and those of the Toronto accent are not related, for instance. Instead, the null findings suggest that how people perceive Torontonians and Latin Americans may be related to how they perceived targets more generally - irrespective of accent. In other words, participants rated the Arabic target Arabic ethnicity pair, and the Indian target - Indian ethnicity pair more similarly than they did other pairings.

It is possible that regionalism may have caused the differential effects in this analysis. The majority of participants in the present research were from the U.S., and all were U.S. citizens or residents. For Americans, Torontonians and Latin Americans are the groups amongst 
the four that are closest both geographically and culturally to themselves. These accents are thus likely more familiar to this sample than the other accents. Potentially, this familiarity may have prompted participants to not rely on over-general stereotypes of the accented groups to an equal degree as they would Indian- and Arabic-accented people, instead drawing on their personal knowledge of Torontonians and Latin Americans. Research has shown that spending positive time with people of an outgroup can improve intergroup perceptions (Pettigrew \& Tropp, 2006; see also Hodson \& Hewstone, 2012). The increased contact with people who have Toronto and Latin American accents may have favourably biased participants toward them in comparison to the other groups studied in the present thesis.

Interestingly, there were variations between participants in how they associated people with the Toronto accent and Torontonians. This effect was not seen for the other accents. Anecdotally, considering the diversity of Toronto and its similarity of accent to that of the standard "American accent," it is possible that participants were not able to identify the Toronto accent as coming from Toronto. Difficulty identifying the source of the accent could lead to much higher variation in how the Toronto-accented targets were perceived. Research has shown that without having access to individuating information about a target (e.g. behaviour, personality characteristics), people tend to rely on stereotypes to a greater degree (for an overview, see Jussim, Crawford, \& Rubinstein, 2015). The current study presented targets with only vocal cues as individuating information from which participants could make their judgements. Therefore, misattributing the Toronto accent to that of a different region or culture could cause participants to rely on entirely different stereotypes, causing high variability in between-participant perceptions. Future research could verify this notion by asking participants 
which accent they think they are listening to and evaluate the effects of correct identification or mis-identification.

Further, even if participants correctly identified the Toronto-accented targets as Canadian, how they envisioned Canadians would have great impact in how they evaluated the targets. Participants may have had widely-varying mental images of the Canadians who were speaking and evaluated the targets accordingly. While some people may conjure images of the stereotypical white lumberjack Canadian, others might resort to prototypes (Justin Bieber) or someone who looks like their "one Canadian friend". Americans on the east coast, for instance, likely envision French Canadians, who elicit a particular stereotype. Because Canada touts its multicultural policy and identity, these images would likely be diverse. Moreover, the Torontoaccented targets used for this study even came from various ethnic heritages. With plenty of exemplars to choose from, these images would likely be diverse. Thus, the variation in how people imagined Torontonians (or Canadians in general) could account for the betweenparticipant effects found.

Amongst these group comparisons, it is also important to note the strength of association between the ethnic evaluations and their respective target evaluations. The regression coefficients suggest that for every 1 unit increase in ethnic evaluations, perceptions of the targets only increased between .309 and .459 units (on scales of 0 to 100). In other words, accent perceptions tended to vary to a lesser degree than ethnic perceptions. While it is possible that this is a product of study design (there were 4 times as many accent target ratings as there were ethnicity ratings), it is also possible that accent and ethnicity are not as closely linked as anticipated. When participants are asked to rate ethnicities, they may take into consideration many sources of potential bias. Skin colour, culture, stereotypes, previous experiences, and even 
accent may come to mind. On the other hand, rating accents alone, without the cue of an ethnic group, may evoke these sources of bias to a much smaller degree. In this way, ethnic evaluations may be compounded from a multitude of factors while accent evaluations are based on a comparatively small number of factors. Some research has indicated that having an intelligible English accent may actually be a positive factor in evaluations of immigrants (Hopkins, 2014). Furthermore, people are aware that accent, ethnicity, and group status do not always align. For instance, someone who has black skin might have an accent from any number of regions or cultures. Conversely, an accent from an individual region or culture does not translate into the person being of that region. Thus, the impact of accent may be much less than that of ethnicity, where it is less salient of a sign of group membership.

\section{SSD versus the SCM}

This study relied on two models of group evaluations - the SCM (Fiske et al., 2002) and the SSD model (Fuertes et al., 2012) - and one goal of the study was to determine the extent to which they overlapped. Competence and status were highly correlated, as were warmth and solidarity. Moreover, the patterns of mean differences discussed in Hypothesis 1a were similar for the pairs. Thus, in line with Hypothesis 5, solidarity and status were accurately reflected through warmth and competence, respectively. Yet, while there were mean differences between accents on dynamism, the factor loadings and reliability scores for the scale were poor, suggesting that its validity in this sample is suspect. Moreover, dynamism did not account for any additional variance over the SCM factors when the models were directly compared. Thus, contrary to Hypothesis 5, dynamism did not emerge as a valid third factor in studying stereotypes of accented groups, in the present research. 
In terms of face validity, Hypothesis 5's prediction that dynamism would relate to accentbased prejudice may not seem logical. For the most part, its items relate to qualities that are not inherently positive or negative. Apart from "aggressive", dynamism seems to relate more to a person's personality or vocal qualities. "Active" and "talkative" both refer to communication style. Yet, the extent to which these dynamism qualities are held or valued in an individual can be cultural. The German accent for instance, might be more active and aggressive; the Italian accent, on the other hand, might be more talkative and active (see Ball, 1983 for some evidence supporting this notion). Hence, the differences in dynamism could exist between accents, but not have any application to prejudice.

In using the facets of the SSD model as substitutes for warmth and competence when examining ideology and accent as predictors, results generally followed the same pattern. Poor model fit could again be attributed to adding latent RWA and SDO to the model, and accent effects were restricted to the within-participant level. Differentially, dynamism proved to be a significant predictor throughout. Across accents, people higher in RWA rated the targets as more dynamic, whereas people higher in SDO rated the targets as less dynamic. One potential explanation for this differential pattern is that more dynamic (i.e. lively or expressive) targets might seem more accustomed to Anglo/American culture. Speaking in a dynamic way requires familiarity with the language and great comfort speaking it. People higher in RWA are most concerned with their way of life changing (Altemeyer, 1981). The dynamic foreigners have put in effort to assimilate by investing in mastering the English language. In doing so, they have acculturated to the English-speaking region, rather than trying to disrupt it by maintaining their foreign culture. While foreigners who linguistically acculturate experience less stress (Archuleta, 2015; Dragojevic \& Giles, 2016) and may receive more positive evaluations from people higher 
in RWA, they may also be forfeiting their rich culture heritage. In contrast, people higher in SDO might perceive dynamic speakers as genuine competition. People who are articulate and extraverted are perceived as having higher chances of obtaining employment (Morrison, 2014) and are likely quite competent (Murphy, 2007). Because people higher in SDO are fiercely competitive, they would despise perceiving positive qualities in the dynamic foreigners (Pratto et al., 1994). Future research might examine the specific relation between dynamism, RWA, and SDO in more detail to test whether these proposed mechanisms hold.

The Toronto accent was also considered more dynamic than the other accents in this model. These findings seem to contrast the previous results, where comparing the SCM to the SSD model indicated that dynamism did not account for additional variance in the examination of accent-based prejudice. However, the relation between Toronto-accented targets (versus the others) and dynamism should be interpreted with caution. First, the poor reliability of the dynamism scale and the insignificant loading of the "Aggressive" item in the MLCFA suggest that the items used do not relate to each other well - a sign that they do not measure the same construct. A post-hoc analysis showed that even when defining dynamism as the average of the two remaining items (Active and Talkative), it did not account for any additional variance over the SCM, $\Delta F=.001, p=.975$. Second, by comparing the Toronto accent to the other three accents, a potential confound emerges. The Toronto-accented speakers were far more accustomed to reading and speaking in English than their ESL counterparts. This comfort would likely translate into a more confidence in the speaker's voice, a greater willingness to abandon monotone speech, and a pace that the participants would be more familiar with. The participants might then be more likely to rate the speakers as more dynamic. Future research might manipulate the extent to which targets demonstrate dynamism (speaking clearly, rarely 
stumbling), perhaps using speakers who have lived in English-speaking regions for a longer period of time, yet who have still retained their native accent. In this way, comfort in speaking English could be controlled for.

In summary, the SCM appears to comparatively account for evaluations of accents as the solidarity/status/dynamism model. Together, these reasons entrench the idea that dynamism may not add any value to the SCM. One potential confound in the findings, was that status accounted for additional variance in the models. However, this added variance negatively predicted accent evaluations. In other words, in the model where warmth, competence, and solidarity were included, higher perceived status led to more negative target evaluations. Furthermore, the change in $R^{2}$ was minimal, with only a .005 difference. Therefore, because of the strong correlations between warmth and solidarity, and competence and status; the data-driven and face-value lack of value in dynamism; and the already widespread use of the SCM, it is recommended that the SCM be used in future research in lieu of the SSD model. By using the SCM, prejudice researchers highlight and maintain parsimony in their discipline.

\section{Limitations and Directions for Future Research}

There are several limitations that should be considered in addition to those discussed above. The stimuli used were entirely mundane and had little similarity to how conversations might organically occur. While the neutrality of the stimuli enhances experimental control over the study, it weakens the extent to which the effects can be generalized. When examining prejudice in particular, content is likely to make a difference in how speech is perceived. According to the DPM (Duckitt, 2001), perceived threats mediate the relation between ideology and prejudice. If there are few threats to perceive, there will be little-to-no prejudice shown. For those higher in RWA, cultural norms and traditions are revered (Altemeyer, 1998; Duckitt, 2001, 
2006); speech discussing immigration or spreading non-Christian religions would likely be threatening to these people and would give reason for them to display prejudice. For those higher in SDO, the world is a competitive jungle (Duckitt, 2001, 2006), where opposition to group dominance ought to be suppressed; speech demanding fair wages, unions, and government benefits for refugees might trigger the urge to quash the potential competition. The stimuli I used may have not provided the opportunity for ideology to predict negative evaluations of accents. Future studies should expand in the breadth of stimuli used, ideally varying by content and emotion. In this way, research could parse the intricacies of how accent-based prejudice and attitudes toward accents manifest.

Though sampling and power issues are common in psychological research, there were features unique to the present study that were particularly problematic. Primarily, the design was only partially-crossed. Instead of using counterbalancing to ensure that each participant listened to each accent, but in a random order, the stimuli were fully randomized. This reduced the probability of non-independence of responses - where participants based their responses on previous ones - and reduced the number of participants necessary to conduct the study. However, it also decreased the statistical power required to find within-subjects effects, prevented analysis by individual stimulus speakers, and eliminated the ability to test interactions. In an ideal scenario, future studies might use purely-crossed designs, where participants would be equally distributed among speaker-script pairings, and responses could be grouped by participant, script, and speaker. However, adding additional random factors greatly increases the number of participants needed to achieve similar power to the current work. Thus, incremental steps should be taken where these factors can be addressed over multiple studies. 
Another potential confound was that speech comprehension was only tested to a limited degree. While it would be reasonable to assume that targets who are more difficult to understand would be perceived less positively than those who are easier to understand, perception is a twoway street. Research has shown that subjective comprehension is related to accent-based prejudice, but objective comprehension is not (Hansen \& Dovidio, 2016). Moreover, people higher in SDO tend to be lower in subjective comprehension. That is, when people feel like they cannot understand, they will rate the target more negatively than when they feel like they can, and higher SDOs are less likely to feel like they understand to begin with. This effect was also shown in the current thesis. Yet, the subjective component makes it difficult to test whether having a higher SDO and being more prejudiced toward an accented group leads to the feeling of not being able to understand, or if experiencing the feeling eventually leads people higher in SDO to holding prejudice. Thus, it is possible that results are a consequence of comprehension difficulties: more negative evaluations of targets could have resulted from poorer understanding of their speech. Yet, a post-hoc examination of the mediating role of comprehension between ideology and target evaluations showed no significant direct or indirect effects (see Figure A2). Still, future studies might include measures of both subjective and objective comprehension, while continuing to examine the role of ideology. These additional measures can additionally double as attention checks, which my study also lacked.

In regard to the study's sample, using participants from Amazon's Mechanical Turk has disadvantages. While the platform provides quick convenience samples that can be readily filtered according to a wide variety of criteria, the participant characteristics are unlike those found in the general population. For instance, Turkers tend to be Whiter, more liberal, and more highly educated than the average American (Clifford, Jewell, \& Waggoner, 2015; Paolacci, 
Chandler, \& Ipeirotis, 2010). Moreover, a small proportion of all MTurk HITs seem to be completed by the same group of people, increasing the likelihood of participants being able to deduce the hypotheses of studies, and of their having encountered questionnaires in previous studies (Hiltin, 2016). Turkers who do not remain workers on the website for long also have a high turnover rate, possibly indicating that only specific types of people remain Turkers over long periods of time (Difallah, Filatova, \& Ipeirotis, 2018). Future studies should expand beyond Mechanical Turk and recruit local, representative samples as well.

A final outstanding issue with this thesis was in the targets used as stimuli. Though there were over 20 speakers across 4 scripts and 4 accents, the accents chosen only corresponded to three of the four quadrants outlined in the SCM. The Latin-American accent was theorized to be high warmth and low competence, the Indian and Arabic accents were low warmth and high competence, and the Toronto accent was high warmth and high competence. There were no accents which corresponded to the quadrant for low warmth and low competence. Not having other group(s) for this quadrant limited the extent it was possible to test the SCM in the context of accents. However, groups traditionally perceived as low warmth and low competence tend to be groups not associated with ethnicities, such as poor and homeless people (e.g. Fiske et al., 2002; Lee \& Fiske, 2006). In this way, while research on the SCM has identified people of economic and social classes to be stereotyped in the low warmth and low competence quadrant, there are no cultural or ethnic groups that have been identified in the literature as being there.

Additionally, despite accent being linked to class and social status (e.g. Giles, 1970), it was difficult to identify and recruit speakers from the Toronto area that may have been stereotyped as low warmth/competence. In planning this study, I had hoped to recruit speakers that held African American English accents and accents from local Indigenous groups. Because 
Indigenous groups experience high amounts of prejudice and discrimination, and because the African American English accent is spoken by people who are typically lower class (Green, 2002), they would have been hypothesized to fit into the low warmth/competence quadrant. However, too few participants from these groups volunteered in during database creation for the accents to be tested. The Toronto accent too, was problematic. Because participants were recruited on Mechanical Turk and were all American citizens or residents, Toronto-accented speakers would be considered in-group allies, but still be part of an outgroup, according to the SCM (Fiske et al., 2002). It is thus uncertain if there would have been differences in how the ingroup (American-accented speakers) would be perceived compared to ingroup allies (Torontoaccented speakers). Future studies should use more accents, including accents native to the region of the participants being tested, to better envision how target perceptions vary according to the SCM.

\section{Conclusion}

In this thesis, I conducted a study examining how the Toronto, Indian, Latin American, and Arabic accents are perceived, and potential predictors of these perceptions. One of my primary goals was to synthesize research from psycholinguistics and social psychology. Academic research permits scientists to approach topics from many different angles, providing an abundance of unique perspectives. However, having multiple perspectives also has the potential to cause fragmentation across the discipline of psychology, particularly when academics are unaware of similar research from their peers in other subdisciplines. It is important to try to bridge these divisions whenever possible. The similarities between the Stereotype Content Model (SCM, Fiske, et al., 2002) and the solidarity/status/dynamism (SSD, Fuertes, et al., 2012) model provide an excellent example of this fragmentation. Though the latter 
was developed first, it was limited to evaluations of accents; moreover, the former has greater reach in general prejudice research. Results from my study indicated that the two are functionally similar. As the link between accent and ethnicity is examined in future research, a common means of measurement is necessary to maximize validity. The SCM's ubiquity is far greater than that of the SSD model. Consequently, I suggest that future researchers rely on the SCM when studying accent evaluations.

In using sociopolitical ideology to predict accent evaluations however, the DPM (Duckitt, 2001) cannot be recommended to the same degree. As the results from this study indicated, RWA, SDO, and even ACT (Duckitt, 2006) do not consistently predict the stereotypes of accents found in the SCM (Fiske, et al., 2002) - at least, not in the present sample. On the other hand, similar to Hansen and Dovidio (2016), SDO predicted accent-based prejudice, specifically; ACT similarly predicted accent-based prejudice. Therefore, while the DPM and ACT may not be useful as a model for predicting stereotypes of various accented groups, it is likely useful in investigating prejudice. These relations between ideology, accent-based prejudice, and accentbased stereotypes should continue to be explored in future studies. Identifying how prejudice and stereotypes differ across the context of accents would illuminate whether the results from this sample were anomalous or representative of the general North American population. Given the growing and continued importance of accent as a source of discrimination and linguistic prejudice (e.g. Giles, Williams, \& Mackie, 1995; Lippi-Green, 2001; Souza, Byers-Heilein, \& Poulin-Dubois, 2013), studying how and why these biases express themselves has the potential to provide answers and solutions to the problem. 


\section{Appendix A: Additional tables and figures}

Table A1

Predicting the Stereotype Content Model with ACT ideology via multilevel structural equation modeling

\begin{tabular}{|c|c|c|}
\hline $\begin{array}{l}\text { Level, scale, } \\
\text { and variable }\end{array}$ & $\begin{array}{l}\text { Model } 1 \\
\text { MLCFA }\end{array}$ & $\begin{array}{c}\text { Model } 2 \\
\text { Predictors }\end{array}$ \\
\hline \multicolumn{3}{|l|}{ Level 1 (within) } \\
\hline \multicolumn{3}{|l|}{ Competence } \\
\hline Competent & 1.000 & 1.000 \\
\hline Independent & .771 & .768 \\
\hline Competitive & 671 & 649 \\
\hline Intelligent & .849 & .837 \\
\hline Confident & .913 & .905 \\
\hline \multicolumn{3}{|l|}{ Warmth } \\
\hline Warm & 1.000 & 1.000 \\
\hline Sincere & .998 & .987 \\
\hline Tolerant & .981 & .996 \\
\hline Good-natured & .935 & .926 \\
\hline \multicolumn{3}{|l|}{ Competence } \\
\hline Accent effect & & .296 \\
\hline \multicolumn{3}{|l|}{ Warmth } \\
\hline Accent effect & & .083 \\
\hline \multicolumn{3}{|l|}{ Covariances } \\
\hline Comp + Warm & .669 & .651 \\
\hline \multicolumn{3}{|l|}{ Level 2 (between) } \\
\hline \multicolumn{3}{|l|}{ Competence } \\
\hline Competent & 1.000 & 1.000 \\
\hline Independent & 1.005 & 1.046 \\
\hline Competitive & .631 & .772 \\
\hline Intelligent & .970 & 1.041 \\
\hline Confident & .744 & .830 \\
\hline \multicolumn{3}{|l|}{ Warmth } \\
\hline Warm & 1.000 & 1.000 \\
\hline Sincere & 1.387 & 1.400 \\
\hline Tolerant & 1.247 & 1.210 \\
\hline Good-natured & .982 & 1.040 \\
\hline \multicolumn{3}{|l|}{ Competence } \\
\hline Authoritarianism & & -.369 \\
\hline Conservatism & & .648 \\
\hline Traditionalism & & -.281 \\
\hline SDO & & -.082 \\
\hline Accent effect & & 1.113 \\
\hline \multicolumn{3}{|l|}{ Warmth } \\
\hline Authoritarianism & & -.397 \\
\hline Conservatism & & .471 \\
\hline Traditionalism & & -.144 \\
\hline SDO & & -.072 \\
\hline Accent effect & & 1.128 \\
\hline \multicolumn{3}{|l|}{ Covariances } \\
\hline Comp + Warm & .346 & .354 \\
\hline Auth + Cons & & 1.472 \\
\hline Auth + Trad & & 1.085 \\
\hline Auth + SDO & & 1.141 \\
\hline Cons + Trad & & 1.374 \\
\hline
\end{tabular}




\begin{tabular}{lcc} 
Cons + SDO & & $\mathbf{1 . 3 6 9}$ \\
Trad + SDO & & $\mathbf{1 . 0 4 2}$ \\
$\chi 2(d f)$ & $145(52)$ & $1994(919)$ \\
$\quad p$ value & $<.001$ & $<.001$ \\
CFI & .967 & .765 \\
RMSEA & .061 & .052 \\
$\quad p$ value & .059 & .209 \\
\hline
\end{tabular}

Note: Loadings are unstandardized. Those in bold were significant at the $p<.05$ level. ${ }^{\dagger}$ Measures of ideology used latent variables at the between-participant level. Loadings were omitted for conciseness. See Table 4 for general factor loadings. RMSEA p-value refers to a test of the alternative hypothesis that RMSEA > .05.

\section{Table A2}

McDonald's omega reliability scores

\begin{tabular}{lcccccc}
\hline Measure & $\omega \_h$ & $\omega \_t$ & Extracted factors & F1 $\lambda$ & F2 $\lambda$ & F3 $\lambda$ \\
\hline RWA & .78 & .97 & 3 & .23 & 2.29 & .34 \\
SDO & .82 & .96 & 2 & 1.59 & .02 & 1.36 \\
ACT & .82 & .97 & 3 & .83 & 1.74 & .79 \\
SCM & .65 & .94 & 3 & 2.24 & .25 & .36 \\
SSD & .75 & .93 & 3 & 1.33 & .25 & .83 \\
\hline
\end{tabular}

Note. Extraction used maximum likelihood and defaulted to three factors. F1-F3 $\lambda$ refers to eigenvalues for factors 1 through 3 . 
Level 1: Within participants

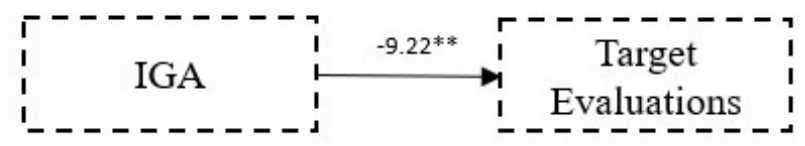

Level 2: Between participants

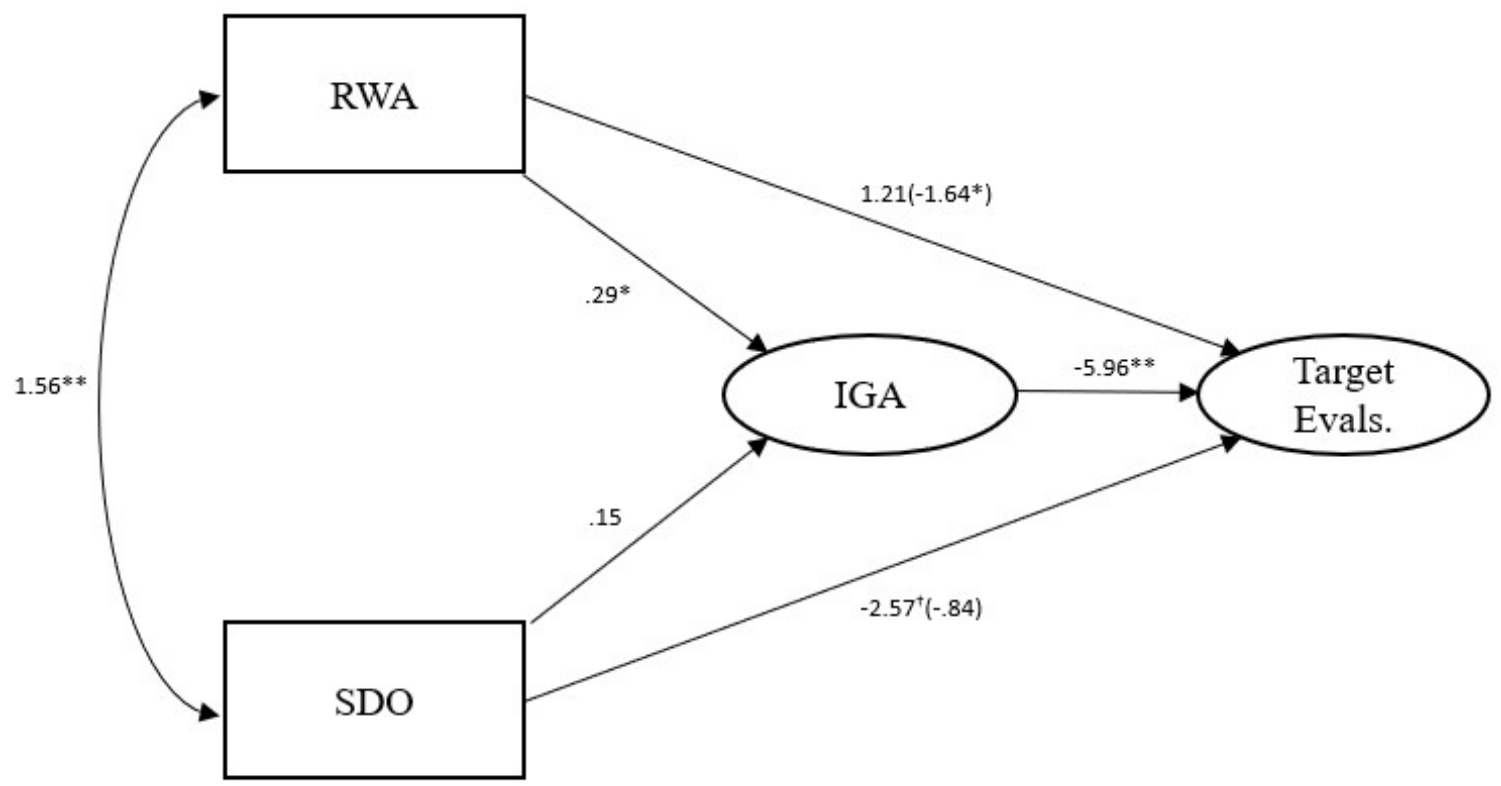

Figure A1. Multilevel mediation of intergroup anxiety between ideology and target evaluations.

Note. Loadings are unstandardized. ${ }^{\dagger} p<.01, * p<.05, * * p<.001$. RWA $=$ right-wing authoritarianism, $\mathrm{SDO}=$ social dominance orientation, and IGA $=$ intergroup anxiety. 
Level 1: Within participants

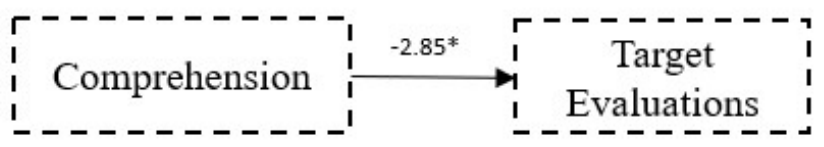

Level 2: Between participants

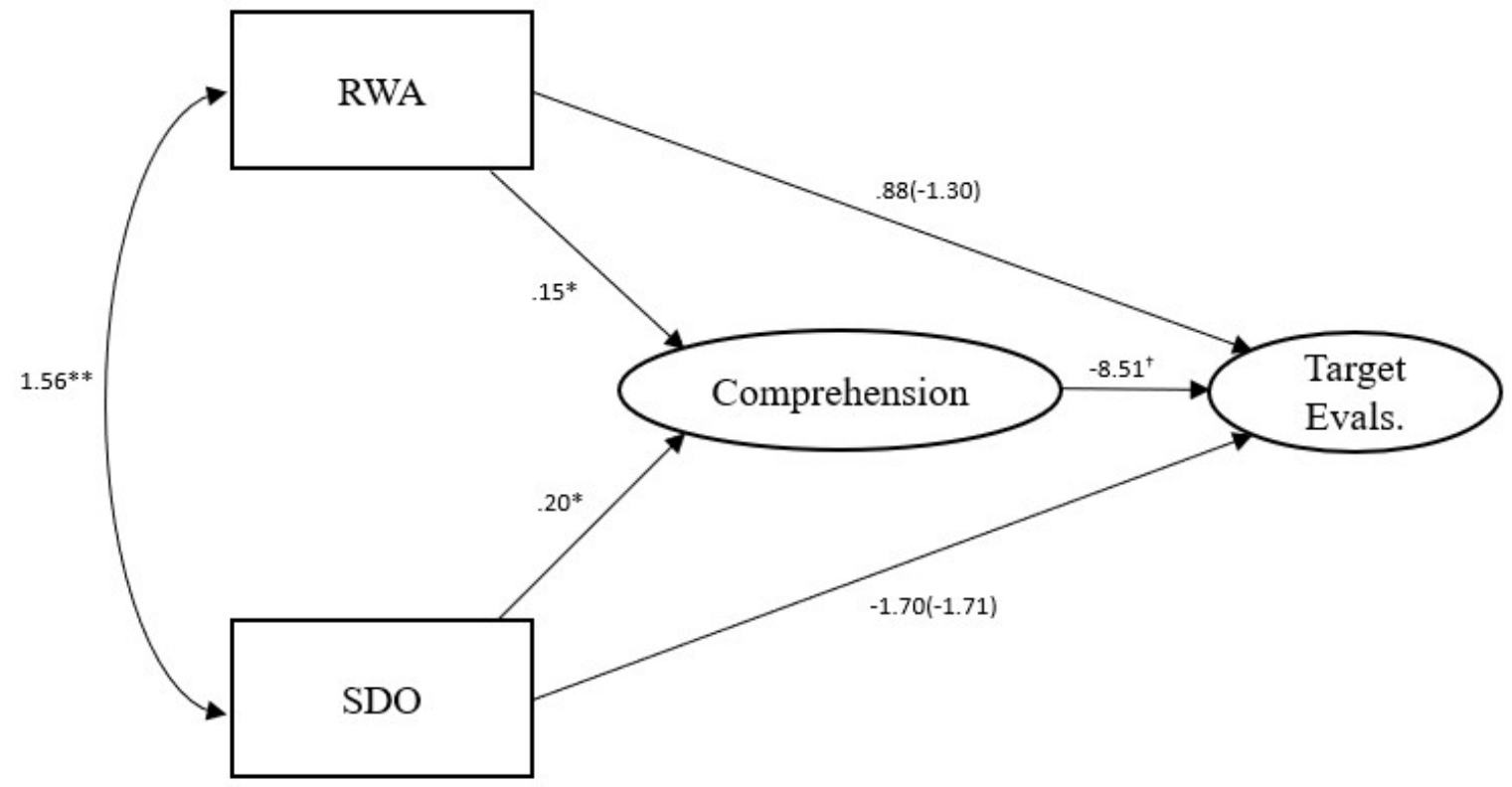

Figure A2. Multilevel mediation of subjective comprehension between ideology and target evaluations.

Note: Loadings are unstandardized. ${ }^{\dagger} p<.01,{ }^{*} p<.05,{ }^{* *} p<.001$. RWA $=$ right-wing authoritarianism, $\mathrm{SDO}=$ social dominance orientation, and Comprehension refers to how difficult it was for participants to understand targets. 
Appendix B: Software for data analyses

\begin{tabular}{|c|c|}
\hline $\mathrm{R}$ & $\begin{array}{l}\text { R Core Team (2018). R: A language and environment for statistical computing } \\
\text { URL: https://www.R-project.org/ }\end{array}$ \\
\hline nlme & $\begin{array}{l}\text { Pinheiro, J., Bates, D., DebRoy, S., Sakar, D., \& \{R Core Team\} (2018). } \\
\text { \{nlme\}: Linear and nonlinear mixed effects models. URL: https://CRAN.R- } \\
\text { project.org/package=nlme }\end{array}$ \\
\hline lme4 & $\begin{array}{l}\text { Bates, D., Machler, M., Bolker, B., \& Walker, S. (2015). Fitting linear mixed- } \\
\text { effects models using \{lme4\}, Journal of Statistical Software, 67(1), 1-48. }\end{array}$ \\
\hline tidyr & $\begin{array}{l}\text { Wickham, H., \& Henry, L. (2018). tidyr: Easily tidy data with 'spread()' and } \\
\text { 'gather()’ functions. R package version 0.8.1. URL: https://CRAN.R- } \\
\text { project.org/package=tidyr }\end{array}$ \\
\hline dplyr & $\begin{array}{l}\text { Wickham, H., François, R., Henry, L., \& Müller, K. (2018). dplyr: A grammar } \\
\text { of data manipulation. R package version 0.7.5. URL: https://CRAN.R- } \\
\text { project.org/package=dplyr }\end{array}$ \\
\hline hmisc & $\begin{array}{l}\text { Harrell, F. E. Jr. (2018). Hmisc: Harrell Miscellaneous. R package version 4.1- } \\
\text { 1. URL: https://CRAN.R-project.org/package=Hmisc }\end{array}$ \\
\hline qualityTools & $\begin{array}{l}\text { Roth, T. (2016). qualityTools : Statistics in quality science. R package version } \\
\text { 1.55. URL: http://www.r-qualitytools.org }\end{array}$ \\
\hline QuantPsyc & $\begin{array}{l}\text { Fletcher, T. D. QuantPsyc : Quantitative psychology tools. R package version } \\
\text { 1.5. URL: https://CRAN.R-project.org/package=QuantPsyc }\end{array}$ \\
\hline psych & $\begin{array}{l}\text { Revelle, W. (2018). psych: procedures for personality and psychological } \\
\text { research. URL: https://CRAN.R-project.org/package=psych Version = 1.8.4. }\end{array}$ \\
\hline car & $\begin{array}{l}\text { Fox, J., Weisberg, S. (2011). An }\{\mathrm{R}\} \text { Companion to Applied Regression }\left(2^{\text {nd }}\right. \\
\text { ed.). Thousand Oaks, CA: Sage. URL: } \\
\text { http://socserv.socsci.mcmaster.ca/jfox/Books/Companion }\end{array}$ \\
\hline boot & $\begin{array}{l}\text { Canty, A., \& Ripley, B. (2017). boot: Bootstrap R (S-Plus) functions. R } \\
\text { package version 1.3-20. }\end{array}$ \\
\hline $\mathrm{ltm}$ & $\begin{array}{l}\text { Rizopoulos, D. (2006). ltm: An R package for latent variable modelling and } \\
\text { item response theory analyses, Journal of Statistical Software, 17(5), 1-125. } \\
\text { URL: http://www.jstatsoft.org/v17/i05/ }\end{array}$ \\
\hline semTools & $\begin{array}{l}\text { semTools Contributors. (2016). semTools: Useful tools for structural equation } \\
\text { modeling. R package version 0.4-14. URL: https://CRAN.R- } \\
\text { project.org/package=semTools }\end{array}$ \\
\hline semPlot & $\begin{array}{l}\text { Epskamp, S., \& Stuber, S. (2017). semPlot: Path diagrams and visual analysis } \\
\text { of various SEM packages' output. R package version 1.1. https://CRAN.R- } \\
\text { project.org/package=semPlot }\end{array}$ \\
\hline ImerTest & $\begin{array}{l}\text { Kuznetsova, A., Prokhoff, P. B., \& Christensen, R. H. B. (2017). lmerTest } \\
\text { package: Tests in linear mixed effects models. Journal of Statistical Software, } \\
82(13) 1-26 .\end{array}$ \\
\hline lmSupport & $\begin{array}{l}\text { Curtin, J. (2018). lmSupport : Support for linear models. R package version } \\
\text { 2.9.13. URL: https://CRAN.R-project.rog/package=lmSupport }\end{array}$ \\
\hline sjstats & $\begin{array}{l}\text { Lüdecke, D. (2018). sjstats: Statistical functions for regression models. R } \\
\text { package version 0.16.0. URL: https://CRAN.R-project.org/package=sjstats }\end{array}$ \\
\hline
\end{tabular}




\begin{tabular}{|l|l|}
\hline MuMIn & $\begin{array}{l}\text { Barton, K. (2018). MuMIn : Multi-Model Inference. R package version 1.40.4. } \\
\text { URL: https://CRAN.R-project.org/package=MuMInj }\end{array}$ \\
\hline ggplot2 & $\begin{array}{l}\text { Wickham, H. (2009). ggplot2 : Elegant graphics for data analysis. New York, } \\
\text { NY: Springer-Verlag. URL: http://ggplot2.org }\end{array}$ \\
\hline SPSS & $\begin{array}{l}\text { IBM Corp. Released 2017. IBM SPSS Statistics for Windows, Version 25.0. } \\
\text { Armonk, NY: IBM Corp. }\end{array}$ \\
\hline PANGEA & $\begin{array}{l}\text { Westfall, J. (2016). PANGEA: Power ANalysis for GEneral Anova designs. } \\
\text { (working paper) }\end{array}$ \\
\hline
\end{tabular}


Appendix C: Scripts

\section{Stella}

Please call Stella. Ask her to bring these things with her from the store: Six spoons of fresh snow peas, five thick slabs of blue cheese, and maybe a snack for her brother Bob. We also need a small plastic snake and a big toy frog for the kids. She can scoop these things into three red bags, and we will go meet her Wednesday at the train station.

\section{Gina's Pizza Shop}

If you want to go to Gina's Pizza Shop, I can tell you the best way to get there. Go straight down this street and follow the signs for the Johnson Expressway. However, don't actually go onto the Johnson Expressway. When you get to the on-ramp, take a left onto Cleveland Street, the main street in town. You'll go past a big school called Cleveland High School, right between a church with a yellow door and a church with a blue steeple. There is a small alley just past the church with the blue steeple. Take this alley for several blocks, and turn left on the third road you come to. Eventually, the road will split in two. Take Fillmore Boulevard, which is the one on the right. A block and a half later you'll see the sign for Gina's Pizza Shop, also known as the best pizza place in town.

\section{North Wind}

The North Wind and the Sun were disputing which was the stronger, when a traveler came along wrapped in a warm cloak. They agreed that the one who first succeeded in making the traveler take his cloak off should be considered stronger than the other. Then the North Wind blew as hard as he could, but the more he blew the more closely did the traveler fold his cloak 
around him, and at last the North Wind gave up the attempt. Then the Sun shone out warmly, and immediately the traveler took off his cloak. And so the North Wind was obliged to confess that the Sun was the stronger of the two.

\section{Comma}

Well, here's a story for you: Sarah Perry was a veterinary nurse who had been working daily at an old zoo in a deserted district of the territory, so she was very happy to start a new job at a superb private practice in North Square near the Duke Street Tower. That area was much nearer for her and more to her liking. Even so, on her first morning, she felt stressed. She ate a bowl of porridge, checked herself in the mirror and washed her face in a hurry. Then she put on a plain yellow dress and a fleece jacket, picked up her kit and headed for work. When she got there, there was a woman with a goose waiting for her. The woman gave Sarah an official letter from the vet. The letter implied that the animal could be suffering from a rare form of foot and mouth disease, which was surprising, because normally you would only expect to see it in a dog or a goat. Sarah was sentimental, so this made her feel sorry for the beautiful bird. Before long, that itchy goose began to strut around the office like a lunatic, which made an unsanitary mess. The goose's owner, Mary Harrison, kept calling, "Comma, Comma," which Sarah thought was an odd choice for a name. Comma was strong and huge, so it would take some force to trap her, but Sarah had a different idea. First she tried gently stroking the goose's lower back with her palm, then singing a tune to her. Finally, she administered ether. Her efforts were not futile. In no time, the goose began to tire, so Sarah was able to hold onto Comma and give her a relaxing bath. Once Sarah had managed to bathe the goose, she wiped her off with a cloth and laid her on her right side. Then Sarah confirmed the vet's diagnosis. Almost immediately, she remembered 
an effective treatment that required her to measure out a lot of medicine. Sarah warned that this course of treatment might be expensive-either five or six times the cost of penicillin. I can't imagine paying so much, but Mrs. Harrison-a millionaire lawyer-thought it was a fair price for a cure. 


\title{
Appendix D: Consent form, study materials, and debrief form
}

\author{
Ryerson University \\ Informed Consent Form \\ Study Title: "Groups and Accents"
}

You are being asked to participate in a research study. Before signing this consent form, it is important that you read the following information. You may contact the researchers to be sure that you understand what the study entails.

\section{Principal Investigator:}

David Sumantry, MA thesis student, Department of Psychology, Ryerson University, Toronto.

Contact Information: david.sumantry@psych.ryerson.ca

Supervised by:

Dr. Becky Choma, Department of Psychology, Ryerson University, Toronto.

Contact Information: (416) 979-5000 ext. 3006; becky.choma@psych.ryerson.ca

\section{Purpose of the Study:}

- Investigate how people evaluate accented groups, looking at a variety of different accents

- 250 people will be recruited to participate in the study

\section{Description of the Study:}

- If you decide to participate, the study will begin immediately after this consent form

- The process will last approximately 20 minutes

○ Completing questionnaires about personal attitudes ( 2 minutes)

- Listening to accented speakers and evaluating groups (14 minutes)

- Providing demographic information (2 minutes)

- Reading through a debrief form (2 minutes)

\section{What is Experimental in this Study:}

- None of the procedures or questionnaires used in this study are experimental in nature, in the sense that they have all been used by other researchers and found to be useful procedures and questionnaires.

- This study is considered 'exploratory.' This means that while we think that there will be differences in how different speakers are evaluated, we don't have specific predictions as to where these differences will be or how they will manifest.

\section{Risks or Discomforts:}

- This is a minimal risk study

- Some individuals may experience fatigue, boredom, or mild emotional discomfort from giving evaluations of others

- If at any point you don't feel comfortable, you are completely free to take a break or stop the study

\section{Benefits of the Study:}

- There is no direct benefit to participants in this study although the information gained from the overall study may improve research into intergroup relations and psycholinguistics, and increase 
your knowledge of psychological research. When the session is over, we will describe the purpose and hypotheses of the study to you in more detail. Personally, it may increase your knowledge of psychological research: what it's like and how it works.

\section{Confidentiality:}

- All information collected during this study will be anonymous because no identifying information (e.g., your name) will be collected

- This survey uses Qualtrics, which is a United States of American (USA) company. Consequently, Qualtrics or USA authorities may access survey data in some forms (e.g., aggregate usage information) and under strict policies

- All responses will be stored online on the Qualtrics survey website. More information can be found here: https://www.qualtrics.com/privacy-statement/

- We do not link your Mechanical Turk ID to your responses

- No IP address data will be collected

- Please note that if you complete the survey using a public computer or a personal computer in public, visual privacy may not be guaranteed

- Aggregate (group-based and de-identified) data will be uploaded to an Open Science company website which stores data for academics.

\section{Incentives to Participate:}

- You will receive $\$ 1$ USD to participate in the study

\section{Voluntary Nature of Participation:}

- Participation in this study is entirely voluntary

- If you decide to participate, you are free to withdraw your consent and to stop your participation at any time without penalty

- If you withdraw, you will still receive the $\$ 1$ incentive

- At the end of the survey, you will be presented with a post-debrief consent form. Here, you will have another opportunity to withdraw consent to have your data be included in analyses

\section{Questions about the Study:}

- If you have any questions about the research now or later, please contact: Dr. Becky Choma or David Sumantry.

\section{Contact information}

Dr. Becky Choma, Department of Psychology, Social and Political Psychology Lab, Phone: 416-9795000 ext. 3006, Email: becky.choma@psych.ryerson.ca.

David Sumantry, MA thesis student, Department of Psychology, Social and Political Psychology Lab, Email: david.sumantry@psych.ryerson.ca

If you have any questions regarding your rights as a human subject and participant in this study, you may contact the Ryerson University Research Ethics Board for information: Ryerson Ethics Board, c/o Office of the Vice President, Research and Innovation, Ryerson University 350 Victoria Street Toronto, ON M5B 2K3, 416-979-5042.

Agreement: Completing below indicates that you have read the information in this agreement and have had a chance to ask any questions you have about the study. Choosing "I agree..." also indicates that you agree to be in the study and have been told that you can change your mind any time during the study and withdraw from it. Choosing "I do not agree..." indicates that you do not wish to complete the study. 
You have been told that by signing this consent agreement, you are not giving up any of your legal rights.

I agree to participate in this study. I have read and understand the description provided, and I understand that my participation is voluntary and that I am free to skip questionnaire items I do not wish to answer. I also understand that I am free to stop participating altogether.

I do not agree to participate in this study. I understand that my choice not to participate will be confidential and that there is no penalty for choosing not to participate.

\section{Study Materials}

\section{SONA ID}

Please enter your 6-digit SONA ID. Please note that this is NOT the same as your Ryerson ID. If you do not enter your 6-digit SONA ID, there will be no way for the researchers to give you credit for participation.

\section{Accent Evaluations}

For this study, you will listen to audio clips. Please take some time to ensure that the audio on your device is working. Use the clip below to adjust your volume to a comfortable level. Then, in the box below, please enter the word given to you by the clip.

The word given in the recording (no capitals):

[situation]

We would like you to listen to this recording of someone who has an accent. Please ensure that the volume on your computer is sufficient to hear the clip. Click the play button once you are ready.

Now we would like you to provide some evaluations based on the clip you just listened to. Respond according to what you genuinely think.

\section{Stereotype Content Model}

For each of the traits below, please indicate how you perceive people with this accent to be viewed by society.

\begin{tabular}{|c|c|c|c|c|c|}
\hline \multicolumn{5}{|c|}{ Very incompetent } & Very competent \\
\hline 1 & 2 & 3 & 4 & 5 & $6 \quad 7$ \\
\hline \multicolumn{5}{|c|}{ Very dependent } & Very independent \\
\hline 1 & 2 & 3 & 4 & 5 & $6 \quad 7$ \\
\hline \multicolumn{5}{|c|}{ Not competitive at all } & Very competitive \\
\hline 1 & 2 & 3 & 4 & 5 & $6 \quad 7$ \\
\hline \multicolumn{5}{|l|}{ Very cold } & Very warm \\
\hline 1 & 2 & 3 & 4 & 5 & $6 \quad 7$ \\
\hline \multicolumn{5}{|c|}{ Very insincere } & Very sincere \\
\hline 1 & 2 & 3 & 4 & 5 & $6 \quad 7$ \\
\hline
\end{tabular}


Not confident at all

Very unintelligent

$\begin{array}{lr}1 & 2 \\ \text { Very intolerant } & \end{array}$

Very intolerant

$\begin{array}{llll}1 & 2 & 3 & 4\end{array}$

Very hostile

1

Status - Solidarity - Dynamism triad (Zahn \& Hopper, 1985; Study 2)

Very illiterate

$\begin{array}{cc}1 & 2 \\ \text { Very uneducated }\end{array}$

Very literate

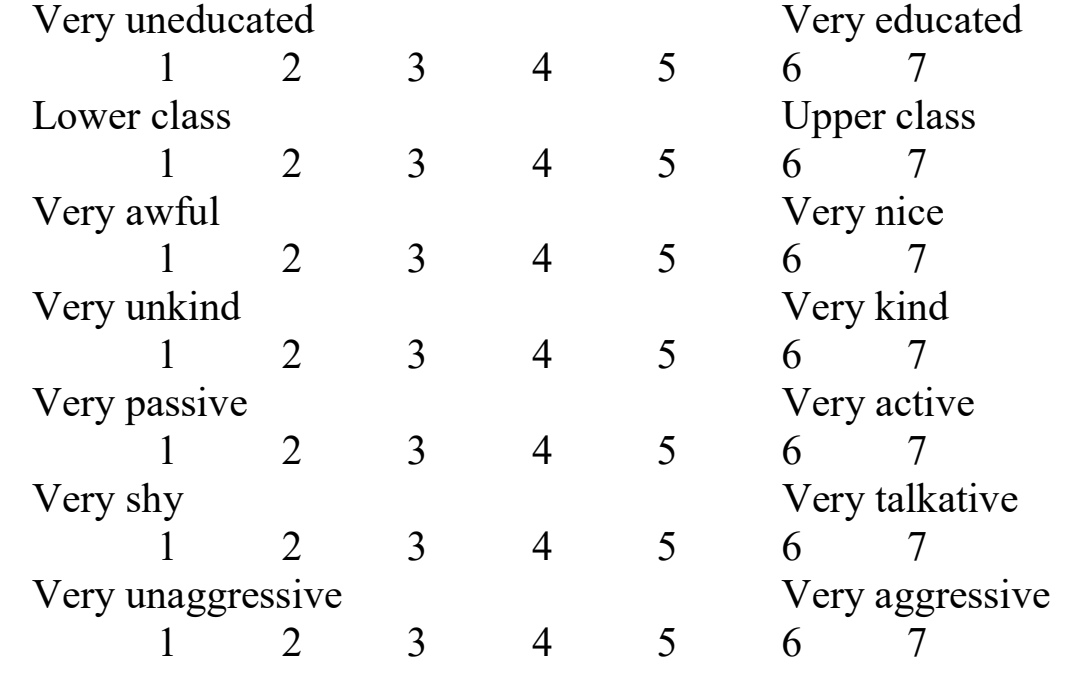

\section{Comprehension Check}

To what degree did you find the speaker easy/difficult to understand?

Very easy to understand

Very difficult to understand

$\begin{array}{lllllll}1 & 2 & 3 & 4 & 5 & 6 & 7\end{array}$

Intergroup Anxiety (Stephan \& Stephan, 2000)

How would you feel interacting with someone who has this accent?

Not anxious at all

$$
\begin{array}{lllllll}
1 & 2 & 3 & 4 & 5 & 6 & 7
\end{array}
$$

Not comfortable at all Very comfortable

$\begin{array}{lllllll}1 & 2 & 3 & 4 & 5 & 6 & 7\end{array}$

\section{Thermometer scales}

Please indicate your attitude toward the speaker by adjusting the slider. The rating scale resembles values on a thermometer. Lower values are used to indicate unfavourable attitudes 
(i.e., disliking them), and higher numbers are used to indicate favourable attitudes (i.e., liking them).

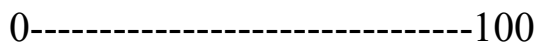

This rating scale resembles values on a thermometer. Lower values are used to indicate unfavourable attitudes (i.e., disliking them), and higher numbers are used to indicate favourable attitudes (i.e., liking them). Please indicate your attitude toward the group by adjusting the slider

People from Toronto

0-------------------100

People from India

0------------------------------100

People from Latin-America

0-----------------------------100

People from Arabic countries

0------------100

Ideology

Right Wing Authoritarianism (Altemeyer, 1998)

Please circle your response, using the scale below.

$\begin{array}{llll}1 & 2 & 3 & 4\end{array}$

Strongly Moderately Slightly Neither

Disagree Disagree Disagree

Disagree
5 Slightly

Agree
6 Moderately

Agree
7

Strongly

Agree

Nor Agree

1. Gays and lesbians are just as healthy and moral as anybody else.
1
2
3
4
5
6
7

2. Atheists and others who have rebelled against the established religions are no doubt every bit as good and virtuous as those who attend church regularly.
1
2
3
4
5
6
7

3. There are many radical, immoral people in our country today who are trying to ruin it for their godless purposes, whom the authorities should put out of action.
1
2
3
4
5
6
7

4. Our country will be destroyed someday if we do not smash the perversions eating away at our moral and traditional beliefs.

$\begin{array}{llllllll}1 & 2 & 3 & 4 & 5 & 6 & 7\end{array}$

5. The situation in our country is getting so serious, the strongest methods would be justified if they eliminated the troublemakers and got us back to our true path.

1

2

3

4

5

6

7 
6. Everyone should have their own lifestyle, religious beliefs, and sexual preferences, even if it makes them different from everyone else.
1
2
3
4
5
6
7

7. People should pay less attention to the Bible and the other old traditional forms of religious guidance, and instead develop their own personal standards of what is moral and immoral.
1
2
3
4
5
6
7

8. The only way our country can get through the crisis ahead is to get back to our traditional values, put some tough leaders in power, and silence the troublemakers spreading bad ideas.
1
2
3
4
5
6 7

9. There is nothing wrong with premarital sexual intercourse.
1
2
3
4
5
6
7

10. What our country really needs, instead of more "civil rights" is a good, stiff dose of law and order.
1
2
3
4
5
6
7

11. Some of the best people in our country are those who are challenging our government, criticizing religion, and ignoring the "normal way" things are supposed to be done.
1
2
3
4
5
6
7

12. The facts on crime, sexual immorality, and the recent public disorders all show that we have to crack down harder on deviant groups and trouble-makers if we are going to save our moral standards and preserve law and order.
1
2
3
4
5
6
7

Authoritarianism, Conservatism, Traditionalism (Duckitt, Bizumic, Krauss, \& Heled, 2013)

Please circle your response, using the scale below.

\begin{tabular}{ccccccc}
1 & 2 & 3 & 4 & 5 & 6 & 7 \\
$\begin{array}{c}\text { Strongly } \\
\text { Disagree }\end{array}$ & $\begin{array}{c}\text { Moderately } \\
\text { Disagree }\end{array}$ & $\begin{array}{c}\text { Slightly } \\
\text { Disagree }\end{array}$ & $\begin{array}{c}\text { Neither } \\
\text { Disagree } \\
\text { Nor Agree }\end{array}$ & $\begin{array}{c}\text { Slightly } \\
\text { Agree }\end{array}$ & $\begin{array}{c}\text { Moderately } \\
\text { Agree }\end{array}$ & $\begin{array}{c}\text { Strongly } \\
\text { Agree }\end{array}$ \\
\hline
\end{tabular}

[Authoritarianism]

1. Strong, tough government will harm not help our country (R).

2. Being kind to loafers or criminals will only encourage them to take advantage of your weakness, so it's best to use a firm, tough hand when dealing with them.

3. Our society does NOT need tougher government and stricter laws (R.)

4. The facts on crime and the recent public disorders show we have to crack 
down harder on troublemakers, if we are going preserve law and order.

5. Our prisons are a shocking disgrace. Criminals are unfortunate people who deserve much better care, instead of so much punishment (R).

6. The way things are going in this country, it's going to take a lot of "strong

medicine" to straighten out the troublemakers, criminals, and perverts.

[Conservatism]

1. It's great that many young people today are prepared to defy authority (R).

2. What our country needs most is discipline, with everyone following our

leaders in unity.

3. Students at high schools and at university must be encouraged to challenge, criticize, and confront established authorities (R).

4. Obedience and respect for authority are the most important virtues children should learn.

5. Our country will be great if we show respect for authority and obey our leaders.

6. People should be ready to protest against and challenge laws they don't agree with (R).

[Traditionalism]

1. Nobody should stick to the "straight and narrow." Instead people should break loose and try out lots of different ideas and experiences (R).

2. The "old-fashioned ways" and "old-fashioned values" still show the best way

to live.

3. God's laws about abortion, pornography, and marriage must be strictly followed before it is too late (Not included in original version of Traditionalism scale).

4. There is absolutely nothing wrong with nudist camps (R).

5. This country will flourish if young people stop experimenting with drugs, alcohol, and sex, and pay more attention to family values.

6. There is nothing wrong with premarital sexual intercourse (R).

Social Dominance Orientation (Pratto et al., 1994; Ho et al. 2016)

Show how much you favour or oppose each idea below by selecting a number from 1

(STRONGLY OPPOSE) to 7 (STRONGLY FAVOUR) on the scale below. You can work quickly; your first feeling is generally best.

$\begin{array}{ccccccccc}\begin{array}{c}\text { Strongly } \\ \text { Oppose }\end{array} & 1 & 2 & 3 & 4 & 5 & 6 & 7 & \begin{array}{c}\text { Strongly } \\ \text { Favor }\end{array}\end{array}$

1. Some groups of people must be kept in their place.

2. It's probably a good thing that certain groups are at the top and other groups are at the bottom.

3. An ideal society requires some groups to be on top and others to be on the bottom.

4. Some groups of people are simply inferior to other groups. 
5. Groups at the bottom are just as deserving as groups at the top.

6. No one group should dominate in society.

7. Groups at the bottom should not have to stay in their place.

8. Group dominance is a poor principle.

9. We should not push for group equality.

10 . We shouldn't try to guarantee that every group has the same quality of life.

11. It is unjust to try to make groups equal.

12. Group equality should not be our primary goal.

13. We should work to give all groups an equal chance to succeed.

14. We should do what we can to equalize conditions for different groups.

15. No matter how much effort it takes, we ought to strive to ensure that all groups have the same chance in life.

16. Group equality should be our ideal.

\section{Demographics}

1. Please indicate your gender by checking one of the boxes: Male $\square$ Female $\square$ Other $\square$

2. Please state your age:

3. Please indicate your ethnic background by checking all that apply.

$\square$ White/Caucasian

$\square$ Black/African American

$\square$ South Asian

$\square$ Chinese

$\square$ Korean

$\square$ Japanese

$\square$ Southeast Asian

$\square$ Arab/West Asian

$\square$ Latin American

$\square$ Native American/Indigenous

$\square$ Other, please specify:

4. What is your relationship with Canada/ the United States?

$\square$ Canadian citizen

$\square$ Canadian resident

$\square$ US citizen

$\square$ US resident

$\square$ Other, please specify:

5. Were you born in Canada/the United States?

$\square$ Canada

$\square$ The US

$\square$ Neither

6. Do you identify as an immigrant?

$\square$ Yes

$\square$ No

7. Is English your first language?

$\square$ Yes

$\square$ No

8. What is the highest level of education that you have completed? 
$\square$ Less than high school graduate

$\square$ High school graduate

$\square$ Some college or university

$\square$ Completed college or university (Bachelor's Degree)

$\square$ Master's degree

$\square$ Doctoral degree

9. What is your best estimate of your household's total annual income (in US dollars) from all sources, before taxes, in the past year?

$$
\begin{aligned}
& \square \text { Under } \$ 15,000 \\
& \square \$ 15,001-\$ 30,000 \\
& \square \$ 30,001-\$ 45,000 \\
& \square \$ 45,001-\$ 60,000 \\
& \square \$ 60,001-\$ 75,000 \\
& \square \$ 75,001-\$ 100,000 \\
& \square \$ 100,000-\$ 150,000 \\
& \square \text { Over } \$ 150,000
\end{aligned}
$$

10. What do you think this study was about?

11. Do you have any additional thoughts that you would like to share about your experience with the study?

12. Some people run through the study without paying much attention and perhaps ignoring the audio clips. If you did this, or if you don't think your data should be included in our analyses for any reason, we would like to know! You won't be penalized in any way, but ensuring we have high-quality data is important to us, so please let us know in the box below. 


\section{Debriefing Form: Groups and Accents}

\section{Project Title: Groups and Accents \\ Principal Investigator: David Sumantry (MA thesis student) Supervised by: Dr. Becky Choma}

Thank you very much for participating in our study! Here is some more information about our hypotheses and the theories we used.

- Much research in social psychology has focused on skin colour as the primary cue for prejudice

- Less research has been done on the role of accents in prejudice.

- People with foreign accents tend to be evaluated less positively than people with the local accent (Fuertes, et al., 2012)

- But we don't know the qualities with which ways people with different accents are evaluated

- One of the prominent theories in social psychology is called the Stereotype Content Model (SCM; Fiske, Cuddy, Glick, \& Xu, 2002)

- The SCM suggests that society classifies social groups according to two dimensions: how warm and competent the groups are. Yet, it hasn't yet been applied to accented groups.

- We wanted to show that accent and ethnicity cue the same kind of prejudice in people: an accented group is evaluated like their stereotypically-associated ethnicity is

- Another prominent theory of prejudice is shown in the Dual Process Model (DPM; Duckitt, 2001) which suggests that two ideologies predict prejudice:

- Right-wing authoritarianism (RWA; Altemeyer, 1998) which describes the tendency for people to rigidly prefer tradition and strictly submit to authority.

- Social dominance orientation (SDO, Pratto et al., 1994) which describes the extent to which people think that society should be arranged in hierarchies.

- Close to the end of this study, you filled out measures of RWA and SDO. Because research has indicated that holding these ideologies stronger leads to greater prejudicial views against a variety of different groups (e.g. homosexuals, immigrants), we wanted to show that they also predict prejudicial views against foreign-accented groups.

- You may have noticed that some of the questions were strongly worded. This is to ensure that our measures properly distinguish people who hold these views to a greater or lesser degree.

- It's important to note that your answers don't mean that you are prejudiced. Research in social psychology is concerned with general, overall effects: not those of an individual, which can vary widely. We are collecting data from many participants and will analyse it all together.

This research program is very important to the field of social psychology. We thank you so much for being a part of it.

Because anonymity is very important to this study, we ask that you please DO NOT DISCUSS any part of this study with anyone who is likely to take part in the study. If you wish to discuss the study with people who have already participated in the study, or people who never will participate, that is acceptable.

The study will be compromised if you discuss its procedures with potential participants. In psychological research, it is often very important that participants are unaware of the specific procedures and hypotheses of a study before they participate in it, otherwise participants may not respond in a natural way (either to 
be helpful or because they believe the researcher wishes them to respond in a specific way). We hope you have learned something about psychological research processes by taking part in this study.

We hope you will learn something about intergroup relations from participating in this research. For further reading on the topics studied by this research, please see the bottom of this page.

Thank you for your time and support in participating in this study! If you have any questions or concerns please feel free to contact any of the researchers (see below).

If you have any questions regarding your rights as a human subject and participant in this study, you may contact the Ryerson University Research Ethics Board for information: Ryerson Ethics Board, c/o Office of the Vice President, Research and Innovation, Ryerson University, 350 Victoria Street, Toronto, ON M5B 2K3, 416-979-5042 rebchair@ryerson.ca

\section{Researchers:}

Dr. Becky Choma

Department of Psychology

Social and Political Psychology Lab

Ryerson University

Phone: 416-979-5000 ext. 3006

Email: becky.choma@psych.ryerson.ca

David Sumantry (MA thesis student)

Department of Psychology

Social and Political Psychology Lab

Ryerson University

Email: david.sumantry@psych.ryerson.ca

\section{$\underline{\text { References for further reading: }}$}

Duckitt, J. (2001). A dual-process cognitive-motivational theory of ideology and prejudice. Advances in Experimental Social Psychology, 33, 41-113.

Fiske, S. T., Cuddy, A. J. C., Glick, P., \& Xu, J. (2002) A model of (often mixed) stereotype content: Competence and warmth respectively follow from perceived status and competition. Journal of Personality and Social Psychology, 82(6), 878-902.

Fuertes, J. N., Gottdiener, W. H., Martin, H., Gilbert, T. C., \& Giles, H. (2012). A meta-analysis of the effects of speakers' accents on interpersonal evaluations. European Journal of Social Psychology, 42, $120-133$.

\section{Post-debrief consent:}

Some people, after reading the debrief, may be uncomfortable with researchers using their data. If you would like to withdraw consent in order to have your data not included in our analyses, please indicate this by typing "I withdraw consent" into the box below. 


\section{References}

Adorno, T. W., Frenkel-Brunswik, E., Levinson, D. J., \& Sanford, R. N. (1950) The Authoritarian Personality. New York: Harper \& Brothers.

Allport, G. W. (1954). The nature of prejudice. Reading, MA: Addison-Wesley.

Altemeyer, B. (2006). The Authoritarians. Bob Altemeyer.

Altemeyer, B. (1998). The other “Authoritarian Personality”. Advances in Experimental Social Psychology, 30, 47-92.

Altemeyer, B. (1996). The authoritarian specter. Cambridge, MA: Harvard University Press.

Altemeyer, B. (1988). Enemies of freedom. San Francisco: Jossey-Bass.

Altemeyer, B. (1981). Right-wing authoritarianism. Winnipeg: University of Manitoba Press.

Amiot, C. E., \& Bourhis, R. Y. (2005). Ideological beliefs as determinants of discrimination in positive and negative outcome distributions. European Journal of Social Psychology, 35, 581-598.

Amodio, D. M. (2009). Intergroup anxiety effects on the control of racial stereotypes: A psychoneuroendocrine analysis. Journal of Experimental Social Psychology, 45, 60-67.

Archuleta, A. J. (2015). Moderated linguistic acculturation and perceived group social capital on economic and occupational stress among people of Mexican descent. Journal of Ethnic \& Cultural Diversity in Social Work: Innovation in Theory, Research \& Practice, 24(2), 130147.

Baker, R. E., \& Bradlow, A. R. (2009). Variability in word duration as a function of probability, speech style, and prosody. Language and Speech, 52(4), 391-413.

Baguley, T. (2012). Serious Stats: A guide to advanced statistics for the behavioral sciences. Basingstoke, United Kingdom: Palgrave Macmillan. 
Ball, P. (1983). Stereotypes of anglo-saxon and non-anglo-saxon accents: Some exploratory Australian studies with the matched guise technique. Language Sciences, 5(2), 163-183.

Bandura, A. (1977). Self-efficacy: Toward a unifying theory of behavioral change. Psychological Review, 84(2), 191-215.

Barlow, F. K., Louis, W. R., \& Terry, D. J. (2010). Minority report: Social identity, cognitions of rejection and intergroup anxiety predicting prejudice from one racially marginalized group towards another. European Journal of Social Psychology, 40, 805-818.

Baugh, J. (2003). Linguistic Profiling. In S. Makoni, G. Smitherman, A.F. Ball, and A.K. Spears (eds.), Black Linguistics: Language, Society, and Politics in Africa and the Americas (155168. New York: Routledge.

Berk-Seligson, S. (1984). Subjective reactions to phonological variation in Costa Rican Spanish. Journal of Psycholinguistic Research, 13(6), 415-442.

Binggeli, S., Krings, F., \& Sczesny, S. (2014). Stereotype content associated with immigrant groups in Switzerland. Swiss Journal of Psychology, 73(3), 123-133.

Bizumic, B., Duckitt, J., Popadic, D., Dru, V., \& Krauss, S. (2009). A cross-cultural investigation into a reconceptualization of ethnocentrism. European Journal of Social Psychology, 39, 871-899.

Blascovich, J., Mendes, W. B., Hunter, S. B., Lickel, B., \& Kowai-Bell, N. (2001). Perceiver threat in social interactions with stigmatized others. Journal of Personality and Social Psychology, 82(2), 253-267.

Block, J., \& Block, J. H. (2006). Nursery school personality and political orientation two decades later. Journal of Research in Personality, 40, 734-749.

Bobo, L. (1988). Group conflict, prejudice, and the paradox of contemporary racial attitudes. In 
P. A. Katz, and D. A. Taylor (eds.), Eliminating Racism (85-114). New York: Springer.

Campbell, D. T., \& McCandless, B. R. (1951). Ethnocentrism, xenophobia, and personality. Human Relations, 4, 185-192.

Chiao, J. Y., Marthur, V. A., Harada, T., \& Lipke, T. (2009). Neural basis of preference for human social hierarchy versus egalitarianism. Annals of the New York Academy of Sciences, 1167, 174-181.

Choma, B. L., Ashton, M. C., \& Hafer, C. L. (2010). Conceptualizing political orientation in Canadian political candidates: A tale of two (correlated) dimensions. Canadian Journal of Behavioural Science / Revue Canadienne des sciences du comportement, 42(1), 24-33.

Choma, B. L., Jagayat, A., Hodson, G., \& Turner, R. (2018). Prejudice in the wake of terrorism: The role of temporal distance, ideology, and intergroup emotions. Personality and Individual Differences, 123, 65-75.

Christie, R., \& Cook, P. (1958). A guide to published literature relating to the authoritarian personality through 1956. The Journal of Psychology, 45, 171-199.

Costello, K., \& Hodson, G. (2011). Social dominance-based threat reactions to immigrants in need of assistance. European Journal of Social Psychology, 41(2), 220-231.

Clifford, S., Jewell, R. M., \& Waggoner, P. D. (2015). Are samples drawn from Mechanical Turk valid for research on political ideology? Research and Politics, 2(4), 1-9.

Creese, G., \& Kambere, E. N. (2015). "What colour is your English?” Canadian Review of Sociology, 40(5), 565-573.

Crowson, M. H., \& Brandes, J. A. (2010). Predicting community opposition to inclusion in schools: The role of social dominance, contact, intergroup anxiety, and economic conservatism. The Journal of Psychology, 144(2), 121-144. 
Cuddy, A., Fiske. S. T., \& Glick, P. (2008). Warmth and competence as universal dimensions of social perception: The Stereotype Content Model and the BIAS Map. In M. P. Zanna (ed.), Advances in Experimental Social Psychology (61-149). New York: Academic Press.

Cuddy, A. J. C., Fiske, S. T., and Glick, P. (2007). The BIAS Map: Behaviors from intergroup affect and stereotypes. Journal of Personality and Social Psychology, 92, 631-648.

Cuddy, A., Fiske, S. T., Kwan, V. S. Y., Glick, P., Demoulin, S., Leyens, J. P.,..., \& Ziegler, R. (2009). Stereotype content model across cultures: Towards universal similarities and some differences. British Journal of Social Psychology, 48(1), 1-33.

Derwing, T. M. (2003). What do ESL students say about their accents? Canadian Modern Language Review, 59(4), 547-566.

Difallah, D.E., Filatova, E., \& Ipeirotis, P.G. (2018). Demographics and Dynamics of Mechanical Turk Workers. Proceedings from WDSM 2018: The Eleventh ACM International Conference on Web Search and Data Mining. Marina Del Rey, CA, USA.

Digman, J. M. (1990). Personality structure: Emergence of the five-factor model. Annual Review of Psychology, 41, 417-440.

Dixon, J. A., Mahoney, B., \& Cocks, R. (2002). Accents of guilt? Effects of regional accent, race, and crime type on attributions of guilt. Journal of Language and Social Psychology, 21(2), 162-168.

Dragojevic, M., \& Giles, H. (2016). I don't like you because you're hard to understand: The role of processing fluency in the language attitudes process. Human Communication Research, 42(3), 396-420.

Duckitt, J. (2001). A dual-process cognitive-motivational theory of ideology and prejudice, Advances in Experimental Social Psychology, 33, 41-113. 
Duckitt, J. (2006). Differential effects of right wing authoritarianism and social dominance orientation on outgroup attitudes and their mediation by threat from and competitiveness to outgroups. Personality and Social Psychology Bulletin, 32(5), 684-696.

Duckitt, J., \& Fisher, K. (2003). The impact of social threat on worldview and ideological attitudes. Political Psychology, 24(1), 199-222.

Duckitt, J., \& Sibley, C. G. (2016). The dual process motivational model of ideology and prejudice. In C. G. Sibley and F. K. Barlow (eds.), The Cambridge handbook of the psychology of prejudice (188-221). Cambridge: Cambridge University Press.

Duckitt, J., \& Sibley, C. G. (2009). A dual-process motivational model of ideology, politics, and prejudice. Psychological Inquiry, 20, 98-109.

Durante, F., Capozza, D., \& Fiske, S. T. (2010). The Stereotype Content Model : The role played by competence in inferring group status. TPM - Testing, Psychometrics, Methodology in Applied Psychology, 17(4), 187-199.

Ekehammar, B., Akrami, N., Gylje, M., \& Zakrisson, I. (2004). What matters most to prejudice: Big five personality, social dominance orientation, or right-wing authoritarianism? European Journal of Personality, 18, 463-482.

Faul, F., Erdfelder, E., Lang, A. G. \& Buchner, A. (2007). G*Power 3: A flexible power analysis program for the social, behavioral, and biomedical sciences. Behavior Research Methods, $39,175-191$.

Field, A. P. (2013). Discovering statistics using SPSS: and sex and drugs and rock ' $n$ ' roll (4 ${ }^{\text {th }}$ ed.). SAGE.

Fiske, S. T. (2018). Prejudice, discrimination, and stereotyping. In R. Biswas-Diener \& E. Diener (Eds.), Noba textbook series: Psychology. Champaign, IL: DEF publishers. 
Fiske, S. T., Cuddy, A. J. C., Glick, P., \& Xu, J. (2002) A model of (often mixed) stereotype content: Competence and warmth respectively follow from perceived status and competition. Journal of Personality and Social Psychology, 82(6), 878-902.

Fiske, S. T., \& North, M. S. (2015). Measures of stereotyping and prejudice: Barometers of bias. In G. Boyle, D. Saklofske, \& G. Matthews (eds.), Measures of Personality and Social Psychology Constructs (752-776). London: Elsevier.

Fuertes, J. N., Gottdiener, W. H., Martin, H., Gilbert, T. C., \& Giles, H. (2012). A meta-analysis of the effects of speakers' accents on interpersonal evaluations. European Journal of Social Psychology, 42, 120-133.

Gallois, C., \& Callan, V. J. (1981). Personality impressions elicited by accented English speech. Journal of Cross-Cultural Psychology, 12(3), 347-359.

Giles, H. (1970). Evaluative reactions to accents. Educational Review, 22(3), 211-227.

Giles, H. (1971). Patterns of evaluation to R.P., south Welsh and Somerset accented speech. The British Journal of Social and Clinical Psychology, 10(3), 280-281.

Giles, H., Williams, A., Mackie, D., \& Rosselli, F. (1995). Reactions to Anglo- and HispanicAmerican accented speakers: Affect, identity, persuasion, and the English-only controversy. Language \& Communication, 15(2), 107-120.

Government of Canada. (2015). Citizenship Act. [Act]. Retrieved from http://lawslois.justice.gc.ca/PDF/C-29.pdf

Gluszek, A., \& Dovidio, J. F. (2010). Speaking with a nonnative accent: Perceptions of bias, communication difficulties, and belonging in the United States. Journal of Language and Social Psychology, 29(2), 224-234. 
Gluszek, A., Newheiser, A. K., \& Dovidio, J. F. (2011). Social psychological orientations and accent strength. Journal of Language and Social Psychology, 30(1), 28-45.

Green, L. J. (2002). African American English: A linguistic introduction. Cambridge: Cambridge University Press.

Hamilton, D. (2008). Measuring the wage costs of limited English. Hispanic Journal of Behavioral Sciences, 30(3), 257-279.

Hansen, K., \& Dovidio, J. F. (2016). Social dominance orientation, nonnative accents, and hiring recommendations. Cultural Diversity and Ethnic Minority Psychology, 22(4), 544-551.

Hellerstein, J., \& Neumark, D. (2003). Ethnicity, language, and workplace segregation: Evidence from a new matched employer-employee data set. Annales d'économie et de statistique, (71-72), 20-78.

Hiltin, P. (2016). Research in the crowdsourcing age, a case study. Retrieved from: http://www.pewinternet.org/2016/07/11/research-in-the-crowdsourcing-age-a-case-study/

Ho, A. K., Sidanius, J., Kteily, N., Sheehy-Skeffington, J., Pratto, F., Henkel, K. E., Foels, R., \& Stewart, A. L. (2015). The nature of social dominance orientation: Theorizing and measuring preferences for intergroup inequality using the new SDO7 scale. Interpersonal Relations and Group Processes, 109(6), 1003-1028.

Hodson, G., \& Hewstone, M. (2012). Advances in Intergroup Contact. New York, NY: Psychology Press.

Honorof, D. N., McCullough, J., \& Somerville, B. (2000). Comma Gets a Cure. Retrieved from: https://www.dialectsarchive.com/comma-gets-a-cure

Hosoda, M., Nguyen, L. T., \& Stone-Romero, E. F. (2012). The effect of Hispanic accents on employment decisions. Journal of Managerial Psychology, 27(4), 347-364. 
Hopper, R. (1977). Language attitudes in the employment interview. Communication Monographs, 44(4), 346-351.

Hopper, R., \& Williams, F. (1973). Speech characteristics and employability. Speech Monographs, 40(4), 296-302.

Huang, B., Alegre, A., \& Eisenberg, A. (2016). A cross-linguistic investigation of the effect of raters' accent familiarity on speaking assessment. Language Assessment Quarterly, 13(1), $25-41$

International Phonetic Association (IPA). (1999). Handbook of the International Phonetic Association: A guide to use of the International Phonetic Alphabet. Cambridge, UK: Cambridge University Press.

Jewel, K. S. (1993). From Mammy to Miss America and Beyond: Cultural Images and the Shaping of US Social Policy. Psychology Press.

Jussim, L., Crawford, J. T., \& Rubinstein, R. S. (2015). Stereotype (in)accuracy in perceptions of groups and individuals. Current Directions in Psychological Science, 24(6), 490-497.

Kuznetsova, A., Prokhoff, P. B., \& Christensen, R. H. B. (2017). 1merTest package: Tests in linear mixed effects models. Journal of Statistical Software, 82(13) 1-26.

Lambert, W. E., Hodgson, R. C., Gardner, R. C., \& Fillenbaum, S. (1960). Evaluational reactions to spoken languages. The Journal of Abnormal and Social Psychology, 60(1), 44-51.

Lee, T. L., \& Fiske, S. T. (2006). Not an outgroup, not yet an ingroup: Immigrants in the Stereotype Content Model, International Journal of Cultural Relations, 30, 751-768.

Levin, S. (2004). Perceived group status differences and the effects of gender, ethnicity, and religion on Social Dominance Orientation, Political Psychology, 25(1), 31-48. 
Lippi-Green, R. (2001). English with an accent: Language, ideology, and discrimination in the United States. New York, NY: Routledge.

Martin, J. L. (2001). The Authoritarian Personality, 50 years later: What lessons are there for political psychology? Political Psychology, 22(1), 1-26.

Matthews, M., \& Levin, S. (2012). Testing a dual process model of prejudice: Assessment of group threat perceptions and emotions. Motivation and Emotion, 36(4), 564-574.

McFarland, S. (2005). On the eve of war: Authoritarianism, social dominance, and American students' attitudes toward attacking Iraq. Personality and Social Psychology Bulletin, 31, $360-367$.

McFarland, S. \& Adelson, S. (1996, July). An omnibus study of personality and prejudice. Paper presented at the meeting of the International Society of Political Psychology, Vancouver, Canada.

McGurn, W. (2014, July 10). Workin' at the carwash - those 'dirty' immigrant jobs. New York Post.

McManus, W. S. (1990). Labor market effects of language enclaves: Hispanic men in the United States. Journal of Human Resources, 25, 228-252.

Meeusen, C. \& Dhont, K. (2015). Parent-child similarity in common and specific components of prejudice: The role of ideological attitudes and political discussion. European Journal of Personality, 29, 585-598.

Miller, D. A., Smith, E. R., \& Mackie, D. M. (2004). Effects of intergroup contact and political predispositions on prejudice: Role of intergroup emotions. Group Processes and Intergroup Relations, 7(3), 221-237. 
Milton, O. (1952). Presidential choice and performance on a scale of authoritarianism. American Psychologist., 7, 597-598.

Mirisola, A., Roccato, M., Russo, S., Spagna, G., \& Vieno, A. (2014). Societal threat to safety, compensatory control, and right-wing authoritarianism. Political Psychology, 35(6), 795 812.

Morrell, C. H. (1998). Likelihood ratio testing of variance components in the linear mixedeffects model using restricted maximum likelihood. Biometrics, 54(4), 1560-1568.

Murphy, N. A. (2007). Appearing smart: The impression management of intelligence, person perception accuracy, and behavior in social interaction. Personality and Social Psychology Bulletin, 33(3), 325-339.

Nielsen, J. M., \& Doyle, P. T. (1975). Sex-role stereotypes of feminists and nonfeminists. Sex Roles, 1(1), 83-95.

Nelson, L. R., Signorella, M. L., \& Botti, K. G. (2016). Accent, Gender, and Perceived Competence. Hispanic Journal of Behavioral Sciences, 38(2), 166-185.

Newman, M., \& Wu, A. (2011). “Do you sound Asian when you speak English?” Racial identification and voice in Chinese and Korean Americans' English. American Speech, $86(2), 152-178$.

OECD. (2014). Migration Policy Debates. [Report]. Retrieved from: https://www.oecd.org/migration/OECD\%20Migration\%20Policy\%20Debates\%20Numero \%202.pdf

Onraet, E., Dhont, K., \& Van Hiel, A. (2014). The relationships between internal and external threats and right-wing attitudes: A three-wave longitudinal study. Personality and Social Psychology Bulletin, 40(6), 712-725. 
Paolacci, G., Chandler, J., \& Ipeirotis, P. G. (2010). Running experiments on Amazon Mechanical Turk. Judgment and Decision Making, 5, 411-419.

Pettigrew, T. F., \& Tropp, L. R. (2006). A meta-analytic test of intergroup contact theory. Journal of Personality and Social Psychology, 90(5), 751-783.

Perrachione, T. K., Chiao, J. Y., \& Wong, P. C. M. (2010). Asymmetric cultural effects on perepetual expertise underlie an own-race bias for voices. Cognition, 114, 42-55.

Pratto, F., Sidanius, J., \& Levin, S. (2006). Social dominance theory and the dynamics of intergroup relations: Taking stock and looking forward. European Review of Social Psychology, 17, 271-320.

Pratto, F., Sidanius, J., Stallworth, L. M., \& Malle, B. F. (1994). Social dominance orientation: A personality variable predicting social and political attitudes. Journal of Personality and Social Psychology, 67(4), 741-763.

Pratto, F., Tatar, D. G., \& Conway-Lanz, S. (1999). Who gets what and why: Determinants of social allocations. Political Psychology, 20, 127-150.

Reitz, J. G. (2012). The distinctiveness of the Canadian immigration experience. Patterns of Prejudice, 46(5), 518-538.

Riek, B. M., Mania, E. W., \& Gaertner, S. L. (2006). Intergroup threat and outgroup attitudes: A meta-analytic review. Personality and Social Psychology Review, 10(4), 336-353.

Ryalls, J., Zipprer, A., \& Baldauff, P. (1997). A preliminary investigation of the effects of gender and race on voice onset time. Journal of Speech, Language, and Hearing Research, 40(3), 642-645

Sapienza, C. M. (1997). Aerodynamic and acoustic characteristics of the adult African American voice. Journal of Voice, 11(4), 410-416. 
Schlueter, E., \& Scheepers, P. (2010). The relationship between outgroup size and anti-outgroup attitudes. Social Science Research, 39(2), 285-295.

Schwartz, S. (1992). Universals in the content and structure of values: Theoretical advances and empirical tests in 20 countries. In M. Zanna (Ed.), Advances in experimental social psychology (Vol. 25, pp. 1-65). San Diego, CA: Academic Press.

Sears, D. O. (1988). Symbolic racism. In P. A. Katz, and D. A. Taylor (eds.), Eliminating Racism (53-84). New York: Springer.

Sibley, C. G., \& Duckitt, J. (2010). The personality bases of ideology: A one-year longitudinal study. The Journal of Social Psychology, 150(5), 540-559.

Sibley, C. G., \& Duckitt, J. (2009). Big-Five personality, social worldviews, and ideological attitudes: further tests of a dual process cognitive-motivational model. The Journal of Social Psychology, 149(5), 545-561.

Sibley, C. G., Osborne, D., \& Duckitt, J. (2012). Personality and political orientation: Metaanalysis and test of a threat-constraint model. Journal of Research in Personality, 46, 664677.

Sibley, C. G., Wilson, M. S., \& Duckitt, J. (2007). Antecedents of men's hostile and benevolent sexism: The dual roles of social dominance orientation and right-wing authoritarianism. Personality and Social Psychology Bulletin, 33(2), 160-172.

Sidanius, J., Cotterill, S., Sheehy-Skeffington, J., Kteily, N., \& Carvacho, H. (2016). Social dominance theory: Explorations in the psychology of oppression. In C. G. Sibley and F. K. Barlow (eds.), The Cambridge handbook of the psychology of prejudice (149-187). Cambridge: Cambridge University Press. 
Sidanius, J., Levin, S., Liu, J., \& Pratto, F. (2000). Social dominance orientation, antiegalitarianism and the political psychology of gender: An extension and cross-cultural replication. European Journal of Social Psychology, 30, 41-67.

Sidanius, J., Levin, S., Van Laar, C., \& Sears, D. O. (2008). The diversity challenge: Social identity and intergroup relations on the college campus. New York: Russell Sage Foundation.

Sidanius, J., \& Pratto, F. (1999). Social dominance: An intergroup theory of social hierarchy and oppression. Cambridge, UK: Cambridge University Press.

Siegal, S. (1954). Certain determinants and correlates of authoritarianism. Genetic Psychology Monographs, 49, 187-229.

Souza, A. L., Byers-Heinlein, K., \& Poulin-Dubois, D. (2013). Bilingual and monolingual children prefer native-accented speakers. Frontiers in Psychology. Online publication. Statistics Canada (2017). Population growth: Migratory increase overtakes natural increase. [Report]. Retrieved from http://www.statcan.gc.ca/pub/11-630-x/11-630-x2014001-eng.htm

Stephan, C. W., Stephan, W. G., Demitrakis, K. M., Yamada, A. M., \& Clason, D. L. (2000). Women's attitudes toward men: An integrated threat theory approach. Psychology of Women Quarterly, 24, 63-73.

Stephan, W. G. (2014). Intergroup Anxiety: Theory, research, and practice. Personality and Social Psychology Review, 18(3), 239-255.

Stephan, W. G., \& Stephan, C. W. (2016). Intergroup threats. In C. G. Sibley and F. K. Barlow (eds.), The Cambridge handbook of the psychology of prejudice (131-148). Cambridge: Cambridge University Press. 
Stephan, W. G., \& Stephan, C. W. (2000). An integrated threat theory of prejudice. In S. Oskamp (ed.), Reducing prejudice and discrimination (23-45), New Jersey: Lawrence Erlbaum Associates, Inc.

Stephan. W. G., \& Stephan. C. W. (1993). Cognition and affect in stereotyping: Parallel interactive networks. In D. M. Mackie, and D. L. Hamilton (eds.), Affect, Cognition, and Stereotyping: Interactive Processes in Group Perception (111-136). San Diego, California: Academic Press Inc.

Stephan, W. G., \& Stephan, C. W. (1985). Intergroup anxiety. Journal of Social Issues, 41, 157175.

Stephan, W. G., Ybarra, O., \& Bachman, G. (1999). Prejudice toward immigrants. Journal of Applied Psychology, 29(11), 2221-2237.

Stephan, W. G., Ybarra, O., \& Morrison, K. (2015). Intergroup threat theory. In T. D. Nelson (ed.), Handbook of prejudice, stereotyping, and discrimination (255-278). New York: Psychology Press.

Travetter, F. J., Wallnau, L. B., \& Forzano, L. B., (2016). Essentials of statistics for the behavioral sciences $\left(9^{\text {th }}\right.$ ed.). Boston, MA: Wadsworth Publishing.

Trawalter, S., Adam, E. K., Chase-Lansdale, P. L., \& Richeson, J. A. (2012). Concerns about appearing prejudiced get under the skin: Stress responses to interracial contact in the moment and across time. Journal of Experimental Social Psychology, 48, 682-693. United Nations High Commissioner for Refugees. (2016). Syria conflict at 5 years: the biggest refugee and displacement crisis of our time demands a huge surge in solidarity. [Press Release]. Retrieved from http://www.unhcr.org/news/press/2016/3/56e6e3249/syriaconflict-5-years-biggest-refugee-displacement-crisis-time-demands.html 
United Nations High Commissioner for Refugees. (2016). Europe: Syria Asylum Applications. [Infographic]. Retrieved from http://data.unhcr.org/syrianrefugees/asylum.php

UNICEF. (2016). Syria crisis situation report: 2016 humanitarian results. [Report]. Retrieved from http://reliefweb.int/sites/reliefweb.int/files/resources/UNICEF\%20Syria\%20Crisis \%20Situation\%20Report\%20-\%20Year\%20End\%202016.pdf

Wadsworth, J., Dhingra, S., Ottaviano, G., \& Van Reenen, J. (2015). Brexit and the impact of immigration on the $U K(\mathrm{CEP}$ Brexit analysis no. 5). London, UK: Centre for Economic Performance.

Walton, J. H., \& Orlikoff, R. F. (1994). Speaker race identification from acoustic cues in the vocal signal. Journal of Speech \& Hearing Research, 37(4), 738-746.

Wang, Z., Arndt, A. D., Singh, S. N., Biernat, M., \& Liu, F. (2013). "You lost me at hello": How and when accent-based biases are expressed and suppressed. International Journal of Research in Marketing, 30, 185-196.

Wated, G., \& Sanchez, J. I. (2006). The Role of Accent as a Work Stressor on Attitudinal and Health-Related Work Outcomes. International Journal of Stress Management, 13(3), 329350.

Weerasinghe, S. (2012). Inequities in visible minority Immigrant Women's Healthcare accessibility. Ethnicity and Inequalities in Heatlh and Social Care, 5(1), 18-28.

Weinberger, S. (2015). Speech Accent Archive. George Mason University. Retrieved from: http://accent.gmu.edu

Willis, R. H. (1956). Political and child-rearing attitudes in Sweden. Journal of Abnormal \& Social Psychology, 53, 74-83. 
Yarmey, A. D. (1995). Earwitness speaker identification. Psychology, Public Policy, and Law, 1(4), 792-816.

Yearny, A. D. (1995). Earwitness speaker identification. Psychology, Public Policy, and Law, 1(4), 792-816.

Zahn, C. J., \& Hopper, R. (1985). Measuring language attitudes: The speech evaluation instrument. Journal of Language and Social Psychology, 4(2), 113-123.

Zhao, B., Ondrich, J., \& Yinger, J. (2006). Why do real estate brokers continue to discriminate? Evidence from the 2000 Housing Discrimination Study. Journal of Urban Economics, 59(3), 394-419. 